INTEGRATING SUSTAINABILITY SUBSYSTEMS IN THE MANAGEMENT OF URBAN FORESTS

by

Christopher Sean Greene

Master of Spatial Analysis, Ryerson University, 2009

Master in Environmental Studies, York University, 2006

Bachelor of Science (Honours), Acadia University, 2003

Bachelor of Science (Agr), Nova Scotia Agricultural College, 1998

\author{
A dissertation \\ presented to Ryerson University \\ in partial fulfillment of the \\ requirements for the degree of \\ Doctor of Philosophy \\ in the Program of \\ Environmental Applied Science and Management
}

Toronto, Ontario, Canada, 2015

(C) Christopher Sean Greene, 2015 


\section{AUTHOR'S DECLARATION FOR ELECTRONIC SUBMISSION OF A DISSERTATION}

I hereby declare that I am the sole author of this dissertation. This is a true copy of the dissertation, including any required final revisions, as accepted by my examiners.

I authorize Ryerson University to lend this dissertation to other institutions or individuals for the purpose of scholarly research.

I further authorize Ryerson University to reproduce this dissertation by photocopying or by other means, in total or in part, at the request of other institutions or individuals for the purpose of scholarly research.

I understand that my dissertation may be made electronically available to the public.

Christopher Greene 


\title{
Integrating Sustainability Subsystems in the Management of Urban Forests
}

\author{
Christopher Greene \\ $\mathrm{PhD}$, Environmental Applied Science and Management \\ Ryerson University, 2015
}

The urban forest is an important natural capital asset providing essential ecological, social, and economic benefits to people living in cities. Research contained within this dissertation examines urban forest structure and management through the lens of strong sustainability and has as its central focus the question of where to prioritize planting of trees in a densely populated, and continually expanding, North American urban centre. Three independent research studies are included, each of which addresses a dimension of the urban forest that falls within one of the three subsystems of sustainability. The first study focuses on urban forest ecological service delivery with a specific focus on the relationship between forest canopy closure and summer surface temperatures across the City of Toronto, Canada. The second study examines a social dimension of the urban forest-identifying distributional inequalities in city resident access to urban tree canopy as a function of their household income. In the third study, an economic dimension of urban sustainability is investigated by examining the legacy of street tree planting decisions and their relationship to ash tree mortality caused by the emerald ash borer (Agrilus planipennis). In addition to adding to scholarship concerning the processes and relationships examined within each sustainability subsystem, common themes arising across each of the studies are identified and discussed. These individual research studies and intersecting themes serve as the basis for an innovative approach to prioritizing urban tree planting that seeks to integrate a sustainability subsystems approach to the decision-making process. 


\section{ACKNOWLEDGEMENTS}

An extraordinary thank-you to my supervisor, Dr. Andrew Millward for his input and support throughout the past seven years and for helping me develop as a more rounded academic. Thank-you to the examination committee, including Dr. Sandy Smith, Dr. Tenley Conway, Dr. Andrew Laursen, Dr. Pamela Robinson, and Dr. Shuguang Wang for their valuable contributions and patience throughout the final months, as well as Dr. Joseph McPhee for chairing the doctoral defence. To my friend and colleague Dr. Peter Kedron, a special note of gratitude for unfailingly providing encouragement and moral support when it was most needed. My appreciation to the EUS and GA students that have taken an interest in this research and for providing yet another reason to be motivated.

And, as always, my gratitude to family for being an indispensable support, especially Donna, Terri, and Gwen. 
For Gwen, who didn't start this journey, but made it more important.

For Eli, who didn't see the end, but provided welcome comfort.

For Terri, who always sees things through. 


\section{TABLE OF CONTENTS}

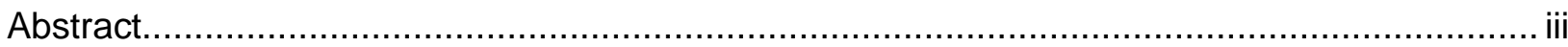

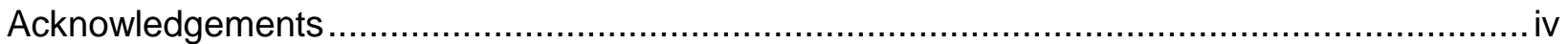

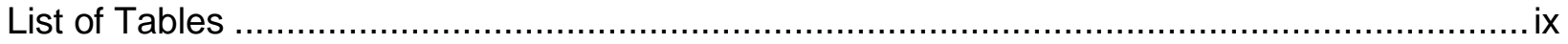

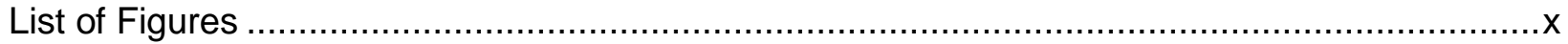

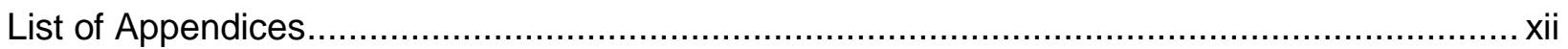

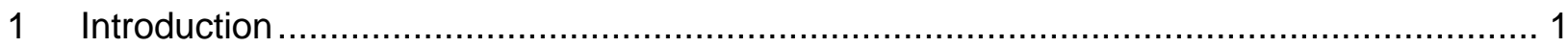

1.1 Research context: sustainability and environmental decision making ...................... 1

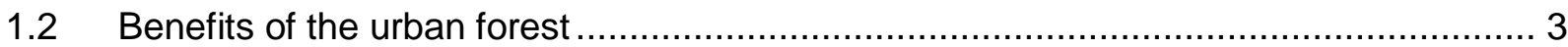

1.3 The important influence of management decisions …...................................... 5

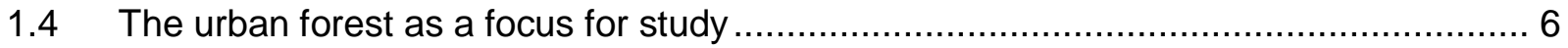

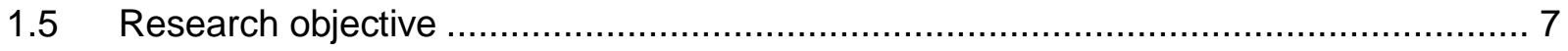

1.6 Subsequent chapter summaries and authorship statements .............................. 8

1.6.1 Chapter 2 - Getting closure: the role of urban forest canopy density in moderating

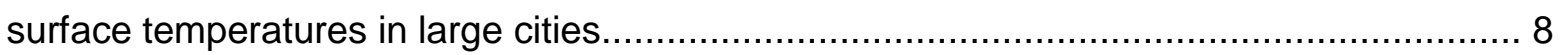

1.6.2 Chapter 3 - Canopy of advantage: who benefits most from city trees? .............. 9

1.6.3 Chapter 4 - The legacy of past tree planting decisions for a city confronting emerald ash borer (Agrilus planipennis) invasion ..................................................10

1.6.4 Conclusion: integrating sustainability subsystems with urban tree planting decisions

2 Getting closure: the role of urban forest canopy density in moderating surface temperatures in large cities

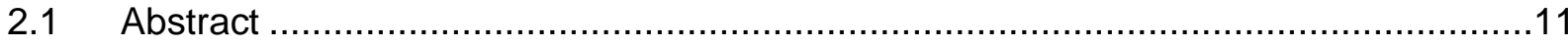

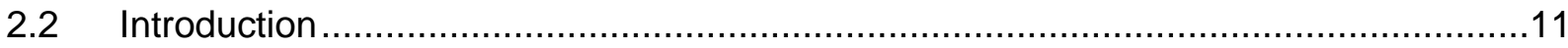

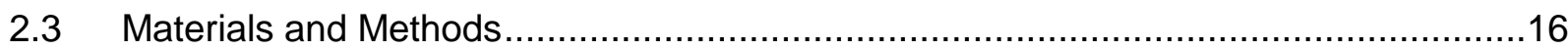

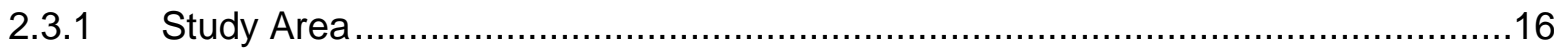

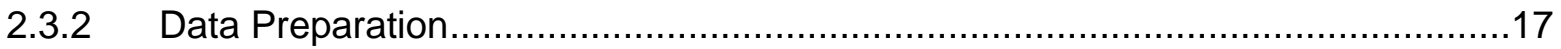

2.3.3 Data Related to Surface Temperature ...........................................................20 


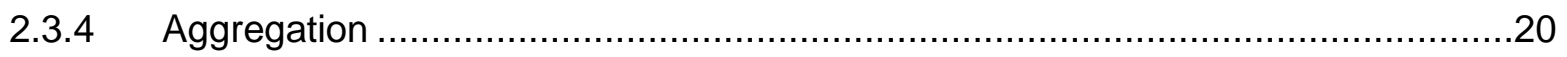

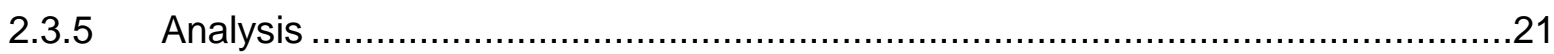

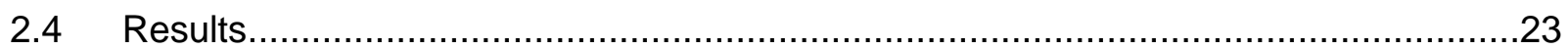

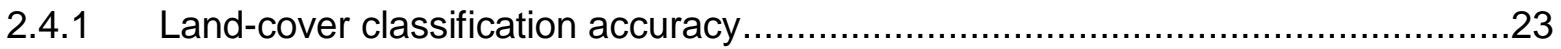

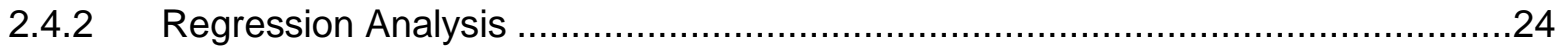

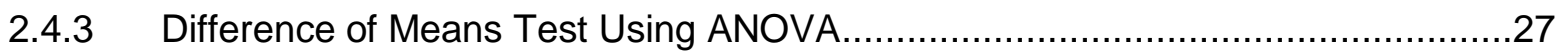

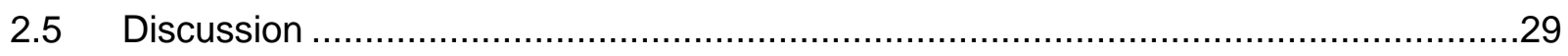

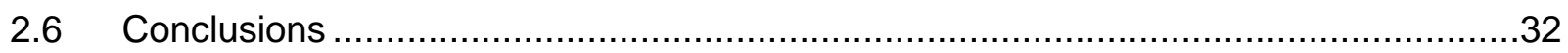

3 Canopy of advantage: who benefits most from city trees? ..........................................33

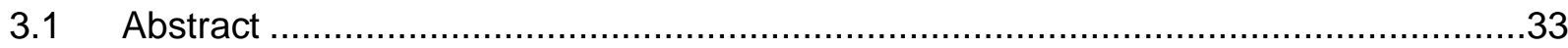

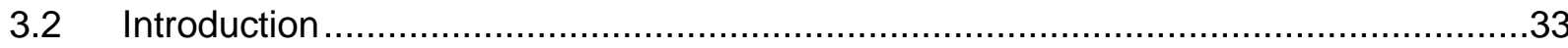

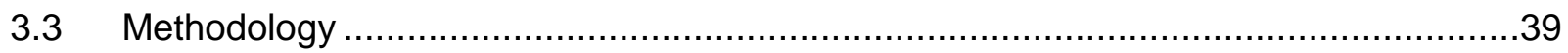

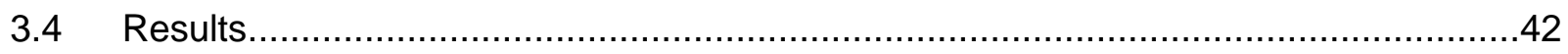

3.4.1 Difference of Means Tests Using ANOVA ......................................................

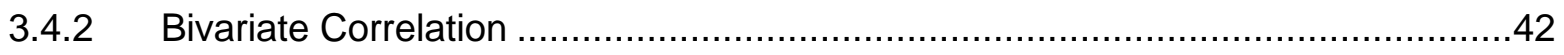

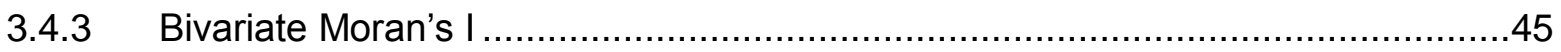

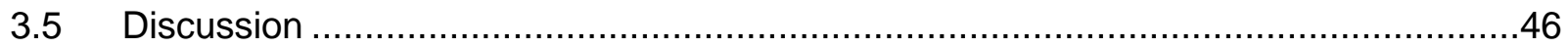

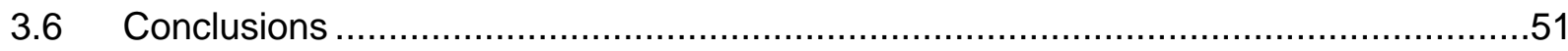

4 The legacy of past tree planting decisions for a city confronting emerald ash borer (Agrilus

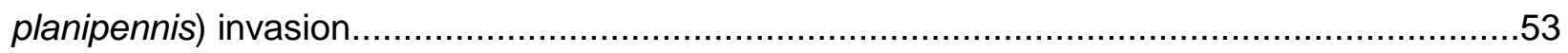

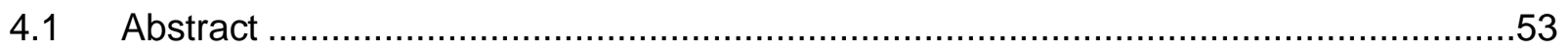

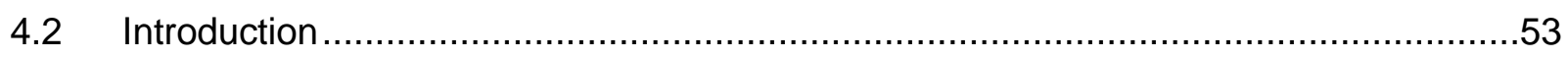

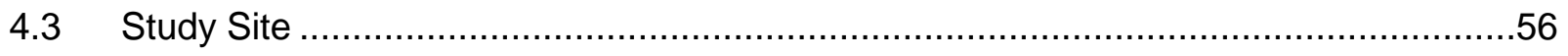

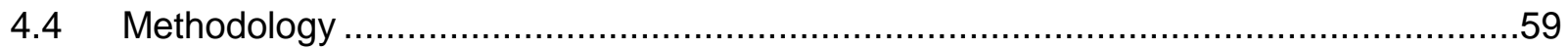

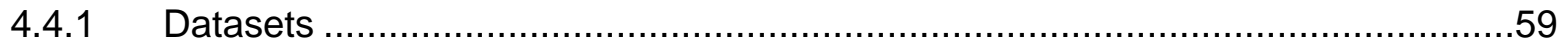

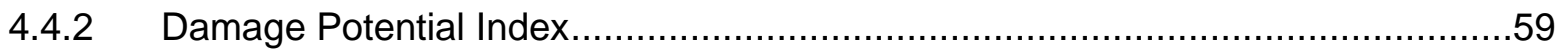

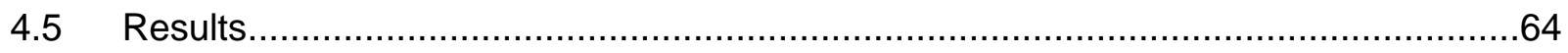




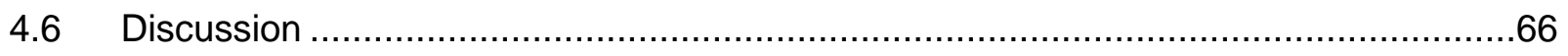

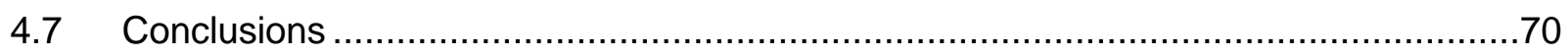

5 Integrating sustainability subsystems with urban tree planting decisions.........................72

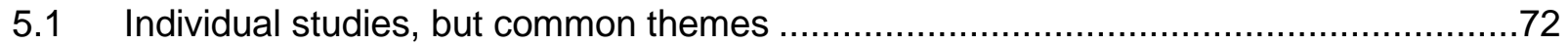

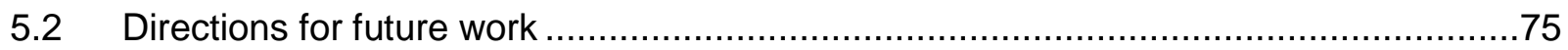

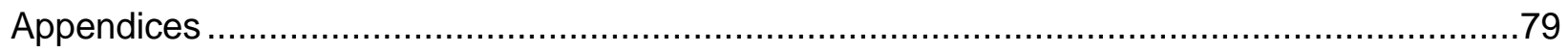

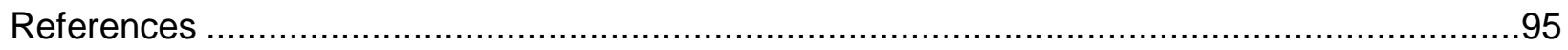

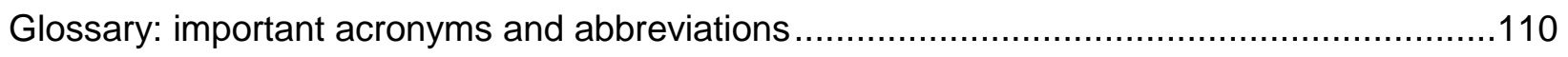




\section{LIST OF TABLES}

Table 2-1: Accuracy assessment related to the classification of land-cover data derived from Landsat TM5 imagery.

Table 2-2: Summary of ordinary least squares (OLS) and geographically weighted regression (GWR) results modelling the relationship between mean surface temperature and tree canopy variables by census tract.

Table 2-3: Summary of analysis of variance (ANOVA) post-hoc mean comparisons for tree canopy variables at the census tract level for Toronto, Canada (2005).

Table 3-1: Summary of analysis of variance (ANOVA) post-hoc mean comparisons of tree canopy type according to median household income by census tract for Toronto, Canada (20062007).

Table 3-2: Summary of Pearson correlation coefficients (or "r") between tree canopy types and median household income by census tract for Toronto, Canada (2006-2007). 


\section{LIST OF FIGURES}

Figure 1-1: Comparison of sustainability subsystem arrangement for $(A)$ weak forms of sustainability and $(B)$ strong forms of sustainability. ...................................................... 3

Figure 1-2: Schematic diagram outlining the overall dissertation structure ......................... 9

Figure 2-1: Population density of Toronto, Ontario Canada (2006) by census tract with superimposed pre-amalgamation boundaries (see inset for identification).

Figure 2-2: Classified land-cover data $(A)$ and surface temperature data $(B)$ derived from 2005 Landsat TM5 imagery for amalgamated City of Toronto, Canada (2005).

Figure 2-3: Input variables for ordinary least squares (OLS) and geographically weighted regression (GWR) models, aggregated to census tract geography including $(A)$ mean surface temperature, (B) percent low-density canopy, (C) percent high-density canopy, and (D) percent closed canopy for the amalgamated City of Toronto, Canada (2005).

Figure 2-4: Distribution of standardized residuals by census tract for the $(A)$ ordinary least squares (OLS) regression model and (B) the geographically weighted regression (GWR) model used to evaluate regression model specification for the relationship between mean surface temperature and canopy in Toronto, Canada (2005).

Figure 2-5: Mean percentage of tree canopy variables factored by median personal income categories at the census tract level for Toronto, Canada (2005).

Figure 3-1: Population density of Toronto, Canada (2006) by census tract with superimposed pre-amalgamation boundaries (see inset for identification).

Figure 3-2: Distribution of input variables for bivariate local indicators of spatial autocorrelation analysis (local Moran's I) for Toronto, Canada (2006-2007). All variables are classified using quintile classification.

Figure 3-3: Results of bivariate local indicator of spatial autocorrelation analysis examining the relationship by census tract between $(A)$ percent realized canopy cover and median household income, (B) percent potential canopy cover and median household income, and (C) percent total canopy cover and median household income for Toronto, Canada (2006-2007)....

Figure 4-1: Proportion of street tree stems that are species of the genus Fraxinus by city ward for Toronto, Canada (2012)

Figure 4-2: The proportion of street trees that belong to the Fraxinus genus calculated for each census tract for Toronto, Canada (2012).

Figure 4-3: Street tree stem density standardized as a function of the street network density and calculated for each census tract for Toronto, Canada (2012).

Figure 4-4: Average proximity of street trees that are ash species calculated for each census tract for Toronto, Canada (2012). 
Figure 4-5: Spatial distribution of theoretical damage potential index values calculated for census tracts. Increasing damage to the street tree resource is expected as index values increase.

Figure 4-6: Spatial distribution of log-transformed theoretical damage potential index values calculated for census tracts for Toronto, Canada (2012). Regardless of sign, increased damage to the street tree resource is expected as values increase.

Figure 4-7: Getis-Ord local Gi* cluster analysis of the log transformed theoretical damage potential index values calculated for each census tract for Toronto, Canada (2012). Hotspots and cold spots represent clusters of transformed index values significantly higher and lower than the distribution mean.

Figure 5-1: Parallel outcomes of weighted raster overlay to prioritize plantable space for preamalgamation Toronto, Canada, including (A) an equal balance option, (B) an ecologically weighted option, (C) a socially weighted option, and (D) an economically weighted option. 


\section{LIST OF APPENDICES}

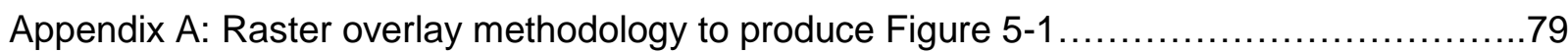

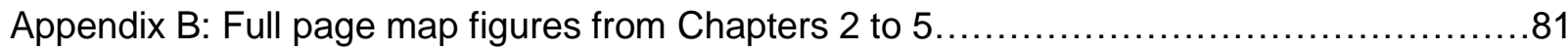




\section{INTRODUCTION}

\subsection{RESEARCH CONTEXT: SUSTAINABILITY AND ENVIRONMENTAL DECISION MAKING}

In many ways, this dissertation falls under the theme of sustainability and how sustainability principles have a role in the environmental decision-making (or EDM) process. Since the popular definition of sustainable development was forwarded by the Brundtland report,

"...development that meets the needs of the present without compromising the ability of future generations to meet their own needs..." (World Commission on Environment and Development, 1987, Chapter 2, paragraph 1)

sustainability theory has undergone an extensive evolution. Work by Johnston et al. (2007) estimated that within two years of the Brundtland Report there were approximately 140 alternative definitions of sustainable development (or sustainability); at present there are nearly 300 definitions that can be found across numerous disciplines. This suite of definitions and descriptions tends to have one commonality - maintenance of the interpretive ambiguity found in the definition contained within the Brundtland Report (Johnston et al., 2007; White, 2013). Of particular concern for critics of the Bruntdland definition is the word "development" and how it appears to be used as a synonym for "growth". Shortly after the Brundtland Report was published, several critiques emerged presenting the argument that sustainable economic growth is a paradox in a finite global ecosystem and, moreover, that an economy can develop qualitatively without expanding/growing according to classical economic theory (Costanza \& Daly; Daly, 1990; Goodland, 1995).

It is interesting to note that while recognizing the interconnection among humans, resource use, and environmental degradation, several early critiques of the Brundtland Report definition advocated for treating environmental sustainability, social sustainability, and economic sustainability as separate categories (Goodland, 1995; Goodland \& Daly, 1996). Over time the acceptability of separating these categories of sustainability has shifted; more contemporary conceptualizations of sustainability recognize that ecology, society, and economy are not silos, but interconnected dimensions or subsystems of sustainability (Gibson, 2006; Haansman et al., 2012; Roseland, 2012). There is, however, disagreement about how these sustainability subsystems are arranged, and the relative importance of each subsystem to economists with competing worldviews (i.e., expansionist or steady-state proponents) (see Rees, 1995 for a thorough comparison of expansionist versus steady-state paradigms). 
Understanding the fundamental difference between these two perspectives, specifically the concept of weak versus strong forms of sustainability, is important because the concept of strong sustainability informs the theoretical perspective of this dissertation (discussed further in Study Context). The concepts of weak and strong sustainability, initially proposed by ecological economists such as Herman Daly and Robert Costanza (Costanza \& Daly, 1992; Daly, 1990) underpin the well-known ecological footprint metric developed by William Reese and Mathis Wackernagal (see Rees \& Wackernagal, 1996; Wackernagal \& Rees, 1997; Wackernagal et al., 1999). The fundamental difference between weak and strong sustainability is rooted in the perception of natural capital.

In the neoclassical view of economics, different forms of capital (specifically natural capital and manufactured capital) are considered to be interchangeable or substitutable (Costanza \& Daly, 1992; Daly, 1990). In other words, natural capital, "a stock [of natural assets] that yields a flow of valuable goods and services into the future" (Costanza \& Daly, 1992, pg. 38) can be transformed or converted to manufactured capital, "factories, buildings, tools, and other physical artifacts" (Costanza \& Daly, 1992, pg. 38). If all capital is understood to be substitutable, then the expansionist view of sustainability is simply a function of aggregate capital; if an equal or greater sum of natural and manufactured capital is transferred from the current generation to subsequent generations, sustainability has been achieved (Costanza \& Daly, 1992; Goodland, 1995; Rees, 1995). Economists identifying with the steady-state or ecological worldview argue this approach is a "weak" form of sustainability because not all capital is transferable; though natural capital can easily be transformed to manufactured capital, that transaction is often not reversible (Costanza \& Daly, 1992; Dietz \& Neumayer, 2007; Goodland 1995). This latter view supports the adoption of a "strong" form of sustainability, where equal or greater natural capital assets are transferred from the current generation to subsequent generations (Costanza \& Daly, 1992; Dietz \& Neumayer, 2007; Goodland, 1995; Rees, 1995). From this argument, sustainability subsystems are less like the pillars in many contemporary definitions, but rather a nested system (see Figure 1-1) with economy as a subsystem of society, which in turn is nested within ecology-economic expansion beyond Earth's biophysical limits is not possible (Daly, 1990; Rees, 1995; Wu 2013).

Integrating sustainability principles as a part of the EDM process should be a priority when making environmental policy decisions with an objective of minimizing the occurrence of tradeoffs between sustainability subsystems (Gibson, 2006). The EDM process can be complex, however, and presents a number of barriers to successfully integrating sustainability principles (Gibson, 2006; McGuire, 2012). Often, there are many stakeholders of differing expertise 
engaging in the EDM process (Kiker et al., 2005; McGuire, 2012). Even those with a high level of expertise in the their own fields may have very little experience in the assumptions, methods, data, and uncertainty related to other fields of study, and may have difficulty evaluating potential trade-offs that result from choosing different alternatives (Kiker et al., 2005). That uncertainty extends to the concept of "value" and how data from different disciplines is integrated and compared as a part of the EDM process. Common tools such as cost benefit analysis (or "CBA") perform well at integrating economic data and resources that are commodities with direct market values into the decision-making process (McGuire, 2012). However, in order to evaluate a resource's entire range of ecological services (i.e., provisioning, regulating, and cultural), an alternate form of calculating indirect values with underlying uncertainty is necessary (Ackerman \& Heinzerling, 2002; de Groot at al., 2002; Farber et al., 2002). With the context of a CBA analysis, the more challenging it is to commodify a benefit or service (i.e., assign monetary units to it), the more likely that benefit will be undervalued (McGuire, 2012).

A. "Weak" Sustainability

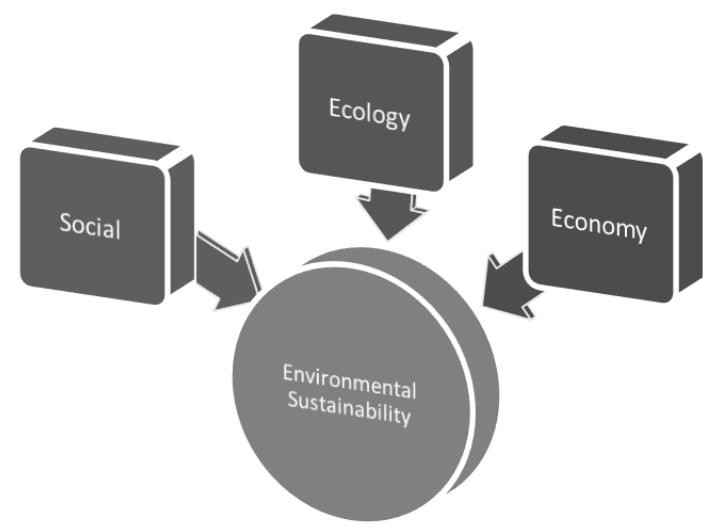

B. "Strong" Sustainability

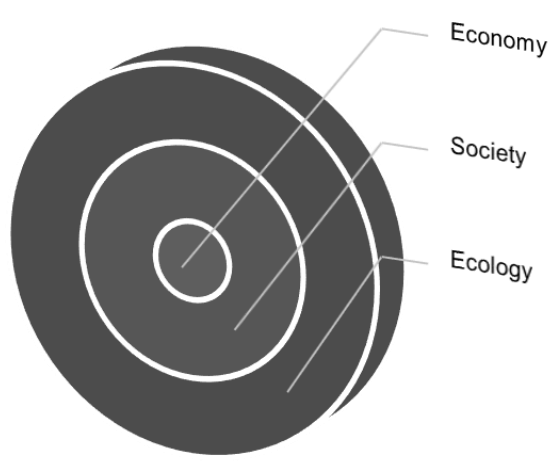

Figure 1-1: Comparison of sustainability subsystem arrangement for $(A)$ weak forms of sustainability and (B) strong forms of sustainability.

\subsection{BENEFITS OF THE URBAN FOREST}

The urban forest is an environmental good, a resource that can considerably improve the quality of living in dense urban environments (Bassuk \& Whitlow, 1988; Nowak et al., 2001). Urban vegetation, particularly trees, is an important provider of ecological services such as the provision of habitat for urban wildlife (Alvey, 2006). The ability of urban tree canopy cover (or "UTCC") to intercept rainfall helps to mitigate storm water runoff (Berland \& Hopton, 2014; Sanders, 1986; 
Xiao et al., 1998) and reduce subsequent damage from flooding (Nowak et al., 2010). Moreover, urban vegetation can also have a positive influence on air quality. In addition to carbon sequestration (Nowak \& Crane, 2002; Rowntree \& Nowak, 1991), the urban forest positively impacts air quality through the reduction of pollutants such as particulate matter (Beckett et al., 2000), ground level ozone (Nowak et al., 2000), and other gaseous pollutants (Nowak et al., 2006). Beyond structural value, there are a number of additional economic benefits associated with the urban forest. In addition to positively influencing property values (Anderson \& Cordell, 1988; Sander et al., 2010), strategically placed trees shade buildings and reduce summertime energy demand for cooling and associated savings related to in electricity costs (Akbari et al., 2001; McPherson \& Simpson, 2003; Sawka et al., 2013). Finally, the social benefit of trees have been demonstrated in a number of recent studies, ranging from an improved sense of community (where trees are present) to individuals experiencing direct health benefits (Grahn \& Stigsdotter, 2003; Kardan et al., 2015; Ulrich, 1984).

The aggregate benefits delivered by the urban forest are a function of a number of structural attributes. The capacity to deliver many ecosystem services is in large part a function of leaf area index or "LAl" (McPherson, 1992; Peper \& McPherson, 1998) and the LAl is determined by the size (i.e., typically synonymous with age) of the tree, the species, and by the condition or health of the individual tree (Millward \& Sabir, 2010). The interdependence of these attributes can explain some of the variance (often counter-intuitive) in the benefits estimated for seemingly similar urban forests in different cities. For example, the urban forest of Los Angeles with 6 million trees was found to have a greater structural (or compensatory) value of $\$ 12.4$ billion, and greater aggregate benefits than Toronto's 10.2 million trees and $\$ 7.1$ billion structural value (Nowak et al., 2011; Nowak et al., 2013). This difference in benefits provided to city residents is influenced by a number of factors, including: 1) local climate differences; 2) different levels of ambient air pollution; and 3) different structural characteristics related to the urban forest resource of both cities. Because Los Angeles remains warmer for a longer period than Toronto, there is a need for cooling for a longer period, and thus greater electrical savings from the reduced need for cooling provided by city trees are expected in Los Angeles over Toronto. With air pollution levels often ranking among the worst in the United States (Künzli et al, 2003), pollution abatement services are expected to be higher for the urban forest of Los Angeles than Toronto as well. In addition to these differences, there is also a direct influence of the size distributions of trees constituting the urban forest in each of these cities, indicated by the percentage of the urban forest with stem diameters less than $15.24 \mathrm{~cm}$ (or 6 inches). Comparing the two cities, the urban forest of Los Angeles contains approximately $40 \%$ of trees with this small diameter; $68.6 \%$ for Toronto's 
urban forest is in this size class (Nowak et al., 2011; Nowak et al., 2013). In other words, although Toronto has a higher overall tree count than Los Angeles, the greater average tree size and subsequent larger LAI of trees in Los Angeles have a greater capacity to deliver benefits to city dwellers.

\subsection{THE IMPORTANT INFLUENCE OF MANAGEMENT DECISIONS}

While the structure of city's urban forest is heavily influenced by the physical environment (Sanders, 1984; Sieghardt et al., 2005; Zipperer et al., 1997), many of its characteristics are also a product of decisions made at several levels of government (Clark et al., 1997; Kirnbauer et al. 2009). Over the past century, human patterns of settlement have become increasingly urban (Alig et al., 2003; United Nations, Department of Economic and Social Affairs, Population Division, 2014). As cities expand and intensify to accommodate population growth, the demand for space increases and the value of that space rises. Policies targeting where and how to grow can have an impact the urban forest resource. If a city pursues low-density and outward sprawl, the result may be that pre-settlement forest is subsumed (Nowak and Walton, 2005). If, on the other hand, a city decides to enact intensification policies and promote density within the city, reforestation and afforestation efforts encounter further barriers. The urban environment is undoubtedly a challenging place to establish and grow trees (Richards, 1983; Whitlow \& Bassuk, 1988). As impervious surface increases, suitable growing conditions for trees become scarcer and can lead to elevated mortality of young trees (Foster \& Blaine, 1978; Lu et al., 2010), reduced growth rates compared to their rural conspecifics (Close et al., 1996; Quigley, 2004; Smiley, et al., 2006), and may frequently exhibit signs of stress (Bassuk \& Whitlow, 1988; Close et al., 1996).

Working with fixed short-term budgets, urban forest managers regularly make decisions that trade long-term consequences for short-term program delivery efficiencies. When faced with adverse urban growing conditions there are few options: 1) limit tree diversity by planting fewer tree species that exhibit higher tolerance of harsh urban growing conditions; 2) plant fewer trees overall and spend more money per tree to improve growing conditions by reclaiming impervious surface or by implementing engineered subsurface solutions; or, 3) plant somewhere else (e.g., public parks, natural areas, vacant land) with less challenging growing conditions more likely to yield greater survivability and longevity. If one of these approaches remains a dominant urban forest management strategy, structural changes to the urban forest will occur. Due to the time lag associated with tree establishment and growth, the consequences of said choices may not be apparent for several decades. 
In many cases, preference for the first option (i.e., prescribing a restricted species selection) results from decision making that prioritizes the economic dimension. Although this alternative likely improves the short-term efficiency of a tree-planting program, once these trees have established and mature, a quasi-monoculture (minimal species richness and/or genera dominant) urban forest will result. Poor species richness increases the susceptibility of the urban forest canopy to catastrophic loss from insect pests or pathogens. A preference for the second option, planting fewer trees but improving growing conditions, can be effective at addressing a social dimension of sustainability through the prioritizing of planting in urban neighbourhoods that are likely to be deficient in large, healthy trees. Over time, minimum levels of UTCC can be provided to all residents, buffering against distributional inequalities in access to UTCC. The result, however, will be a negative in terms of effect on short-term program efficiency and ecosystem service delivery because improving opportunities for trees in these difficult growing conditions is more costly and, moreover, these trees may still not reach their maximum growth potential. The final option (i.e., planting largely in areas with more ideal growing conditions) will undoubtedly improve short-term program efficiency. Moreover, these trees are more likely to live longer and grow larger, thus improving the efficiency of ecosystem services delivery through greater aggregate per tree benefits. There is, however, a risk with this last option of creating or exacerbating distributional inequalities of access to UTCC.

\subsection{THE URBAN FOREST AS A FOCUS FOR STUDY}

The urban forest (and management of this resource) was chosen as the focus of this research for several reasons. This work is both informed by, and interpreted through, the belief that sustainability must be "strong". As such, natural capital is non-substitutable and there is a human responsibility to protect and enhance natural capital for future generations. Within the broader context of this work, the urban forest is understood to be an important natural capital resource to cities, particularly in densely populated urban settings. In many circumstances, tree cover in cities has diminished, but with informed management that embraces strong sustainability principles, this resource can be restored and enhanced over time. Reducing the ecological deficit in cities, which is experienced by many urban inhabitants, can occur through either, or both, of the following: 1) limiting consumptive behaviours so as to reduce the resources required to both feed per capita consumption and to process waste, and 2) enhancing and expanding the ability of natural capital resources to deliver ecological services. Protection and enhancement of the urban forest exemplifies strong sustainability. 
The urban forest provides a unique opportunity to investigate the impacts of past EDM, and findings of such investigations can offer insights into how to improve future processes specific to EDM. The protection, loss, or enhancement of the urban forest is dependent on a suite of decisions made by a spectrum of stakeholders, from the broad policies adopted by municipal representatives, to the planting decisions related to an individual tree. Over time, the sum of these decisions influences the structure, resilience, and total benefits provided to the city by an urban forest. These management decisions also influence how city trees, and their associated benefits, are distributed and accessible to urban residents. The time required for trees to reach a mature stature, a state where their benefits are maximized, adds a novel temporal dimension to the case studies presented herein. In summary, the urban forest of a densely populated city like Toronto, Canada provides an excellent context to consider the longer term consequences of EDM for the urban forest.

Finally, though Toronto's urban forest represents approximately $26-28 \%$ city coverage by area (City of Toronto City of Toronto, Parks, Forestry and Recreation, Urban Forestry, 2013), the city's urban forest continues to face significant pressures, including invasive species, disturbance from urban redevelopment and intensification, as well as longer term climate change. The potential decline of Toronto's urban forest canopy, a common trend observed among many North American cities (Nowak \& Greenfield, 2012), supports the need for an improved understanding of past management decisions in an effort to better protect and enhance this natural capital resource.

\subsection{REsEARCH OBJECTIVE}

The intention of this study is to demonstrate empirically how past decisions related to urban forest management in a dense city setting like Toronto can lead to unsustainable outcomes when sustainability subsystems are considered separately, as opposed being considered as a complement. From this purpose, the following research objectives have been identified: 1) to contribute to urban forestry theory by investigating a process or relationship related to each subsystem of sustainability and, accordingly, by advancing understanding of that process or relationship; 2) to enhance urban forestry policy and management discourse by demonstrating a set of approaches that can integrate evidence from all three sustainability subsystems and advance a decision-making framework that provides a more balanced approach to EDM; and, 3) to adapt and apply existing methods, developed in other EDM contexts, to yield new insights concerning the protection and enhancement of urban forest function, accessibility and resilience. 
The variables operationalizing the relationships for each subsystem were chosen because of their topical relevance to the study area as well as data availability. These variables should not be viewed as absolute exemplars for each individual sustainability subsystem as urban forest structure is highly context-specific, varying by location and temporally.

\subsection{SUBSEQUENT CHAPTER SUMMARIES AND AUTHORSHIP STATEMENTS}

This dissertation is organized in five chapters (see Figure 1-2). Beyond this introductory chapter that sets the disciplinary context and conceptual framework for the dissertation, three original research studies are presented in manuscript style (Chapters 2, 3, and 4). Each manuscript addresses a dimension of the urban forest that has a connection to one of three discrete subsystems of sustainability (i.e., ecological, social, and economic). Within the individual manuscripts, a relationship or process is examined in an effort to 1) contribute to urban forestry theory through an improved understanding of that relationship or process; 2) contribute to environmental decision-making theory by exploring the trade-offs that result when priority is given to a single dimension of the urban forest; and 3) inform policy decisions through demonstrating the implications of focusing on a single dimension of the urban forest as a sole metric for prioritizing management decisions, particularly tree planting decisions. The concluding chapter (Chapter 5) examines the connection between the three research studies and provides thematic context related to the broader scope of this work.

\subsubsection{Chapter 2 - Getting closure: the role of urban forest canopy density in moderating surface temperatures in large cities}

This chapter focuses on an ecological dimension of the urban forest with the objective of quantifying the function of urban tree canopy density (or canopy closure) to deliver an important ecological service: mitigating rise in summer urban surface temperatures. The results of this study provide strong empirical support for municipalities to direct attention to tree canopy quality metrics such as increasing the density of existing urban forest stands, should their objective be to achieve the more effective delivery of ecosystem services by the urban forest. This chapter also identifies preliminary evidence to support the existence of distributional inequalities in access to the urban forest, though this evidence is not location specific, and thus provides impetus for the study developed in Chapter 3.

Authorship Statement: Christopher Greene wrote Chapter 2 as a single author manuscript for submission as original research with editorial support from Dr. Andrew Millward, 
Principal Investigator with Ryerson University's Urban Forest Research \& Ecological Disturbance (UFRED) Group.

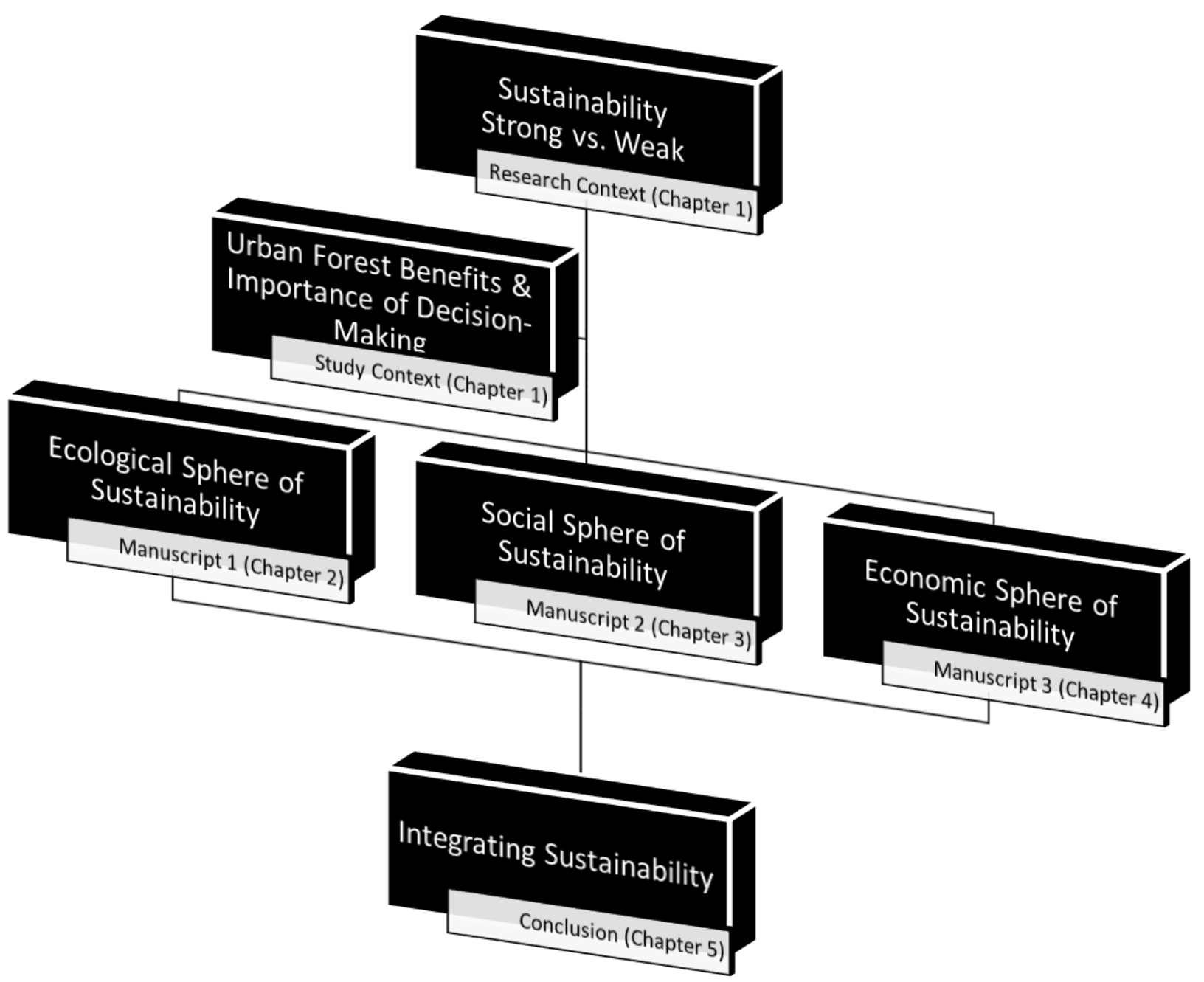

Figure 1-2: Schematic diagram outlining the overall dissertation structure

\subsubsection{Chapter 3 - Canopy of advantage: who benefits most from city trees?}

The study contained within this chapter focuses on a social dimension of the urban forest by investigating the relationship between resident household income and geographic proximity to urban tree canopy (i.e., accessibility to the urban forest and its associated benefits). In addition to identifying distinct distributional inequalities (both aspatial and spatial), this study identifies and discusses several challenges associated with moderating distributional inequalities from the perspective of policy creation. 
Authorship Statement: Christopher Greene wrote Chapter 3 as a single author manuscript for submission as original research with editorial support from Dr. Andrew Millward, Principal Investigator with Ryerson University's Urban Forest Research \& Ecological Disturbance (UFRED) Group.

\subsubsection{Chapter 4 - The legacy of past tree planting decisions for a city confronting emerald ash borer (Agrilus planipennis) invasion}

An important economic dimension of city trees is explored in this chapter by constructing a theoretical urban forest damage potential index for Toronto using spatial analytical methods and used as a framework to investigate the legacy of past tree planting decisions on Toronto's urban forest vulnerability with respect to the emerald ash borer (Agrilus planipennis). This damage potential index serves as a transferable framework to evaluate the time-lagged consequences of planting decisions that trade short-term efficiency considerations for the potential long-term effects of decreased tree species diversity. Findings from this study demonstrate that legacy effects of past tree planting decisions are geographically extensive and multi-scalar.

Authorship Statement: Christopher Greene wrote Chapter 4 as a single author manuscript for submission as original research with editorial support from Dr. Andrew Millward, Principal Investigator with Ryerson University's Urban Forest Research \& Ecological Disturbance (UFRED) Group.

\subsubsection{Conclusion: integrating sustainability subsystems with urban tree planting decisions}

This final chapter discusses how the original research contained in Chapters 2 through 4 is positioned within the broader context of strong sustainability and the discourse concerning urban forest structure, function and resilience. Potential contributions of this work to sustainability theory and to urban forestry policy, as well as directions for future research, are further discussed. 


\section{GETTING CLOSURE: THE ROLE OF URBAN FOREST CANOPY DENSITY IN MODERATING SURFACE TEMPERATURES IN LARGE CITIES}

\subsection{Abstract}

With a growing number of people living in urban areas, residents are more frequently exposed to stresses related to the built environment including increased surface temperatures resulting from the urban heat island (UHI) effect. This study examines the role of urban trees in moderating microclimatic variation in a densely populated city (Toronto, Canada), specifically the relationship between tree canopy density and surface temperature. By applying parallel aspatial (OLS) and spatial regression (GWR) approaches with satellite derived data describing tree canopy density and surface temperature, this study demonstrates how one dimension of canopy quality (i.e., canopy density) directly contributes to a reduction in the UHI effect at the local scale. Though the model fit differed between the two regression approaches, both exhibited moderately strong explanatory power and demonstrated that observed surface temperature decreases with the increase in area of closed canopy and high-density canopy. These results provide an empirical basis for municipalities to direct attention to tree canopy quality metrics such as increasing the density of existing urban forest stands as a part of municipal tree planting objectives that can more effectively deliver ecosystem services.

\subsection{INTRODUCTION}

Over the past several decades the proportion of people living in urban areas has grown at a considerable pace (United Nations, Department of Economic and Social Affairs, Population Division, 2014). Life in urban centres can be attractive for a number of reasons, including access to economic opportunities, culture and recreation (Newman, 2006). Moreover, cities continue to be incubators for innovation (Botkin \& Beveridge, 1997). Despite these opportunities, urban living (often correlated with intensification of the built environment) can result in exposure of city residents to a number of environmental stressors that are more concentrated than those found in natural settings, or in surrounding rural areas. The increased density of built structures and the associated human population creates pressure on, and often the loss of, naturally occurring vegetation or vegetation planted historically by city dwellers as an amenity to counter increases in impervious surface (Nowak \& Greenfield, 2012). Intensification of automobile use increases city inhabitant exposure to ambient air pollution in the form of ground level ozone $\left(\mathrm{O}_{3}\right)$, particulate 
matter (PM), nitrous oxides (NOx), and sulphur dioxides (SOx) (Dockery et al., 2003; Sarnat et al., 2000). Meeting the electricity demands of urban populations can also result in increases in air and water pollution with the potential to impact ambient air and water quality of the city region (Satterthwaite, 1997; World Health Organization, 2006). The removal of naturally occurring or planted vegetation is of particular concern. Many studies have demonstrated the ecological services provided by city trees, which include carbon sequestration (Nowak \& Crane, 2002; Rowntree \& Nowak, 1991), the removal of particulate matter (Beckett et al., 1998; Becket et al., 2000), as well as ability to reduce local concentrations of a suite of other air pollutants originating from industry, transportation vehicles, and electrical power generation (Escobedo and Nowak, 2009; McPherson et al., 1998; Nowak et al. 2006).

One particular stress that urban residents are exposed to is elevated summer temperatures in the form of the Urban Heat Island (or 'UHI') effect. This UHI refers to a microclimatic phenomenon: under constant conditions (i.e. time of day, insolation), urbanized areas generally exhibit higher temperatures than their rural surroundings (Oke and Maxwell 1975; Voogt and Oke 2003). Within the predominately built environment of cities, the extensive horizontal and vertical distribution of impervious surfaces absorb and trap heat during the daylight hours and then slowly release that stored heat during the evening and nighttime hours (Federer, 1976; Roth et al., 1989). As a consequence, there is a strong diurnal trend, with highest magnitude surface temperatures occurring midday, and highest magnitude air temperature differences occurring in the early evening, a few hours after sunset (Roth et al., 1989).

In addition to this diurnal trend in temperatures, broader geographic patterns have been identified linking observed variance in the UHI with the ecological setting of the city. In an examination of cities in the continental United States, Immhoff et al. (2010) concluded that cities located in temperate deciduous forest biomes exhibited the highest differences in urban-rural temperatures. Expanding this methodology beyond the US to a suite of 3000 cities across different global settings, work by Zhang et al. (2010) showed similar findings.

Though urban temperatures are elevated through all seasons when compared to the city's rural surroundings, elevated temperatures in the summer season are particularly concerning. Urban centres have been reported by Jim and Chen (2008) to be, on average, 0.5 to $1.5^{\circ} \mathrm{C}$ hotter than adjacent rural areas; Rosenzweig et al. (2006) state that this average temperature deviation can exceed $4^{\circ} \mathrm{C}$ in large metropolitan areas such as New York City. In addition to associated deleterious health consequences for urban inhabitants (Huang et al., 2010; Kershaw and Millward, 2012; Klinenberg, 2002), elevated temperatures also contribute to an increased demand 
for cooling energy (Akbari et al., 2001; Donovan \& Butry, 2009; Sawka et al., 2013) and are correlated with elevated air pollution levels (Akbari et al., 2001; Akbari, 2002) as higher ambient temperatures create favourable conditions for the formation of photochemical smog.

Despite the diverse benefits provided by urban trees, recent analyses of urban forest cover in U.S. cities point toward a general decline in urban tree canopy cover (Nowak \& Greenfield, 2012). Furthermore, Nowak and Walton (2005) project that approximately 11.8 million hectares (or 29.2 million acres) of natural forestland will be "subsumed" by expanding urban areas from 2000 to 2050 . Though not all of this vegetation will be completely lost, remaining forest patches will be considerably more fragmented and are likely to influence or modify related ecosystem services. This removal of urban vegetation is concerning because this loss can result in multiplicative negative effects. First, city trees mitigate or moderate a rise in urban summer temperatures through a number of mechanisms, including (1) reflection, absorption, and diffraction of solar radiation; (2) shading concrete and asphalt minimizing radiant energy conversion to sensible heat; (3) evapotranspirative cooling of ambient air temperature; and, (4) modification of air flow (Arnfield, 2003; Federer, 1976; McPherson, 1984; Millward et al, 2014; Nowak et al., 2006). A deterioration in the moderating effect of trees through their removal can lead to an increased demand for additional electricity for cooling, resulting in increased pollution from power generation. Moreover, a declining urban forest has the added effect of reducing the capacity of existing city trees to mitigate increases in pollutant concentrations from such sources as heightened energy production for summertime indoor cooling demand.

Recent estimates of global population dynamics and predicted scale of urbanization suggest that the problems associated with urban development, like the UHI effect, are likely to remain a concern for the foreseeable future (Grimmond, 2007). These population estimates by the United Nations Population Division suggest that nearly 50 per cent of the world's population currently live in urban areas and will pass 67 per cent by 2050 (United Nations, Department of Economic and Social Affairs, Population Division, 2014). Though the full extent of the subsequent impacts from this transition to more people living in cities is difficult to predict, the expected growth in urban populations cannot be accommodated without consequences to existing vegetation, both within the present urban boundaries, and on the urban fringes. This predicted growth in the proportion of global population living in urban areas will require that cities either continue to expand their geographic boundaries (i.e., urban expansion) and / or attempt to increase the population density within their present boundaries (i.e., intensification). Regardless of which approach takes precedence, or whether some weighted combination of approaches is preferred 
by individual cities, this continued urban growth will result in both direct and indirect consequences for existing city trees and will undoubtedly set a trajectory for the future potential of urban vegetation cover.

The expanding areal coverage of cities, and the intensification of built structures (often at the expense of vegetation cover), will continue to exacerbate observed urban-to-rural air temperature gradients. Moreover, it has been suggested that the UHI phenomenon is likely to increase with global climate change (McCarthy et al., 2010; Meehl and Tabaldi, 2004). Empirical evidence for the ability of tree canopy cover to mitigate increased summertime urban temperatures has been established at two extremes of spatial scale. At the local scale, Heisler (1986) demonstrated that a single sugar maple (Acer saccharum) tree can reduce the amount of solar radiation incident on the wall of an adjacent building by as much as $80 \%$, when strategically planted (i.e., adjacent to the south and southwest facing walls of the built structure). Measuring urban temperatures at the scale of the entire city, by using vehicle transverses of Portland, Oregon, Hart and Sailor (2009) related city neighbourhoods with greater tree canopy coverage to lower ambient air temperatures, when compared with urban neighbourhoods exhibiting less tree canopy coverage.

It is reasonable to hypothesize, however, that the more regional, aggregated measure of percent tree canopy presents an inherent limitation, specifically that the measure masks local variation in ecosystem service delivery linking directly to the attributes of the individual trees comprising an urban forest patch, including the species, spatial arrangement and age of individual trees. Therefore, it would be expected that a cohesive patch of mature, dense trees should have a greater capacity for the realization of ecosystem services such as temperature mitigation (through greater shading and increased rates of evapotranspiration) when compared to the same and equal, but highly fragmented, area comprised of a smaller or younger trees. This increase in expected temperature mitigation benefits is related to a greater vertical extent of vegetation and associated increase in leaf area index (LAl).

At present, there is limited research that moves beyond the more regional metric of tree canopy percentage to consider measures of tree canopy quality and its subsequent influence on specific, local ecosystems. In one example, Escobedo \& Nowak (2009) investigated the influence of spatial heterogeneity in tree canopy cover on air pollution removal in Santiago Chile, identifying differential rates of pollution removal rate related to differing sub-regional forest structures. However, few studies consider the influence of tree canopy quality on the mitigation of rise in summer urban air temperature. Minimal research in this area may result from the difficulty in 
integrating a multi-dimensional, complex attribute such as "quality" into statistical models. Tree canopy quality is an aggregate of the attributes of individual trees that contribute to forest patches. The species distribution, size distribution, age distribution, and health of the individual trees that comprise the canopy determine the overall quality of each forest patch. The aggregation of those forest patches determine the quality of the overall urban forest. As a result it is more common to see measures of quality applied at a very local level (i.e., small sample plots) rather than over a broader region such as an entire city. Developing continuous data for many of the measures that contribute to canopy quality can be quite prohibitive. Not all potential measures of canopy quality are affected by these limitations, however. The availability of medium-resolution satellite imagery, such as the Landsat series of satellites, allows for a variable such as tree canopy density to be processed as a continuous dataset across a large study area.

The availability of a spatially continuous dataset related to tree canopy density opens new opportunities for examining the relationship between the $\mathrm{UHI}$ and urban vegetation at a more local level (e.g., sub-city units such as census tracts) than the more generalized measure of canopy percentage that is commonly considered at the broader city-scale. A local focus is an important consideration because urban vegetation presents a special set of circumstances, being both publically and privately owned. Despite property rights being assigned to individual trees, in some circumstances the ecological services flowing from this natural capital benefit all city inhabitants (Sawka et al., 2013), making urban vegetation (especially trees) a valuable common property asset (Lohr et al., 2004). The moderation of temperature by urban trees may represent an exception as the benefits of tree canopy presence are likely to be more localized, extending beyond an individual household but not to the city-level.

Though the distribution of tree canopy is frequently heterogeneous across many cities (Zipperer et al., 1997), this heterogeneity may result in unbalanced access to local system services, such as mitigation of surface temperature increases, depending on a resident's income or other socioeconomic variables. The potential for an environmental injustice scenario is of particular concern whenever the distributional equality of urban canopy and benefits are considered; several studies have demonstrated a connection between socioeconomic variables and access to green space. For example, an examination of forest cover in Chicago, Illinois derived from Landsat imagery by Iverson \& Cook (2000) determined that wealthier regions of the city benefitted from higher tree cover than poorer areas of the city. Similarly, Landry \& Chakraborty (2009) determined access to existing urban vegetation in Tampa, Florida was less likely in areas of lower income and higher ethnicity. When evaluating the Greening Milwaukee program provided 
by the City of Milwaukee, Wisconsin, Perkins et al. (2004) identified a weak but significant correlation between median household income and tree canopy cover. Using a path analysis approach, a study of vegetation, median household income, and surface temperature at the census tract level for Phoenix, Arizona, Jenerrette et al. (2007) demonstrated the positive relationship between income and vegetation and the negative relationship between vegetation and surface temperature.

This study seeks to advance understanding of the relationship between urban tree canopy quality and the variation in urban surface temperature, by focusing on a single aspect of tree canopy quality, canopy density, and its influence on built surface temperatures. Specifically, regression analyses (both Ordinary Least Squares [OLS] Multiple Regression and Geographically Weighted Regression [GWR]) are used to evaluate the relative explanatory power of low-density and high-density tree canopy to predict surface temperature distribution across Toronto, Canada, a large North American city with considerable heterogeneity in urban form. With the relationship between canopy density and surface temperature established, this study will also explore the management implications of integrating the hypothesized findings (i.e., the presence of higher tree canopy quality is positively correlated with cooler built surface temperatures) as a primary criterion for prioritizing planting locations in an urban afforestation program. Analysis of Variance (ANOVA) of land-cover tree canopy classes and categorized by median personal income (MPI) is used to establish whether an initial imbalance in access to higher quality canopy types exists within the study area to complement the discussion of management implications.

\subsection{Materials and Methods}

\subsubsection{Study Area}

This project is focused on the City of Toronto in southern Ontario, Canada. In 1998, the geographic boundary of the City of Toronto was greatly expanded based upon the amalgamation of six contiguous municipal units: Toronto, York, East York, North York, Etobicoke, and Scarborough (Schwartz, 2004). Prior to amalgamation, each municipal unit operated independent of one another and was subject to its own municipal planning bylaws. Differences in planning regimes have led to differences in urban form, such as population density (see Figure 2-1). Amalgamated Toronto covers an area of $630 \mathrm{~km}^{2}$ and, according to the 2011 Census, has an associated population of 2.6 million people (an increase of $4.5 \%$ from 2006) making it the largest city in Canada. An estimated 10.1 million trees make up Toronto's urban tree canopy: 0.6 million street trees; 3.5 million are growing in parks and natural areas; while the remaining 6.1 million 
trees are located on private property (City of Toronto, Parks, Forestry and Recreation, Urban Forestry, 2013).

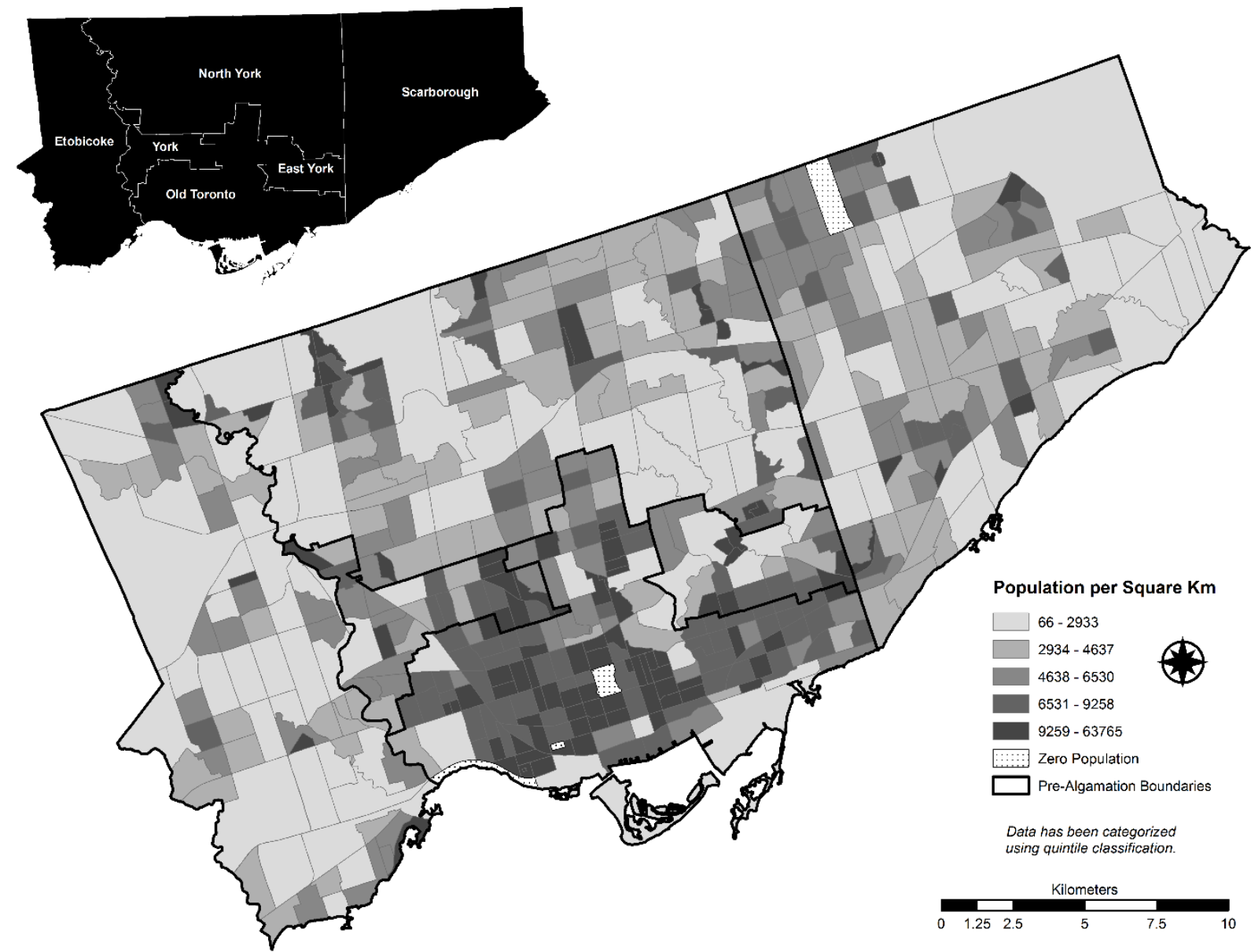

Figure 2-1: Population density of Toronto, Ontario Canada (2006) by census tract with superimposed preamalgamation boundaries (see inset for identification).

\subsubsection{Data Preparation}

\subsubsection{Land-Cover Classification and Identification of Canopy Type}

A land-cover map of Toronto (Figure 2-2A.) was produced using a Landsat Thematic Mapper 5 (TM5) satellite image acquired 25 July 2005 (ID: LT50180302005206GNC01). Data from mid-summer was chosen for contextual purposes: the imagery content is reflective of a time instance when tree canopies are fully 'leafed out'. Other conditions, such as the absence of significant cloud cover and lack of atmospheric haze, also influenced the choice of imagery. Image data were acquired with Standard Terrain Correction (Level 1T), ensuring both radiometric and geometric accuracy. Prior to classification of the image data, the spatial resolution of pixels was 
resampled from 30 metre pixels to 25 metres using a nearest neighbour resampling procedure to simplify subsequent computational analyses (Jensen, 2005).

Supervised maximum likelihood classification (MLC) was performed on the Landsat TM5 image to identify five land-cover classes. The MLC approach is a de facto standard for image classification, using statistical parameters (i.e., mean, standard deviation, covariance matrix, and correlation matrix of the spectral signatures of each derived image feature) calculated from the training sites (aggregations of pixels with known land-cover characteristics) identified for input in to the classification (Jensen, 2005). The raster seeding approach implemented in Geomatica (PCI Inc.) was applied to select locations for training site classification (Campbell and Wynne, 2011) provide a detailed review of training site selection criteria). Six thematic land-cover classes were delineated for this study and included: (1) closed canopy / forested areas (pixels representing $100 \%$ canopy cover); (2) high-density canopy (pixels containing $>40 \%$ to $<100 \%$ canopy cover); (3) low-density canopy (pixels containing 10-40\% canopy cover); (4) open pervious surface; (5) impervious surface; and (6) water. The design of this classification scheme was intended to differentiate among tree canopy densities so as to identify a potential proxy metric for defining urban forest quality.

Using an iterative approach to feature identification, four techniques were deemed to be the most effective at maximizing spectral signature separability among the five land-cover classes. Principal component analysis (PCA) was used to transform the original Landsat TM5 spectral channels into a smaller set of uncorrelated variables (Jensen, 2005; Millward et al., 2006); the first three components were selected (accounting for $99.2 \%$ of the variation contained within the six original spectral channels) for inclusion in the supervised MLC. Normalized difference vegetation index (NDVI) has been used successfully in urban land-cover classifications and change detection studies to differentiate between vegetated and non-vegetated surfaces (Prol-Ledesma et al., 2002; Millward, 2011; Weng, 2001) and was an essential input to the image classification in this study. The usefulness of NDVI was determined by visually examining preliminary classification results with and without its inclusion. The calculation of tasseled cap coefficients provides detail concerning the abundance and vigour of vegetation (Campbell and Wynne, 2011; Kauth and Thomas, 1976). This study used tasseled cap coefficient two, representing 'greenness'. Finally, a mean texture surface was generated using a 3 x 3 pixel moving window applied to the raw Landsat TM5 spectral bands. Output from each of these data transformation provided the basis for the MLC in lieu of the raw data from Landsat TM5 spectral channels. 


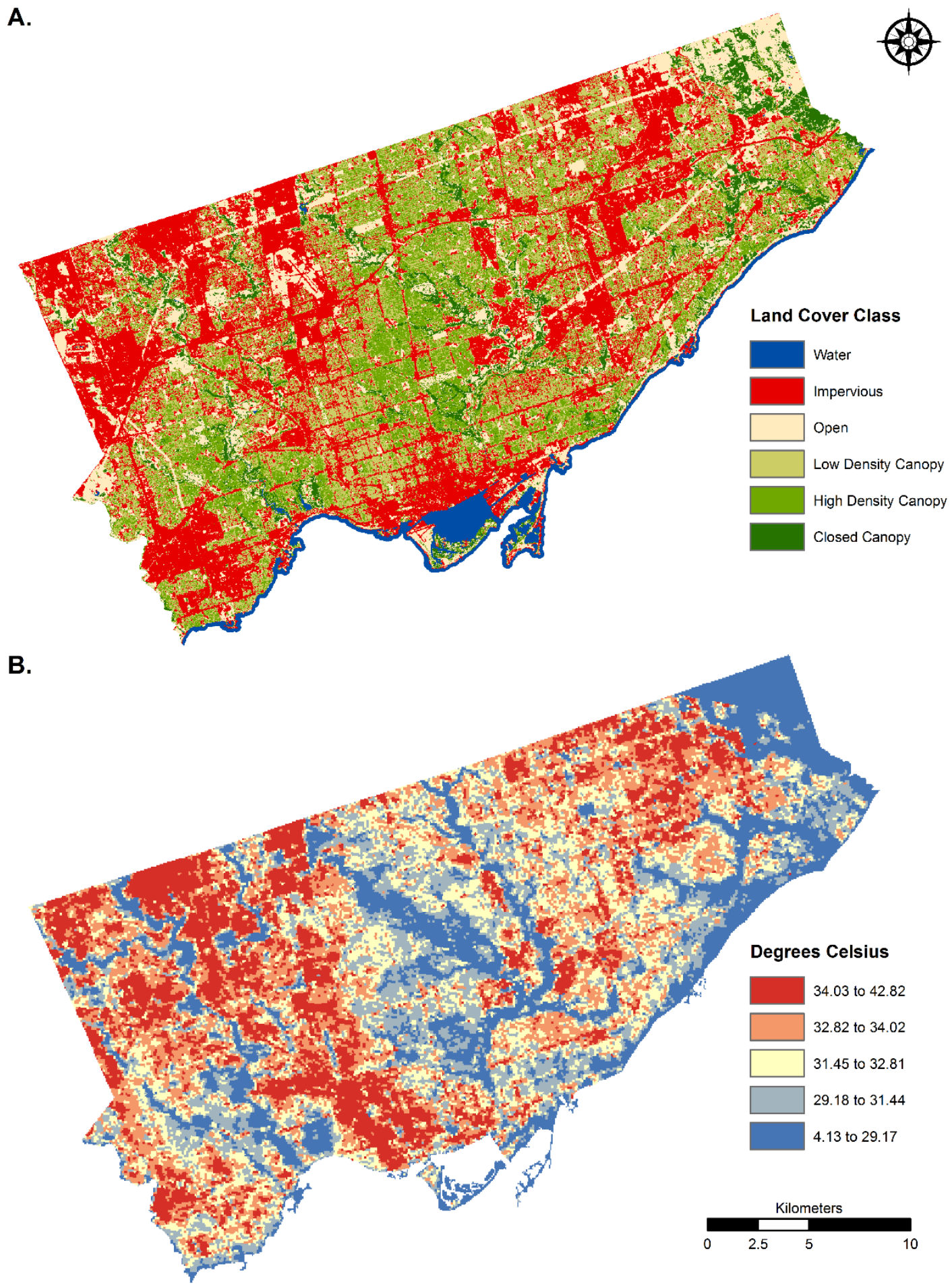

Figure 2-2: Classified land-cover data (A) and surface temperature data (B) derived from 2005 Landsat TM5 imagery for amalgamated City of Toronto, Canada (2005). 


\subsubsection{Verification of land-cover classification}

A post-classification accuracy assessment was conducted to evaluate the reliability of the MLC results. Using land-cover classifications as divisions, a stratified random sampling design was created to compare the MLC results to ground-reference information. A total of 292 classified pixels, proportioned based on land-cover area, were manually inspected and compared to 2005 colour orthorectified air photos with $20 \mathrm{~cm}$ a side spatial resolution (J.D. Barnes First Base Solutions). This approach to land-cover classification accuracy assessment mirrors many other study approaches in urban areas, including Phinn et al. (2002) who mapped urban composition in Brisbane, Australia using Landsat TM5 data and Lu and Weng (2006) who classified land-cover in Indianapolis, Indiana using Landsat Enhanced Thematic Mapper (ETM+) satellite imagery.

\subsubsection{Data Related to Surface Temperature}

Surface temperature data for the study region were obtained from Natural Resources Canada (Figure 2-2B). These data were originally derived from Landsat TM5 Band 6 (thermal infrared) as part of an investigation into the changing urban heat island in the Greater Toronto Area (for more descriptive methodology refer to Maloley, 2010). Imagery was collected on 3 June 2005 from Path 18 and Row 30, approximately one and a half months prior to the imagery acquired for preparation of the land-cover map. Separate images were selected not as a default methodological choice, but because the each dataset was processed for different purposes at different institutions.

\subsubsection{Aggregation}

Initially the two datasets (land-cover and surface temperature) were not comparable due to differing data scales (land-cover $=$ nominal; surface temperature $=$ interval). A quantitative evaluation of the relationship between surface temperature and canopy requires commonality between data types and the scale of areal unit. For the purpose of this investigation, aggregation to the census tract (CT) level was deemed an appropriate choice as: 1) the CT provides a common areal unit for all of the target variables; 2 ) the unit is large enough to provide adequate variability within the distribution of observations, but small enough in size to maintain a significant number of observations ( $n=531)$ for a robust analysis; 3$)$ the areal unit is appropriately sized and convenient for completion of the complementary ANOVA analysis; and 4) the CT provides an aggregation unit that facilitates studies beyond this specific investigation to further research related to the relationship between socio-demographic data, canopy, and urban micro-climate. 
Aggregation of the surface temperature data produced a mean surface temperature in degrees Celsius $\left({ }^{\circ} \mathrm{C}\right)$ for each CT within the study area. Mean temperature serves as the dependent variable for this investigation. Aggregation of the land-cover data involved determining the area $\left(\mathrm{m}^{2}\right)$ of each land-cover class within each census tract; that area was then expressed as a percentage (\% area) of the CT. Three classes, low-density canopy, high-density canopy, and closed canopy, were chosen to act as the independent (or explanatory variables).

Prior to performing any statistical analysis, the dependent (mean surface temperature) and independent variables were evaluated to ensure assumptions related to the chosen statistical analysis (i.e., multiple regression) were met by the data. Though the dependent variable (surface temperature) appeared to exhibit some negative skewness in its distribution (skewness statistic $=-0.543$ ), this deviation from normality was not considered severe enough to warrant reexpression through the application of a transformation function. In contrast, all explanatory variables (low-density canopy, high-density canopy, and closed canopy) exhibited various levels of positive distributional skewness. It is important to note that although $211 \mathrm{CTs}$ lacked any closed canopy (i.e., 0\% coverage) and exhibited high positive distributional skewness, there was little concern about including this variable in the analysis. Each explanatory variable in a multivariate regression is not required to exhibit normality as each variable represents a partial slope in the regression equation, however the residuals resulting from the regression model should approximate a normal distribution (Rogerson, 2006). The distributions of aggregate variables acting are presented in Figure 2-3.

\subsubsection{Analysis}

Prior to modelling the relationship between tree canopy density and surface temperature, a one-way analysis of variance (ANOVA) was performed for each tree canopy land-cover class to determine whether the mean coverage of each differed within the study area when categorized by median personal income (MPI). Because the land-cover classes were aggregated to CTs, socio-demographic variables derived from the Canadian Census (2006) were available at the spatial scale of the analysis and provided the basis for the variable used to sort the data into classes. This categorization variable (or factor variable) was derived by determining the quartile boundaries of the MPI variable and assigning an ordinal value to each CT ( 1 = low income; 2 = medium income; 3 = high income; 4 = very high income. In other words, if the MPI for a CT fell within the first quartile the CT was assigned a value of 1 , if the MPI for a CT fell within the second quartile the CT was assigned a value of 2 , etc. Values representing quartile breaks and used to delineate the four income classes were $\$ 20,008.75, \$ 23,923.50$, and $\$ 31,155.50$. Testing for 
homogeneity of variances using Levine's Statistic verified unequal variances among groups for each of the tree canopy land-cover classes, thus a Games Howell post hoc comparison was chosen for this analysis.
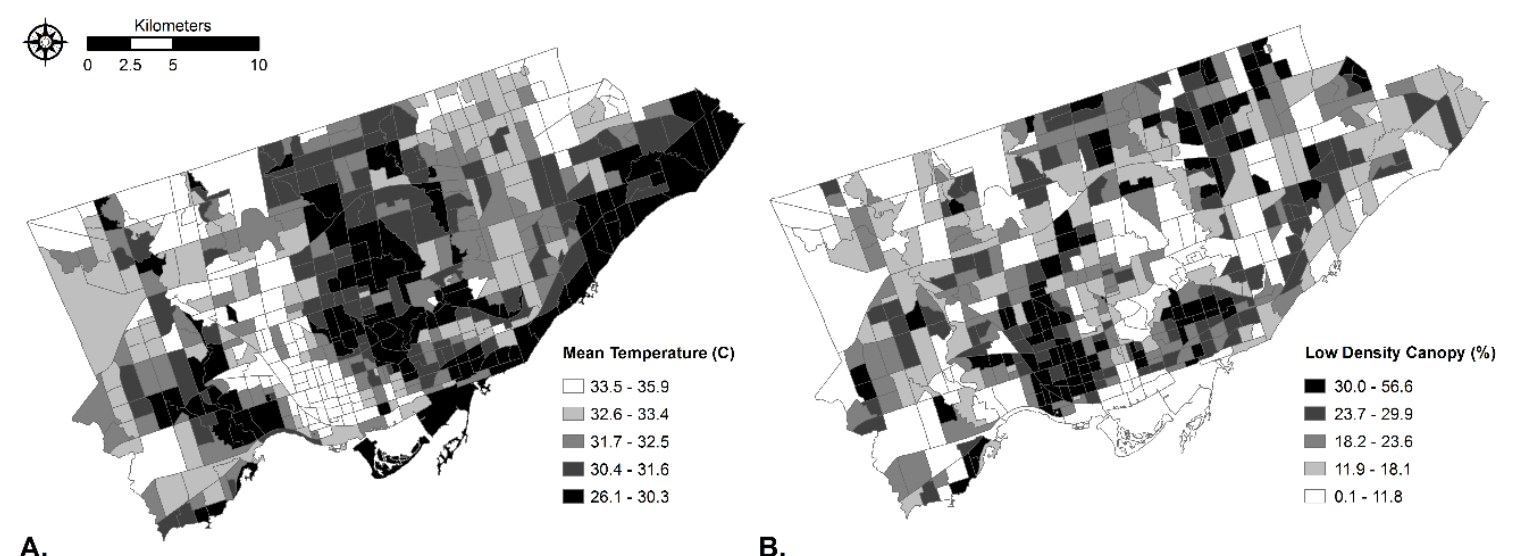

B.
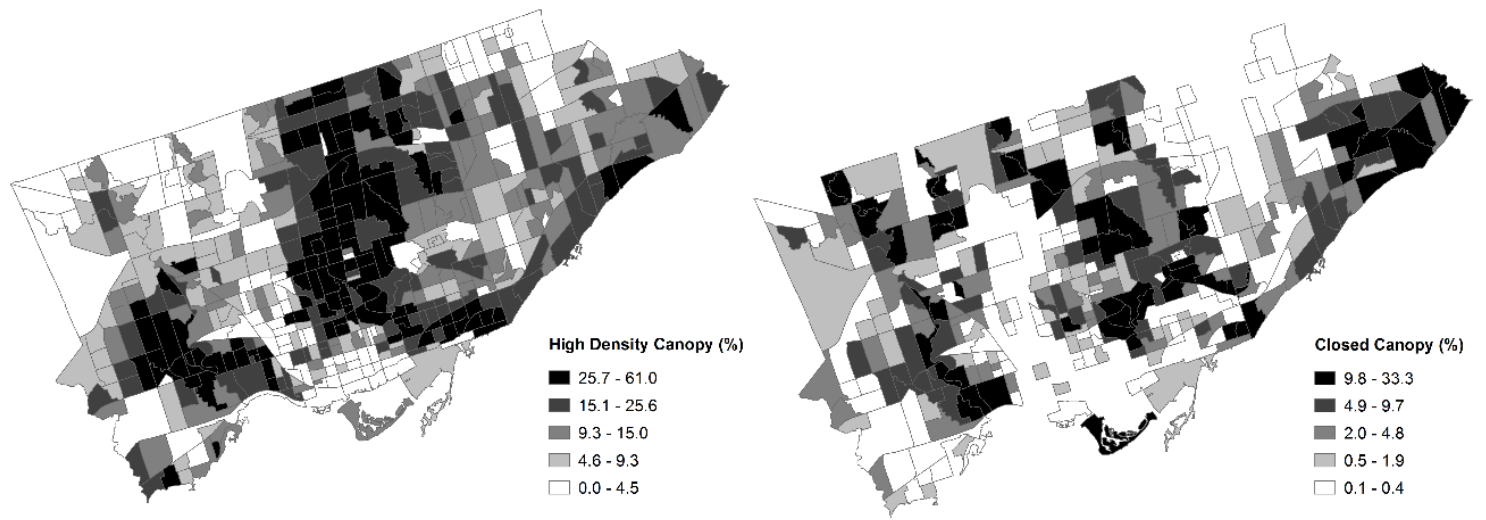

C.

D.

Figure 2-3: Input variables for ordinary least squares (OLS) and geographically weighted regression (GWR) models, aggregated to census tract geography including (A) mean surface temperature, (B) percent low-density canopy, (C) percent high-density canopy, and (D) percent closed canopy for the amalgamated City of Toronto, Canada (2005).

Both OLS and GWR were used to model the relationship between urban canopy and surface temperature (see Equation 2-1). While the OLS approach is the traditional standard for an analysis of this type, there is an inherent conflict between the type of data, namely spatial data, and the related assumption of independence between observations. Tobler's First Law of Geography, illustrates how the examination of spatial data inherently violates this OLS assumption. This law, "everything is related to everything else, but near things are more related than distant things" (Tobler, 1970, pg. 236), suggests that as proximity between two observations increases, the correlation between the two observations also increases. As such, spatial data do not truly represent independent observations, and are likely to exhibit spatial autocorrelation. 
Mean Surface Temperature ${ }_{i}$

$=\alpha+\beta_{1}$ Low Density Canopy $_{i}+\beta_{2}$ High Density Canopy $_{i}+\beta_{3}$ Closed Canopy $_{i}+\varepsilon_{i}$

Toronto's political history contributes an added layer of complexity to the investigation of tree canopy cover in the study region. Prior to 1998, what is now the amalgamated City of Toronto was composed of six distinct municipal units with independent planning regimes (Schwartz, 2004). Before amalgamation was legislated, several municipal units followed a path of development that encouraged higher density development in what is considered to be the core area for Toronto (i.e., Old Toronto). Other municipal units (e.g., Etobicoke, Scarborough, North York) followed development paths that did not encourage density on the same scale. As a result, the temperature moderation effect of urban tree canopy is expected to vary by locality as a result of the influence of historical municipal planning regimes and their resulting urban form. Thus, the more global measure provided by a statistical method such as OLS is unlikely to adequately capture the expected local variations in the ability of city trees to mitigate temperature increases across the study area.

Due to this limitation in the aspatial regression method, a GWR was also performed using the same independent and dependent variables. Use of a GWR model allows for the calculation of local weighting factors for the independent variables and minimizes spatial autocorrelation. Moreover, the heterogeneity in urban form is likely to result in spatially varying parameters and be better accounted for through the local weighting measures of the GWR. A limitation of this approach, however, is that the resulting model fit (pseudo $R^{2}$ ) tends to be inflated. By running both an OLS and GWR in parallel, an upper and lower threshold for the relationship between canopy density and surface temperature is established.

Standardized residuals were generated for both regression models, mapped, and evaluated for spatial autocorrelation and to inform the validity of model specification.

\subsection{Results}

\subsubsection{Land-cover classification accuracy}

The MLC of the Landsat TM5 imagery achieved an overall accuracy of $81.5 \%$ (Table 2-1), a result consistent with other land-cover classification accuracies reported in the literature (e.g. Lu \& Weng, 2006; Prol-Ledesma et al., 2002). The overall Kappa statistic of 0.762 for this 
classification implies the methodology provided a result $76.2 \%$ better than what would occur by chance (Lillesand et al., 2007). Additionally, an examination of the user's accuracy, a measure that quantifies errors of commission, revealed a strong measure of agreement between the classified map and actual ground characteristics (ground characteristics were determined through air photo interpretation) (Jensen, 2005). At the class level, user's accuracy was greatest for impervious surface, followed by contiguous canopy and low-density canopy. While slightly less accurate, classification of open land and high-density canopy remained moderate to strong.

Table 2-1: Accuracy assessment related to the classification of land-cover data derived from Landsat TM5 imagery.

\begin{tabular}{|c|c|c|c|c|c|c|c|c|c|}
\hline \multirow[b]{2}{*}{$\begin{array}{l}\text { Classified } \\
\text { Data }\end{array}$} & \multicolumn{5}{|c|}{ Reference Data } & \multicolumn{4}{|c|}{ Row Statistics } \\
\hline & $\begin{array}{l}\text { Impervious } \\
\text { Surface }\end{array}$ & $\begin{array}{l}\text { Closed } \\
\text { Canopy }\end{array}$ & Open & $\begin{array}{c}\text { High- } \\
\text { density } \\
\text { Canopy }\end{array}$ & $\begin{array}{l}\text { Low- } \\
\text { density } \\
\text { Canopy }\end{array}$ & $\begin{array}{l}\text { Row } \\
\text { Total }\end{array}$ & $\begin{array}{c}\text { Conditional } \\
\text { Kappa }\end{array}$ & $\begin{array}{c}\text { Producer's } \\
\text { Accuracy }\end{array}$ & $\begin{array}{l}\text { User's } \\
\text { Accuracy }\end{array}$ \\
\hline $\begin{array}{l}\text { Impervious } \\
\text { Surface }\end{array}$ & 51 & 0 & 2 & 0 & 6 & 59 & 0.83 & 0.85 & 0.86 \\
\hline $\begin{array}{l}\text { Closed } \\
\text { Canopy }\end{array}$ & 0 & 22 & 0 & 4 & 1 & 27 & 0.80 & 0.81 & 0.81 \\
\hline Open & 3 & 4 & 39 & 4 & 1 & 51 & 0.73 & 0.93 & 0.76 \\
\hline $\begin{array}{l}\text { High-density } \\
\text { Canopy }\end{array}$ & 1 & 1 & 0 & 57 & 14 & 73 & 0.71 & 0.79 & 0.78 \\
\hline $\begin{array}{c}\text { Low-density } \\
\text { Canopy }\end{array}$ & 5 & 0 & 1 & 7 & 69 & 82 & 0.77 & 0.76 & 0.84 \\
\hline $\begin{array}{c}\text { Column } \\
\text { Total }\end{array}$ & 60 & 27 & 42 & 72 & 91 & 292 & - & - & - \\
\hline
\end{tabular}

Overall Accuracy $=81.5 \%$; Overall Kappa $=76.2 \%$

\subsubsection{Regression Analysis}

The OLS regression analysis resulted in a good model fit $\left(R^{2}=0.602 ; p<0.001\right)$ and the coefficients associated with the independent, explanatory variables illustrate an important difference in the relationship between tree canopy density and surface temperature (Table 2-2). As expected, closed canopy and high-density canopy exhibited a negative relationship with mean surface temperature (Standardized Beta $=-0.505$ and -0.388 , respectively): increases in these explanatory variables corresponded with lower mean surface temperatures. In contrast, and largely unexpected, was the positive relationship identified between the percentage of low-density tree canopy and surface temperature (Standardized Beta $=+0.194$ ). In other words, increases in the percentage of low-density tree canopy corresponded with some increase in the mean surface temperature of a CT. 
Additionally, there were observed differences in the explanatory value of the three independent variables. Applying a forward stepwise regression approach, explanatory variables are added to the model one at a time; the explanatory power of the model is evaluated with each addition. The observed change in $\mathrm{R}^{2}$ related to the addition of a variable provides a measure of explanatory power for that variable. In this analysis the percentage of closed canopy had the greatest explanatory power (accounting for $44.1 \%$ of variation in surface temperature), followed by the percentage of high-density canopy (13.3\%), with the percentage of low-density tree canopy accounting for the least variation (3.1\%).

Table 2-2: Summary of ordinary least squares (OLS) and geographically weighted regression (GWR) results modelling the relationship between mean surface temperature and tree canopy variables by census tract.

\begin{tabular}{|c|c|c|c|c|c|}
\hline \multirow{2}{*}{ Regression Model } & \multicolumn{3}{|c|}{ Standardized Beta Coefficient ( $p$-value) } & \multirow{2}{*}{ Model $\mathbf{R}^{2}$} & \multirow{2}{*}{$\begin{array}{l}\text { Moran's I } \\
\text { (p-value) }\end{array}$} \\
\hline & $\begin{array}{l}\% \text { Area Low- } \\
\text { density Canopy }\end{array}$ & $\begin{array}{l}\% \text { Area High- } \\
\text { density Canopy }\end{array}$ & $\begin{array}{l}\text { \% Area Closed } \\
\text { Canopy }\end{array}$ & & \\
\hline Ordinary Least Squares & $+0.194(0.000)$ & $-0.388(0.000)$ & $-0.505(0.000)$ & 0.602 & $0.376(0.000)$ \\
\hline $\begin{array}{c}\text { Geographically Weighted } \\
\text { Regression }\end{array}$ & - & - & - & 0.796 & $0.080(0.001)$ \\
\hline
\end{tabular}

The overall model fit of the GWR was strong (i.e., $R^{2}=0.799$ ) and considerably higher than the OLS regression model, the result of the regional weighting of coefficients. Mapping the distribution of the weighted coefficients calculated for each independent variable by the GWR (Figure 2-4) illustrates similar qualitative trends to the OLS model. In other words, regardless of the regional weighting applied to the dataset, a negative relationship between the percentage of high-density tree canopy and surface temperature, and a positive relationship between the percentage of low-density tree canopy and surface temperature were still identified.

Standardized residuals generated for both models revealed distributions that were approximately normal. Though the magnitude of the minimum and maximum residual values was slightly higher for residuals associated with the GWR, the distribution of values appeared to be somewhat less dispersed than the residual values associated with the OLS regression model. Furthermore, there appears to be an east-west trend in residual values with a higher frequency 
A.

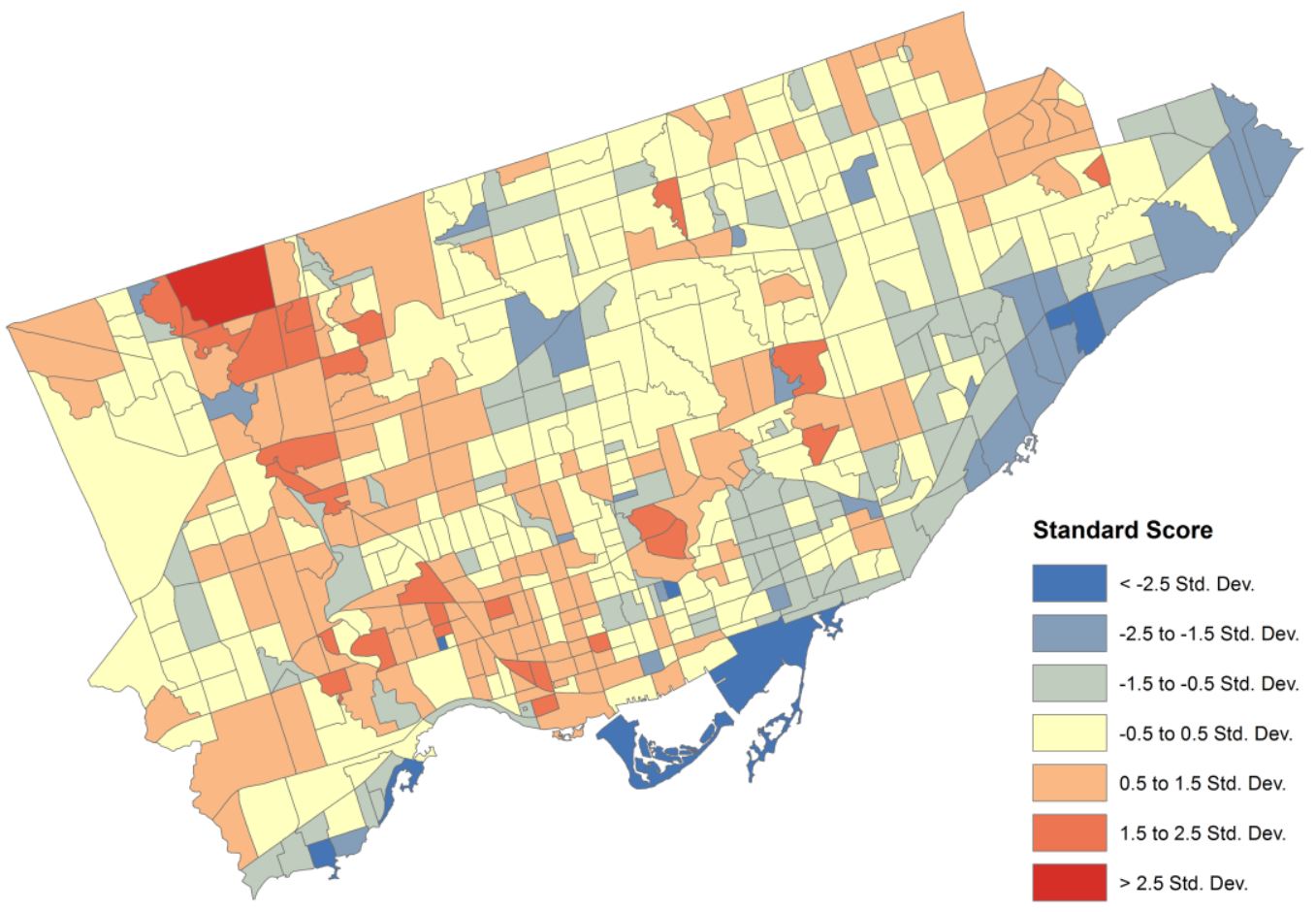

B.

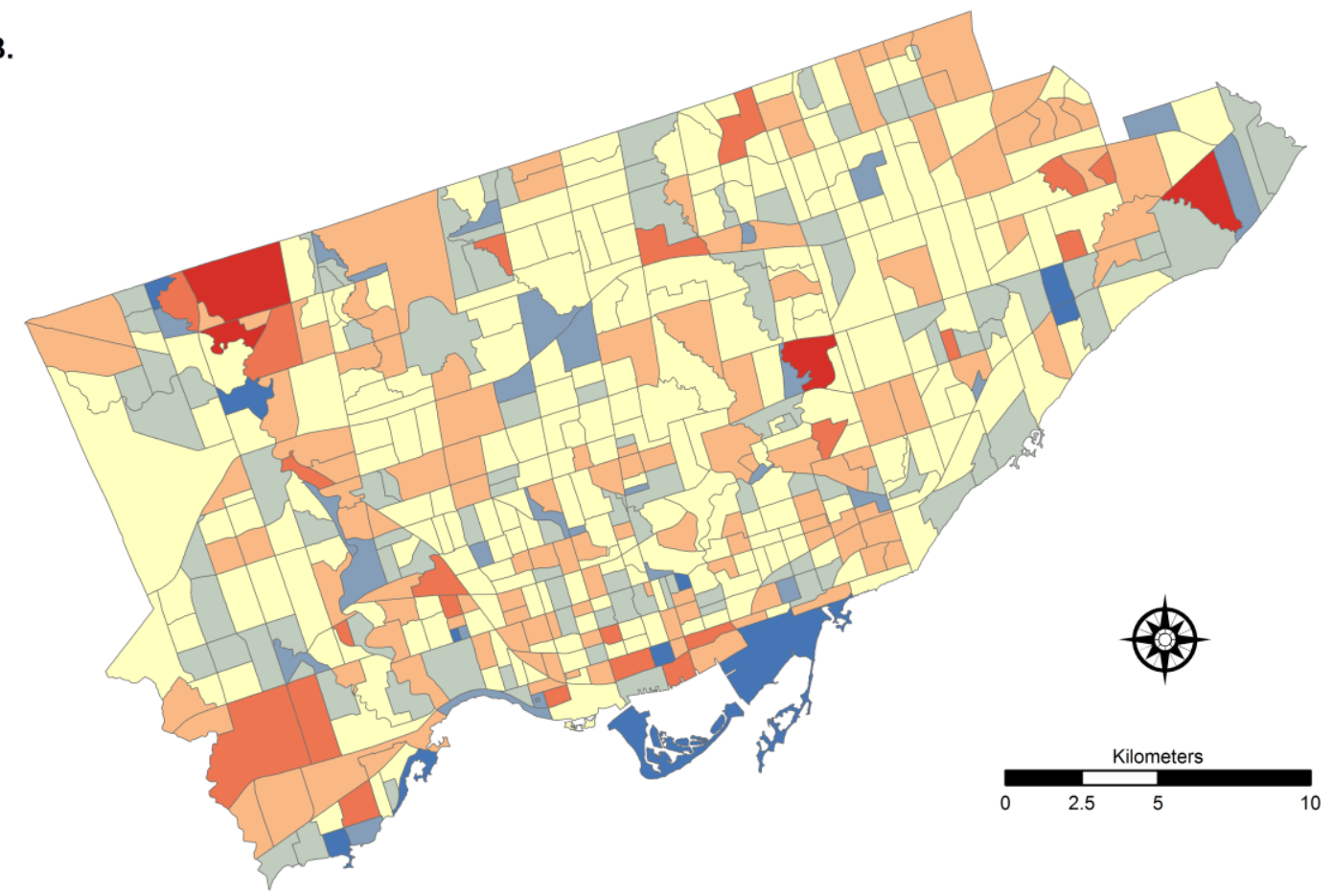

Figure 2-4: Distribution of standardized residuals by census tract for the $(A)$ ordinary least squares (OLS) regression model and (B) the geographically weighted regression (GWR) model used to evaluate regression model specification for the relationship between mean surface temperature and canopy in Toronto, Canada (2005). 
of negative residuals in the eastern half of the study area, and a higher frequency of positive residuals in the western portion of the study area (i.e., Scarborough). Evaluating the standardized OLS residuals for the presence of spatial autocorrelation reveals moderate clustering of similar values (high-high and low-low) among the standardized errors (Global Moran's $\mathrm{I}=0.376$, $\mathrm{p}<0.001)$. OLS regression assumes that observations, and resultant model error terms, are independent of one another; however, these conditions are rarely met when employing spatial data and are why spatially explicit forms of regression are recommended (Rogerson, 2006). The Moran's I value related to standardized residuals resulting from the GWR was substantially reduced (Global Moran's I = 0.080); however, the associated z-score of 3.44 ( $p=0.001)$ suggests the residuals still contain clustering of similar high-high and low-low values.

This clustering suggests that there is likely one or more additional underlying phenomena not accounted for by either the OLS regression or GWR approaches. Several census tracts in close proximity to Lake Ontario, for example, exhibit standardized residuals representing moderate to extreme over-prediction (i.e., greater predicted surface temperatures than measured in satellite imagery). Because of this proximity to a large water body, these CTs are likely to experience some moderating effects of this Great Lake (Bosselman et al., 1995; Changnon \& Jones, 1972). Though a distance variable could have been integrated into the model, this effect appears to be highly localized, decaying very quickly as distance from Lake Ontario increases and, therefore, does not add any relevant insight to the relationship between urban tree canopy and surface temperature.

\subsubsection{Difference of Means Test Using ANOVA}

When urban tree canopy is categorized by income, trends related to the mean percentage of tree canopy classes are observed, particularly for the low MPI and very high MPI classes. An overview of mean coverage for the three tree-tree canopy classes categorized by MPI is presented in Figure 2-5. Of particular note is the overall increase in mean coverage for the higher density canopy types with increasing income category. The percentage of high quality canopy increases from a mean of $8.0 \%$ (low MPI) to a mean to $26.6 \%$ (very high MPI). Similarly, the percentage of closed canopy increases from a mean of $2.2 \%$ (low MPI) to a mean of $5.4 \%$ (very high MPI). When tested for significance (alpha is $p \leq 0.05$ ) through the application of an ANOVA, the very high MPI class was found to have significantly less mean coverage of low-density canopy $(17.6 \%)$ than mean coverage for the remaining three income categories. In contrast, the very high MPI category was found to have significantly higher mean coverage of high-density canopy and closed canopy than the remaining MPI categories. 


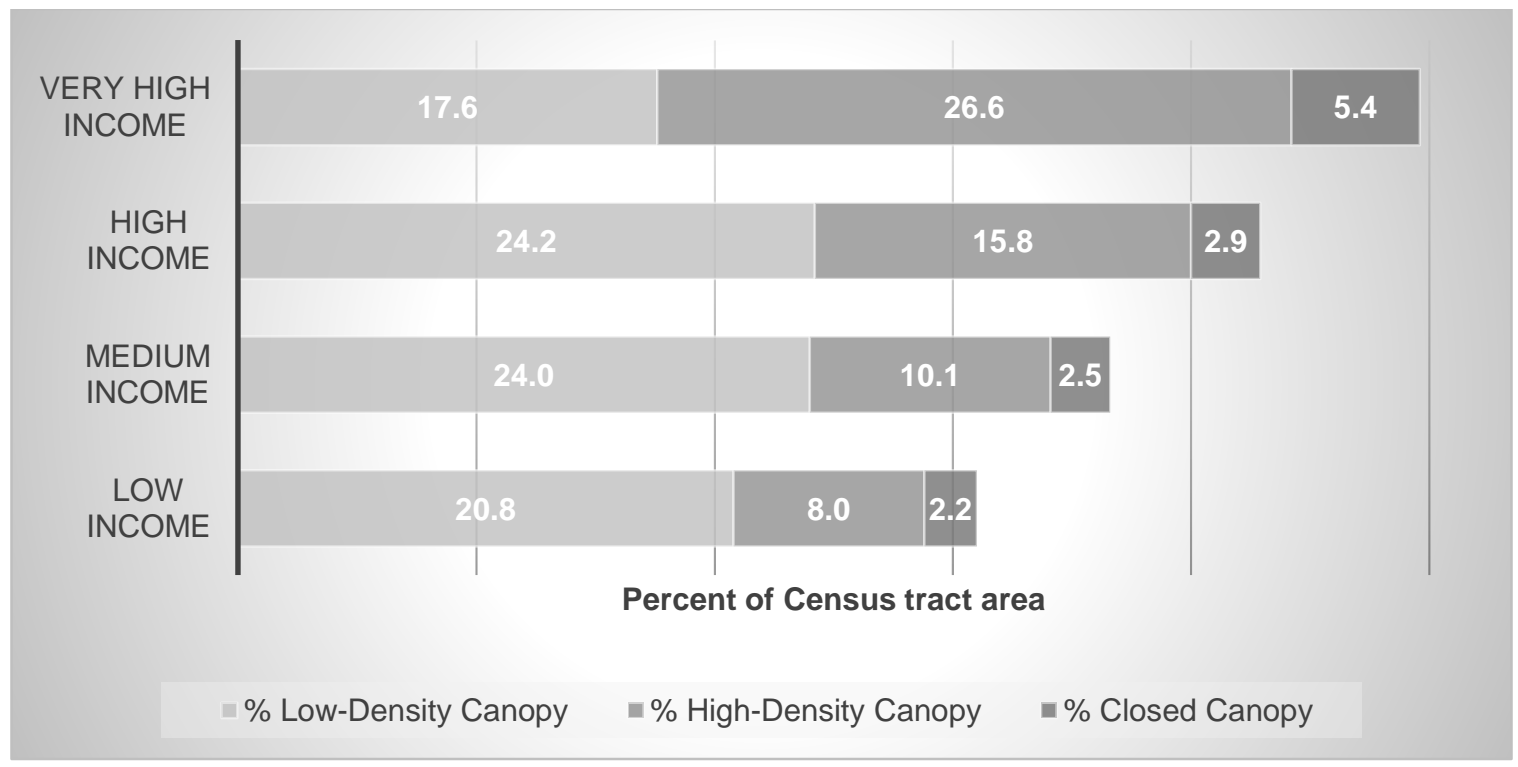

Figure 2-5: Mean percentage of tree canopy variables factored by median personal income categories at the census tract level for Toronto, Canada (2005).

Table 2-3: Summary of analysis of variance (ANOVA) post-hoc mean comparisons for tree canopy variables at the census tract level for Toronto, Canada (2005).

\begin{tabular}{|c|c|c|c|c|}
\hline \multicolumn{2}{|c|}{$\begin{array}{l}\text { Log of Median Personal Income } \\
\text { (MHI) }\end{array}$} & \multicolumn{3}{|c|}{ Mean Difference $(\mathbf{I}-\mathbf{J})$} \\
\hline I & $\mathbf{J}$ & $\begin{array}{l}\text { \% Low-density } \\
\text { Canopy }\end{array}$ & $\%$ High-density Canopy & $\begin{array}{l}\% \text { Closed Canopy } \\
\text { Cover }\end{array}$ \\
\hline \multirow[t]{3}{*}{ Low } & Medium & -3.21948 & -2.06325 & 0.36695 \\
\hline & High & -3.41828 & $-7.73318^{\star \star \star}$ & -0.3638 \\
\hline & Very High & $3.24811^{*}$ & $-18.55250^{\star \star \star}$ & $-2.84023^{\star \star \star}$ \\
\hline \multirow[t]{3}{*}{ Medium } & Low & 3.21948 & 2.06325 & -0.36695 \\
\hline & High & -0.1988 & $-5.66992^{\star \star \star}$ & -0.73075 \\
\hline & Very High & $6.46759^{\star \star \star}$ & $-16.48925^{\star \star \star}$ & $-3.20718^{\star \star \star}$ \\
\hline \multirow[t]{3}{*}{ High } & Low & 3.41828 & 7.73318 & 0.3638 \\
\hline & Medium & 0.1988 & $5.66992^{\star \star \star}$ & 0.73075 \\
\hline & Very High & $6.66639^{\star \star \star}$ & $-10.81932^{\star \star \star}$ & $-2.47643^{\star \star}$ \\
\hline \multirow[t]{3}{*}{ Very High } & Low & $-3.24811^{\star \star \star}$ & $18.55250^{\star \star \star}$ & $2.84023^{\star \star \star}$ \\
\hline & Medium & $-6.46759^{\star \star \star}$ & $16.48925^{\star \star \star}$ & $3.20718^{\star \star \star}$ \\
\hline & High & $-6.66639^{\star \star \star}$ & $10.81932^{\star \star \star}$ & $2.47643^{\star \star}$ \\
\hline
\end{tabular}

* indicates $p \leq 0.05,{ }^{* *}$ indicates $p \leq 0.01,{ }^{* * *}$ indicates $p \leq 0.001$ 
Significant mean differences were not limited to the very high MPI category. Despite exhibiting a smaller mean coverage of high-density canopy than the very high MPI group, the high MPI group of CTs did demonstrate a significantly higher mean coverage than the low MPI and medium MPI group of CTs. A summary of ANOVA results for all land-cover classes and MPI categories are provided in Table 2-3.

\subsection{Discussion}

The findings of this study related to the relationship between surface temperature and urban canopy density clearly demonstrate the importance of canopy density in microclimatic variation. The value of high-density and closed urban tree canopy considerably outweighed the value of low-density canopy from the perspective of urban surface temperature moderation. Although this analysis resulted in a positive relationship between the percentage of low-density urban canopy, this result is likely an anomaly related to the data preparation, specifically the aggregation of individual pixels to a zone (in this case CT boundaries). It is not likely that the pixels classified as low-density canopy exhibit a positive relationship with surface temperature, but instead temperature moderating benefits of these trees are being overshadowed by the underlying materials and adjacent land-cover.

The ability of low-density canopy to moderate temperatures may be reinforced when in close proximity to areas with other vegetation (i.e., grass or shrubs; higher density classes of canopy) and nullified when adjacent to surface materials that absorb and store short wave radiation, slowly releasing that stored energy as long wave (thermal) radiation such as asphalt (Gallo, 1993; Stone \& Rodgers, 2001). Because individual land-cover pixels were aggregated to CT boundaries and percentages of that geographic area produced, the relationships between neighbouring land-cover pixels could not be adequately captured and applied in this analysis. This hypothesis, that the spatial arrangement of pixels may have an important influence that is not accounted for in either regression model, appears to be supported by the geographic distribution of standardized residuals (see Figure 2-4), particularly related to clusters of negative residuals, or the under-prediction of surface temperature by the regression equation. A visual appraisal of several CTs exhibiting moderate to extreme under-prediction reveal some similarities, specifically a higher frequency of contiguous pixels classified as impervious surface and very little highdensity or closed canopy. 
These results imply that forest patch characteristics matter, even at the medium spatial resolution of Landsat TM5 imagery. The results of this analysis clearly demonstrate the importance of canopy closure in the mitigation of surface temperature increases. Unfortunately the spatial resolution of the remote sensing imagery and nature of the methodology does not allow more comprehensive conclusions regarding the role of forest patch characteristics in mitigating local surface temperatures. More specifically, without applying complex pixel un-mixing methodologies (see Frazier \& Wang, 2010; Keshava \& Mustard, 2002), the forest patch size within the low-density and high-density land-cover classes cannot be derived from the spatial resolution of the available imagery. The availability of finer resolution imagery would allow for the inclusion of patch specific variables such as core area or perimeter to be included as explanatory variables in the regression equation and more directly quantify the role of forest patch characteristics in providing temperature mitigation services. Furthermore, the ability to calculate patch characteristics allows for more complex methodologies to be applied (e.g., path analysis, hierarchical linear modelling, logistic regression) that can control for the overall canopy coverage and directly evaluate the effect of patch characteristics.

Beyond an improved understanding of the relationship between city trees and surface temperature, the results of this study have important implications related to the management of reforestation and afforestation programs in dense urban environments. As demonstrated by this research, the relationship between urban tree canopy density and surface temperature appears to be clear: large areas of high-density contiguous canopy are more effective at mitigating increases in mean surface temperature (or minimizing temperature variation across the built environment) than areas of low-density tree canopy. If the objective of an afforestation program is to improve living conditions for residents through the targeted mitigation of local UHI effects, it can be concluded that planting efforts should be focused on protecting and expanding existing areas of high-density tree canopy. And, while this protection of high-density urban canopy is of great importance to summer temperature moderation, it would be unadvisable from the perspective of management to discount the importance of low-density canopy outright.

Implicit in the approach taken in this research is that one temporal snapshot is examined to evaluate the distribution of tree canopy, the distribution of surface temperature, and their relationship across the study area. This discrete temporal snapshot, however, is the product of decades of competing processes, as large growing trees require lengthy periods of time to reach structural maturity, a form in which the ecological benefits of urban trees are maximized (Nowak, 1994; McPherson et al., 1999). The positive effects on tree canopy contributed by planting efforts 
and growth of existing vegetation are often in competition with the fragmentation or outright removal of vegetation from development pressures. There are two likely paths that can lead to the existence of high-density tree canopy. The first path, residential neighbourhoods (or other planning areas) were carved into existing patches of forest and remaining trees were protected over time to maintain a high level of canopy density. Alternatively, in the second path, areas considered open or areas of low-density forest were sheltered from development and vegetation cover enhanced through planting efforts. In both paths, protection is the common theme; existing areas of vegetation would require shelter from development pressures to be maintained (in the case of existing high-density canopy) or enhanced (in the case of open, low-density canopy). The timeframe of this protection would have to span several decades and represent many political cycles.

The influence of tree protection reveals an important tension underlying this research related to ideas of distributional inequalities that can lead to environmental injustice. The ANOVA analysis confirms there is already some broad level of distributional inequality within boundaries of the study area, with higher mean coverage of high-density and closed canopy in CTs that also exhibit very high MPI. This observation is consistent with studies of other North American cities that have observed a relationship between access to canopy and variables related to affluence (e.g., Iverson and Cook, 2000; Grove et al., 2006; Heynen \& Lindsey, 2003; Perkins et al., 2004). Conversely, CTs with lower percentages of high-density tree canopy appear to be associated with larger percentages of impervious surface, lower MPI, and a greater proportion of high-density type dwellings, though statistical testing is required to determine the extent of this relationship.

Based on the results of this study, an urban tree planting program with a primary focus on maximizing the environmental service of temperature moderation will inevitably be biased towards more affluent areas where there is a higher beginning tree canopy base. This bias is likely to be most evident where cost benefit analysis represents the primary tool for policy makers. Maximizing the ratio of benefits to costs involves expanding patches of high-density and closed canopy as the top priority. These patches are more likely to be located in and around affluent neighbourhoods. Once these opportunities have been exhausted, the second objective is to expand remaining patches of low-density canopy where, again, the lower cost option is most likely. It is more costly to either reclaim impervious surface or implement more innovative planting methods in areas with expansive hard surface common to less affluent areas of a city. If reducing distributional inequalities is not an explicit objective of an afforestation program, preference can easily be swayed towards an option that does not consider access to the benefits of green-space 
when trying to maximize the number of trees planted, the survivability of those trees, the total benefits realized, and the minimization of costs related to both planting and maintenance.

\subsection{Conclusions}

With the pace of urbanization in North America, and trend toward more people living in urban areas globally, future city dwellers are likely to experience more frequent stress from UHI effects, a phenomenon further exacerbated by a warming climate. The results of this study demonstrate the importance of urban tree canopy quality to more effectively deliver ecosystem services effective at mitigating summer surface temperature increases in a dense urban setting, where results clearly indicate that higher density tree canopy is positively correlated with cooler surface temperatures. Moreover, findings from this study provide an empirical basis for municipalities to consider improvements to tree canopy quality (expressed as canopy density) as an important metric necessary to more effectively deliver ecosystem services necessary to address the effects of the UHI. From a policy perspective, however, it is also important that canopy quality metrics not be considered in isolation. The categorical distributional inequality of urban tree canopy identified as a part of this study points to the fact that a primary management objective of expanding existing tree stands to be of higher density and more contiguous could also contribute to further widening of the distributional inequalities among city residents related to urban forest cover access. As such, urban forest quality metrics are best included as a part of a suite of variables that consider not only ecological priorities, but also balance social and economic criteria in future tree planting decisions. 


\section{CANOPY OF ADVANTAGE: WHO BENEFITS MOST FROM CITY TREES?}

\subsection{Abstract}

Urban tree canopy provides a suite of ecological, social, and economic benefits to the residents of urban areas. With an expanding recognition of these benefits among city residents, there is growing concern that access to these benefits are not distributed equally and could represent the presence of an environmental injustice. This study examines the spatial relationship between median household income and tree canopy variables, specifically realized tree canopy cover and potential tree canopy cover, for Toronto, Canada a densely populated urban setting reported to be exhibiting an increase in the geographic polarization of residents based upon household income. Spatial relationships between median household income and tree canopy variables are evaluated using the bivariate Moran's I statistic, a specialized local indicator of spatial autocorrelation (LISA). Several significant spatial clusters of correlated extreme values between variables are identified and illustrate the extent of distributional inequality of resident access to tree canopy across Toronto. Finally, the importance of these spatial clusters are examined from the perspective of understanding the impact of urban change (both sociodemographic and built form) and from the standpoint of improving equality of access to city trees and their benefits resulting from future tree planting decisions.

\subsection{INTRODUCTION}

With the emergence of urban forestry as a substantive discipline over the last several decades (see Konijnendijk et al., 2006), there has been rapid expansion in the quantity and focus of scholarship relating to city trees. Initially concentrating on definitions and determinants of urban forest structure (Rowntree, 1984; Sanders, 1984; Talarchek, 1990), the research emphasis quickly expanded to include the identification and quantification of a wide range of perceived ecological, social, and environmental benefits (Dwyer et al., 1992; McPherson, 1992; McPherson et al., 1997). With a considerable area of forest loss projected from continuing urbanization (Nowak and Walton, 2005) the focus on the quantification of benefits was an important step in moving an understanding of the importance of urban vegetation outside the academic sphere and into public focus to inform policy decisions at the municipal level. As a consequence of this broader recognition, several of North America's largest cities have undertaken large-scale urban forest studies to quantify the value of this environmental good. In some cases, such as the Million Trees initiatives in Los Angeles (McPherson et al., 2011) and New York (Locke et al., 2010), new commitments to expand urban tree canopy coverage have resulted. With this broader public 
awareness, however, has come yet another important expansion in the scope of urban forestry research: who receives the benefits of access to the urban forest?

The benefits of urban trees are considerable. In addition to higher residential property values observed with greater levels of mature urban tree cover (Anderson \& Cordell, 1988; Sander et al., 2010), city trees provide a number of ecological services often leading to direct economic benefits for both individual residents and to municipalities. The ability to mitigate storm water runoff through increased interception of rainfall can reduce stress on storm water management infrastructure (Berland \& Hopton, 2014; Sanders, 1986; Xiao et al., 1988), thus offsetting maintenance and expansion costs to the municipality, as well as reducing the frequency, and damage, associated with residential flooding (Nowak et al., 2010). The shading properties of city trees, complemented by cooling through evapotranspiration, can play an important role in reducing built surface temperatures in cities. At the local level, individual dwellings with strategically planted trees have been shown to exhibit reduced temperatures and associated reductions in energy for summer cooling (Akbari et al., 2001; McPherson et al., 1988; McPherson \& Simpson, 2003; Sawka et al., 2013). Energy savings at the household scale provide direct financial benefits to residents and can contribute to additional pollution reduction by offsetting energy generation required to meet cooling demands (Akbari, 2002).

By lessening demand for energy required for air conditioning, urban trees are indirectly responsible for pollution reduction in cities. Moreover, in addition to the ability to remove and sequester atmospheric carbon (Nowak \& Crane, 2002; Rowntree \& Nowak, 1991), trees are of great importance to the direct removal of several airborne pollutants common in urban environments (Dwyer et al., 1992; McPherson et al., 1998; Nowak et al., 2006). Examining several locations throughout the United Kingdom, Beckett et al. (2000) demonstrated direct reduction of particulate matter less than 10 micrometers $\left(\mathrm{PM}_{10}\right)$, through physical filtration mechanisms, by trees of varying size and age. Formation of ground level ozone is inhibited in urban environments when temperature extremes are minimized; microclimatic temperature moderation by city trees has been shown by Nowak et al. (2000) to lower ozone concentrations. Although results varied by city, season, and the time of day, further work by Nowak et al. (2006) demonstrated significant reductions of several airborne pollutants $\left(\mathrm{O}_{3}, \mathrm{PM}_{10}\right.$, nitrogen dioxide, sulphur dioxide, carbon monoxide) in cities across the conterminous United States. The ability to estimate and quantify reductions in air pollution is now a routine feature in a number of urban forest software tools (Nowak et al., 2010). 
While the tangible and intangible values of urban trees are considerable, prior literature indicates access to such benefits may be unequal, often preferencing certain socio-demographic groups while reducing access for others. A positive relationship between median household income and proximity to tree canopy cover has been established in several notable studies with a focus on North American cities (Iverson and Cook, 2000; Jenerette et al. (2011); Landry and Chakraborty, 2009; Perkins et al., 2004), though the strength of this positive relationship varied by urban centre. As well, other variables have been found that exhibit significant relationships with the spatial distribution of urban tree cover at the micro-scale (i.e., how the percentage of urban tree canopy varies among sub-city units such as census aggregation units). For example, several recent studies have identified a positive relationships between level of resident education and proximity to trees (Greene et al., 2011; Grove et al., 2006; Iverson \& Cook, 2000; Heynen \& Lindsey, 2003; Luck et al., 2009; Troy et al., 2007); other authors have uncovered connections between the ethno-cultural background of city residents and their relationship to trees (Berland et al., 2015; Conway \& Bourne, 2013; Grove et al., 2006; Heynen et al. 2006; Landry \& Chakraborty, 2009; Troy et al., 2007).

With the frequency of studies identifying unequal access to the benefits of the urban forest for residents of several large North American cities, it is reasonable to infer these inequalities could constitute an environmental injustice. It is challenging, however, to definitively conclude that this inequality does indeed constitute injustice as the definition of an environmental injustice remains contentious (Agyeman \& Evans, 2004). The body of literature examining the urban forest through an environmental justice lens has more commonly focused on descriptive studies of inequality (e.g., Jenerette et al. (2011); Landry \& Charaborty, 2009; Troy et al., 2007); there are fewer examples of research that have examined the more normative dimension of justice (e.g., Heynen, 2003; Heynen et al., 2006) or on deconstructing the underlying processes leading to observed inequalities (e.g., Conway et al., 2011; Iverson \& Cook (2000); Heynen et al., 2006; Perkins et al., 2004). As a consequence these studies tend to align with earlier conceptualizations of environmental justice as distributive justice, with less focus on procedural justice, or justice as recognition (see Walker, 2010, for a detailed review). This focus on identifying inequalities may in part be related to a more recent shift in environmental justice studies from a focus on environmental harms to include environmental goods (Bell, 2004). As such, understanding who has access to the urban forest and who does not remains an important prerequisite to developing an understanding of the processes leading to those inequalities and is a primary focus of the present study. 
A persistent challenge when determining whether some level of distributional inequalities in access to the benefits of city trees is acceptable, or whether unequal access has become injustice, can be related to the difficulty of assigning a standard of minimum resident access. More specifically, what is an acceptable amount of canopy a resident should have access to and at what minimum distances? This standard for urban canopy is particularly difficult to establish for a number of reasons. One challenge is related to competing perceptions of greenspace. What is viewed as an environmental good to one group of residents can be perceived as a place of danger and harm to another group of residents (Ching-Hua et al., 2005; Herzog \& Chernick, 2000; Sreetheran, M., \& Konijnendijk van den Bosch, 2015). Efforts to expand green space in an effort to meet a minimum canopy standard may actually be viewed as undesirable by members of the group lacking access to this environmental good.

Developing a minimum standard of tree canopy access is further complicated by the models used to estimate the perceived benefits of the urban forest. While the value of the benefits delivered by an individual tree are estimated using empirical data, they contain uncertainty as establishment and growth potential are connected to a number of contextual variables (e.g., climatic conditions, exposure to sunlight, soil quality) (Sanders, 1984; Sieghardt et al., 2005; Trowbridge \& Bassuk, 2004). From an ecological perspective, these models assume that the suite of benefits provided by the urban forest are linear collective properties, or an additive sum of individual trees (Müller \& Nielsen, 2009; Odum \& Barrett, 2005). Though this assumption is valid for some benefits, particularly for a number of processes occurring at the surface of the leaf in deciduous trees such as carbon dioxide exchange, other benefits may be multiplicative when individual trees are grouped together in close geographic proximity, as stands or communities or are remnant patches of pre-settlement forest. At the very least some of these benefits may move from being additive collective properties to multiplicative collective properties. The interception of insolation by tree canopy provides a good example. In natural systems the amount of incoming radiation intercepted increases with leaf area and canopy closure with considerably less radiation reaching the forest floor (Law et al., 2001). In other words, as trees group together in closer proximity and the leaves from these individuals intermingle and increase canopy closure, greater shading of the forest floor occurs than when those same trees are separated by distance and do not intermingle. It is reasonable to expect that some of these multiplicative benefits of tree proximity are translatable to an urban setting.

In addition to the uncertainty related to a minimum standard of access to city trees, developing statistical evidence of distributional inequality can also prove difficult for an urban 
centre with heterogeneous urban form. More traditional statistical tests, such as Analysis of Variance (ANOVA) or Kruskal-Wallis, can identify significant differences between and among broad income groups or the racial identity of city residents for example. Such difference in means tests, however, are not spatially explicit and offer little insight to the local spatial processes that may be leading to these inequalities or the strength of relationships. Other statistical methods such as Pearson Correlation or Ordinary Least Squares (OLS) regression may not be effective when applied to an environmental good that exhibits clustering in space. The distribution of urban vegetation is one example of a land cover feature complicated by a range of factors that impact tree growth and mortality as well as the impact of urban processes (e.g., economic and occupational restructuring) in urban areas. Natural growing conditions vary over space and limit where trees can grow (Sanders, 1984); these growing conditions are then differentially modified depending on past and present land use (McBride \& Jacobs, 1986; Nowak, 1993). Urban land use has often influenced biophysical growing conditions for city trees through past planning decisions and urban-economic processes (e.g., industrial restructuring, redevelopment). Furthermore, spatial arrangement of urban vegetation is often influenced by socioeconomic patterns, where more affluent groups have better resources to properly maintain trees on residential property and lower income groups become more reliant on public space for access to the urban forest (Heynen et al., 2006). This relationship between vegetation and socioeconomic patterns and land-use make linear modelling of a complex study area, with considerable spatial heterogeneity in urban form, problematic.

The City of Toronto, Canada, is one North American city whose socio-demographic pattern of resident dwellings and associated urban vegetation demonstrates a high degree of spatial heterogeneity in urban form. The present City of Toronto's jurisdictional boundaries are the result of amalgamating six separate municipal units in 1998 (Schwartz, 2004). In addition to Toronto's pre-settlement variation in biophysical conditions and vegetation types, each preamalgamation municipal unit pursued independent planning objectives over time and were subject to different socioeconomic processes and land use histories resulting in a considerable variation of built urban form (e.g., population density; see Figure 3-1). These former municipal units are now sub-components of a single city representing the largest city in Canada and fourth largest in North America by population (O'Toole, 2013).

Though spatial heterogeneity in urban form can lead to analytical complexity, this complexity does not necessarily negate the ability to detect patterns of spatial inequality in access to environmental goods manifest as tree cover. Spatial patterns of socio-demographic inequity 
were examined by Hulchanski (2010) and Walks \& Twigge-Molecey (2013), who concluded that not only is income inequality growing in Toronto, income is becoming more polarized and segregated (or clustered) in geographical space. These findings provide strong motivation for further investigations of the spatial arrangement of environmental goods and their relationship to resident income; such bivariate association may better detect and delineate distributional inequalities across the study area. Specifically, this research seeks to determine if the distribution of urban trees across Toronto is associated with resident income. Because there is a proven trend towards increasing polarization of income (Hulchanski, 2010; McLachlan \& Sawada, 1997; Walks \& Twigge-Molecey, 2013), and if a significant relationship between income and tree canopy cover exists, then it is reasonable to conclude there is also growing polarization in access to tree canopy by resident income.

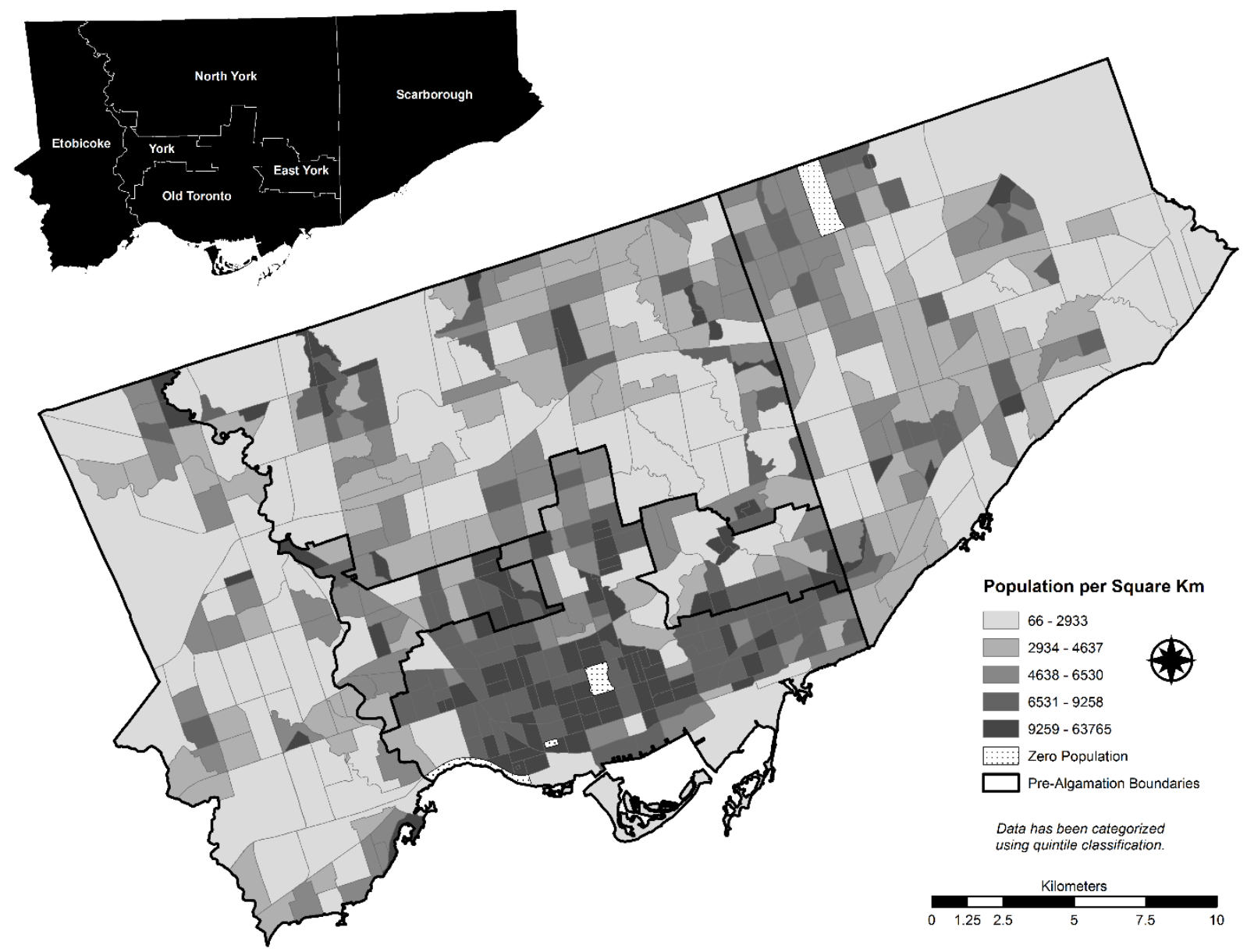

Figure 3-1: Population density of Toronto, Canada (2006) by census tract with superimposed pre-amalgamation boundaries (see inset for identification). 
This research uses median household income $(\mathrm{MHI})$ for residents of Toronto and, by employing aspatial and spatial methods, seeks to determine whether and to what degree there is a relationship between tree canopy cover and resident affluence. For the purpose of this study, tree canopy is defined as follows: total canopy is the sum of realized canopy cover (i.e., existing tree canopy cover) and potential canopy cover (i.e., pervious surface that could be utilized as plantable space). Identifying present patterns of inequality is required to begin to understand the impacts of past policy decisions and processes resulting in these identified patterns. By examining the potential for inequitable spatial access to city trees, this research can contribute to future policy decisions related to urban forest management. Should inequitable access exist, identification of such communities or neighbourhoods experiencing inequity could become targets for higher priority tree planting, especially in light of Toronto's ambitious goal to increase its tree cover by 10 to 12 percentage points in the coming decades (City of Toronto, Parks, Forestry and Recreation, Urban Forestry, 2013b).

\subsection{Methodology}

This research examines two questions related to the spatial distribution of urban tree canopy in the City of Toronto, each of which have important implications for environmental justice contextualized through resident access to city trees and the benefits they provide. The first line of enquiry uses ANOVA to examine whether access to tree canopy differs according to broader categories of resident income. The second line of enquiry examines the relationship of canopy variables and $\mathrm{MHI}$ across space through the use of a local indicator of spatial autocorrelation (LISA). The census tract (CT) was selected as the common geographic unit (or zone) for this analysis and all subsequent methods discussed because it is one of two geographic boundaries used by Statistics Canada to gather and disseminate census data. The CT was selected over the smaller dissemination area (DA) unit in order to constrain the sample size. The study area is composed of 531 CTs (equivalent to 3577 DAs); as sample sizes become large (i.e., use of DAs) there is an increased likelihood of very small changes (of questionable practical importance) being identified as statistically significant.

Median household income (MHI) for 2006 was selected as the focus for analysis because this variable is consistent with those used in many environmental justice studies identified in the literature. Data from the 2006 Canadian Census was selected over the more recent 2011 Canadian Census as these data were better matched temporally to the available land cover data. A $\log _{10}$ transformation (assume base 10 in all subsequent references to log) was applied to the $\mathrm{MHI}$ variable to reduce strong positive skew in the raw data. Once transformed, the quartile breaks 
for the re-expressed variable were calculated. Each CT was assigned an ordinal value based on its associated median income; a CT falling within quartile 1 (Q1; upper limit $=\$ 44,057$ ) was assigned an ordinal value of 1 and a nominal designation of low income. A CT falling within quartile 2 (Q2; upper limit $=\$ 53,572$ ) was given an ordinal value of 2 and a nominal designation of medium income. Subsequent quartiles (Q3 and Q4) were assigned ordinal values of 3 (high income; upper limit $=\$ 66,169$ ) and 4 (very high income; maximum $=\$ 246,341$ ), respectively.

Data describing Toronto's tree canopy were derived from QuickBird satellite imagery classified by the USDA Forestry Service. This imagery was originally collected in summer 2007 and was acquired as part of the Every Tree Counts study of Toronto's urban forest resource (City of Toronto, Parks, Forestry and Recreation, Urban Forestry, 2013a; Nowak et al., 2013). The classified imagery was obtained through the City of Toronto's Open Toronto data portal and was provided as eight land cover classes: tree canopy, water, bare earth, buildings, pavement, transportation, grass/shrub, agriculture. Pixels classified as existing tree canopy cover or "realized tree canopy cover", further referenced as "RCC", were isolated and extracted. Classes representing plantable space (i.e., pixels classified as bare earth or grass/shrub) or "potential tree canopy cover", further referenced as PCC, were identified and reclassified to a single class. These target canopy land cover classes (RCC and PCC) were then aggregated from pixel level to the chosen geographical unit (i.e., the CT) and expressed as a percentage of coverage of the CT. Separate ANOVA procedures were applied to the percentage of tree canopy variables (realized, potential, and total tree canopy), each classified by the income categories described previously. Informed by previous studies (Hulchanski, 2010; Walks \& Twigge-Molecey, 2013), higher income categories were expected to have significantly higher geographically proximate mean tree canopy coverage.

To further inform the nature of the relationship between $\mathrm{MHI}$ and percentage of tree canopy coverage, the significance and associated strength of correlation between the percentage of tree canopy variables and the Log of $\mathrm{MHI}$ were evaluated. Due to the heterogeneity of urban form; the previous findings of increasing polarization of income in Toronto (see Hulchanski, 2010; McLachlan \& Sawada, 1997; Walks \& Twigge-Molecey, 2013); as well as the variation in the relationship between income and canopy in the literature, a weak to moderate correlation is expected in this study. A significant yet low correlation coefficient suggests a lack of understanding of the spatial relationship between the variables; in this research a weak correlation provides evidence that assumptions related to the study area are correct with strong agreement among the tails of each variable but not in the middle portion of the distributions. 

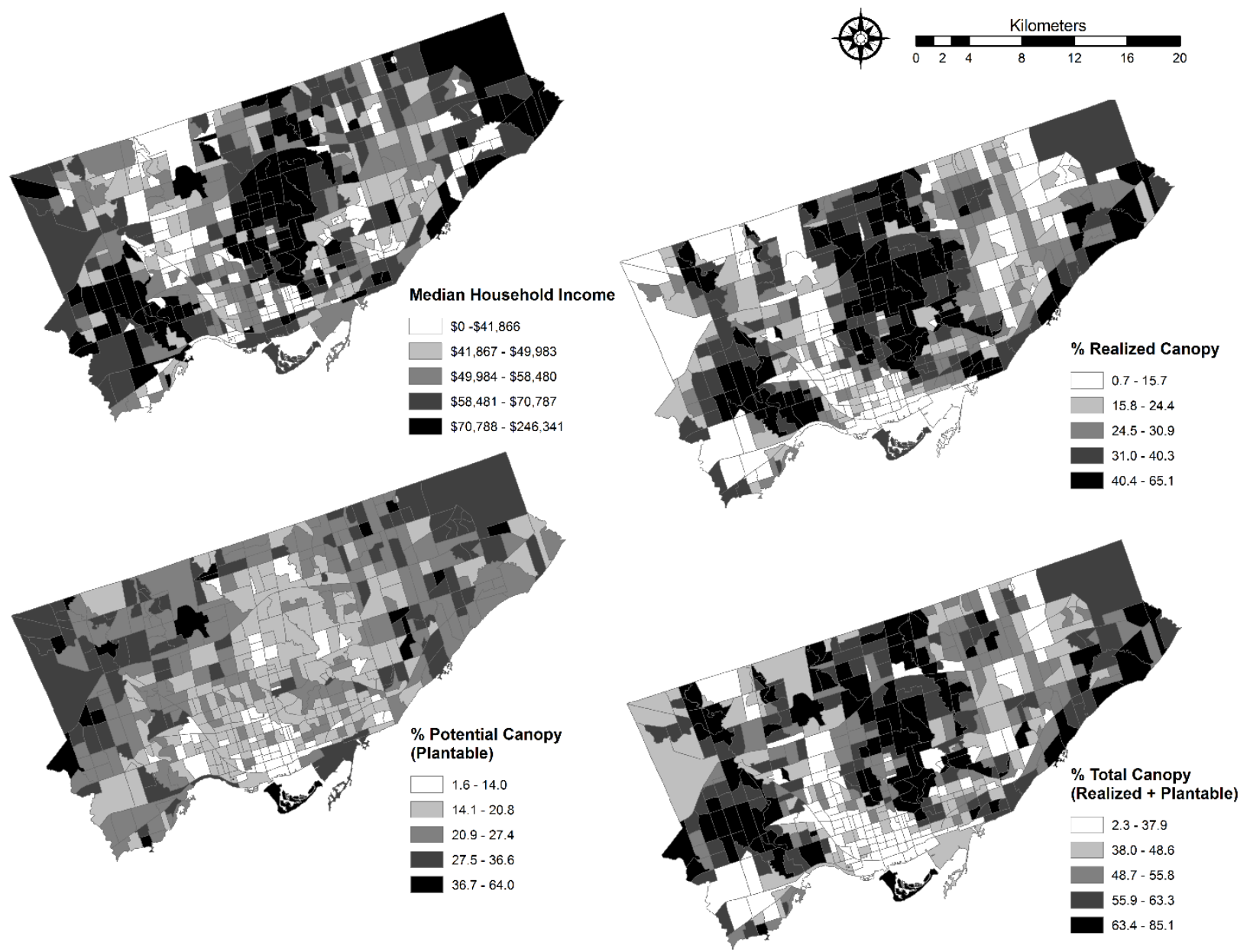

Figure 3-2: Distribution of input variables for bivariate local indicators of spatial autocorrelation analysis (local Moran's I) for Toronto, Canada (2006-2007). All variables are classified using quintile classification.

Finally, the relationship of tree canopy variables and $\mathrm{MHI}$ across space as this relationship may not be geographically linear; in fact, significant spatial clusters of extreme values for canopy variables and $\mathrm{MHI}$ are assumed to exist across the study area. A local indicator of spatial autocorrelation or "LISA" (Anselin, 1995) was applied to identify the location, significance, size, and nature of spatial clusters of correlated extreme values between canopy and resident income variables. Where more traditional measures of autocorrelation such as Getis-Ord Local G* and Local Moran's I* identify spatial clusters of extreme values for a single attribute (Anselin, 1995; Getis-Ord, 1992), the measure selected for this analysis (i.e., bivariate Moran's ${ }^{\star}$ ) identifies spatial clustering of extreme values between two attributes (Ansellin et al., 2002). Three attribute pairs were examined using this technique: RCC-MHI, PCC-MHI, and TCC-MHI (spatial distribution of input variables are illustrated in Figure 2). For this analysis, neighbouring features were defined through contiguity criteria; adjacent CTs were considered neighbours if any segment 
or corner of their spatial boundaries coincided with any segment or corner of the spatial boundary of the focal CT.

\subsection{Results}

\subsubsection{Difference of Means Tests Using ANOVA}

No significant differences in means were observed for PCC among the $\mathrm{MHI}$ categories. However, significant differences between MHI categories were observed for RCC and TCC (mean differences and associated model significance values are provided in Table 3-1). Of particular note is the observed relationship between RCC and $\mathrm{MHI}$; as the $\mathrm{MHI}$ group increases so too does mean RCC, though significant differences favour the higher MHI groups. More specifically, the very high $\mathrm{MHI}$ group exhibits a significantly larger mean RCC than all other income groups. Although less than the very high $\mathrm{MHI}$ group, the mean RCC of the high $\mathrm{MHI}$ group is significantly greater than the observed means for the low $\mathrm{MHI}$ and medium $\mathrm{MHI}$ groups. A similar trend is observed in the relationship between TCC and MHI groups, with mean values of TCC again increasing with $\mathrm{MHI}$ group. The trend is weaker, however, with only one category (very high $\mathrm{MHI}$ ) exhibiting significantly higher mean values than all other income groups.

\subsubsection{Bivariate Correlation}

With the exception of potential canopy, there is a moderately strong correlation between canopy variables and the log of median household income (Pearson correlation coefficients for variable pairs and associated significance are shown in Table 3-2). The strongest positive correlation $(r=0.452, p<0.001)$ is observed between the variables RCC and log of $\mathrm{MHI}$. Correlation between TCC and log MHI was also moderately strong $(r=0.369, p<0.001)$, but less than the correlation observed with the RCC. The correlation coefficient between PCC canopy and the log $\mathrm{MHI}$ was not significant at the $95 \%$ confidence level but was at the $90 \%$ confidence level $(r=-0.077 ; p=0.078)$. 
Table 3-1: Summary of analysis of variance (ANOVA) post-hoc mean comparisons of tree canopy type according to median household income by census tract for Toronto, Canada (2006-2007).

\begin{tabular}{|c|c|c|c|c|}
\hline \multicolumn{2}{|c|}{$\begin{array}{l}\text { Log of Median Household } \\
\text { Income (MHI) }\end{array}$} & \multicolumn{3}{|c|}{ Mean Difference $(\mathbf{I}-\mathbf{J})$} \\
\hline I & $\mathbf{J}$ & $\begin{array}{l}\text { \% Total Canopy Cover } \\
\text { (TCC) }\end{array}$ & $\begin{array}{l}\text { \% Realized Canopy } \\
\text { Cover (RCC) }\end{array}$ & $\begin{array}{l}\text { \% Potential Canopy } \\
\text { Cover (PCC) }\end{array}$ \\
\hline \multirow[t]{3}{*}{ Low } & Medium & -1.85213 & -2.25912 & 0.40662 \\
\hline & High & -3.81220 & $-3.70035^{\star \star}$ & -0.11277 \\
\hline & Very High & $-14.36465^{\star \star \star}$ & $-15.46080^{\star \star \star}$ & 1.09678 \\
\hline \multirow[t]{3}{*}{ Medium } & Low & +1.85213 & 2.25912 & -0.40662 \\
\hline & High & -1.96008 & -1.44122 & -0.51939 \\
\hline & Very High & $-12.51252^{\star \star \star}$ & $-13.20168^{\star \star \star}$ & 0.69015 \\
\hline \multirow[t]{3}{*}{ High } & Low & 3.81220 & $3.70035^{\star}$ & 0.11277 \\
\hline & Medium & 1.96008 & 1.44122 & 0.51939 \\
\hline & Very High & $-10.55244^{\star \star \star}$ & $-11.76046^{\star \star \star}$ & 1.20954 \\
\hline \multirow[t]{3}{*}{ Very High } & Low & $14.36465^{\star \star \star}$ & $15.46080^{\star \star \star}$ & -1.09678 \\
\hline & Medium & $12.51252^{\star \star \star}$ & $13.20168^{\star \star \star}$ & -0.69015 \\
\hline & High & $10.55244^{\star \star \star}$ & $11.76046^{\star \star \star}$ & -1.20954 \\
\hline
\end{tabular}

* indicates $p<0.05,{ }^{* *}$ indicates $p<0.01,{ }^{* * *}$ indicates $p<0.001$

Table 3-2: Summary of Pearson correlation coefficients (or " $r$ ") between tree canopy types and median household income by census tract for Toronto, Canada (2006-2007).

\begin{tabular}{|c|c|c|c|c|}
\hline & $\begin{array}{l}\text { Log of Median } \\
\text { Household Income }\end{array}$ & $\begin{array}{l}\% \text { Potential } \\
\text { Canopy Cover }\end{array}$ & $\begin{array}{c}\text { \% Realized Canopy } \\
\text { Cover }\end{array}$ & $\begin{array}{l}\% \text { Total Canopy } \\
\text { Cover }\end{array}$ \\
\hline $\begin{array}{l}\text { Log of Median } \\
\text { Household Income }\end{array}$ & 1 & -0.077 & $0.452^{\star \star \star}$ & $0.369^{\star \star \star}$ \\
\hline $\begin{array}{c}\% \text { Potential Canopy } \\
\text { Cover }\end{array}$ & -0.077 & 1 & -0.074 & $0.438^{\star \star \star}$ \\
\hline $\begin{array}{c}\text { \% Realized Canopy } \\
\text { Cover }\end{array}$ & $0.452^{\star \star \star}$ & -0.074 & 1 & $0.864^{\star \star \star}$ \\
\hline$\%$ Total Canopy Cover & $0.369^{\star \star \star}$ & $0.438^{\star \star \star}$ & $0.864^{\star \star \star}$ & 1 \\
\hline
\end{tabular}

${ }^{*}$ indicates $p<0.05,{ }^{* *}$ indicates $p<0.01,{ }^{* * *}$ indicates $p<0.001$ 


\section{A. RCC - MHI}

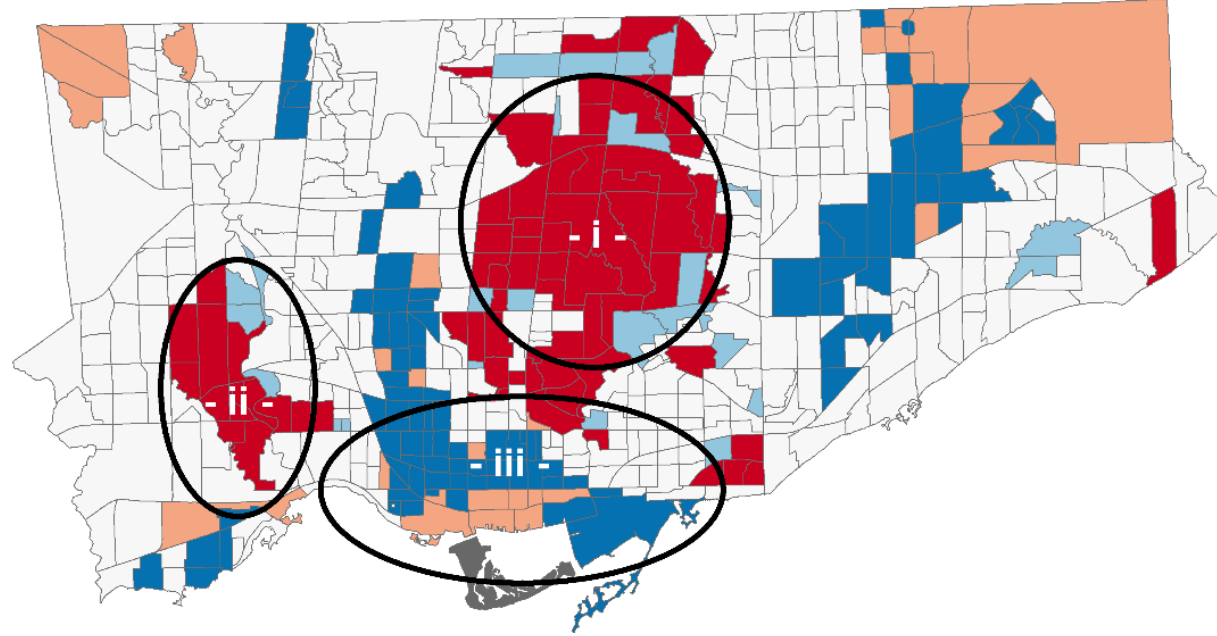

B. PCC - MHI

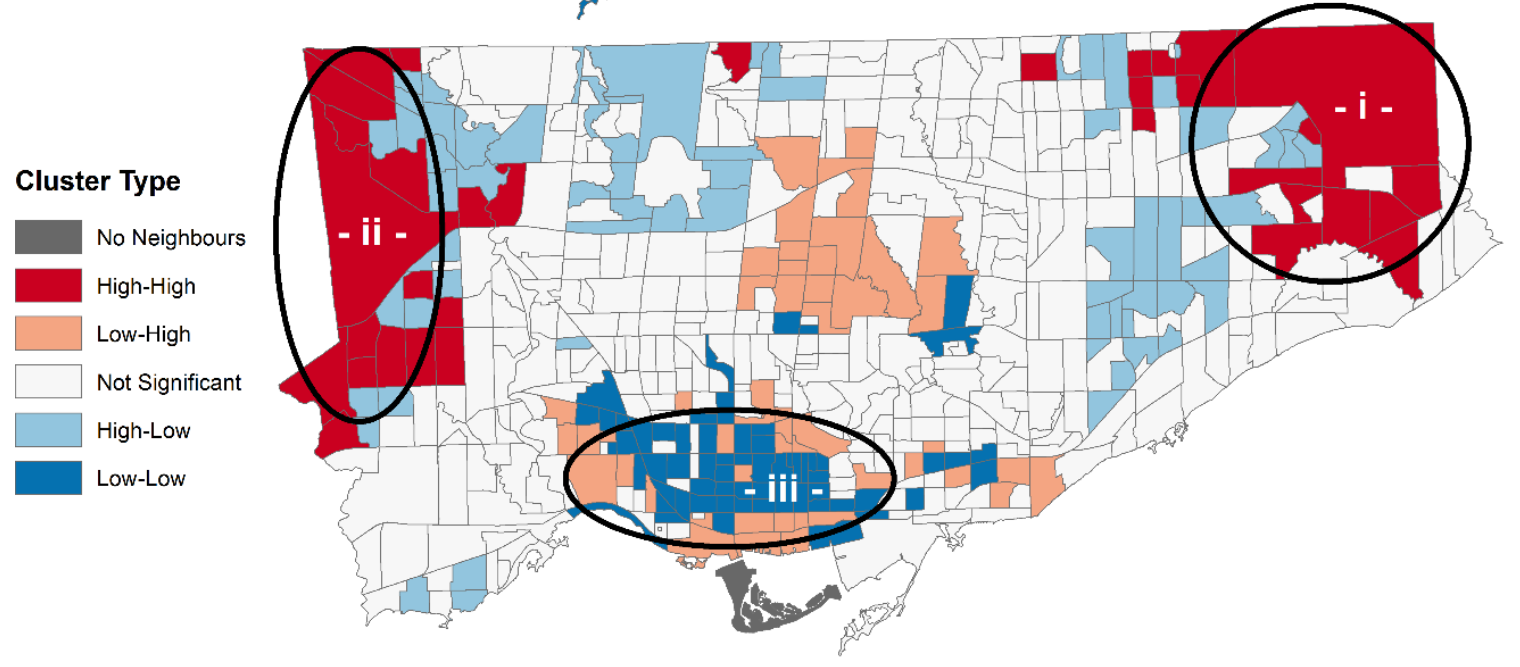

C. TCC - MHI

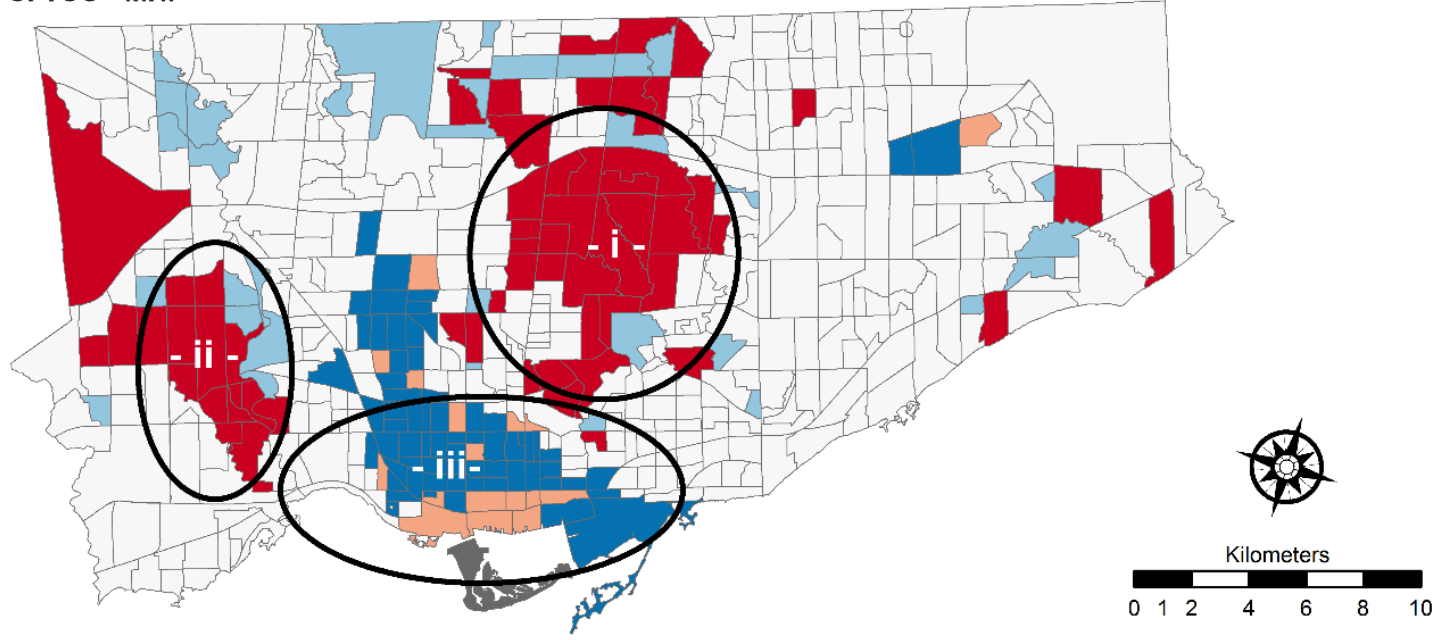

Figure 3-3: Results of bivariate local indicator of spatial autocorrelation analysis examining the relationship by census tract between $(A)$ percent realized canopy cover and median household income, (B) percent potential canopy cover and median household income, and (C) percent total canopy cover and median household income for Toronto, Canada (2006-2007). 


\subsubsection{Bivariate Moran's I}

When examining the RCC-MHI variable pair, a large number of CTs do not belong to any significant cluster of variable extremes. The largest significant areal cluster of high $\mathrm{MHI}$ and high RCC CTs (Figure 3-3A, cluster i) is present in the central portion of the study area. This cluster contains portions of several neighbourhoods locally recognized as more affluent (e.g., Forest Hill South, Rosedale-Moore Park, Lawrence Park North and Lawrence Park South, Bridle PathSunnybrook-York Mills). A geographically smaller, yet still significant, spatially coincident cluster of high $\mathrm{MHI}$ and high RCC (Figure 3-3A, cluster ii) is evident in the western portion of the study area and includes sections of neighbourhoods bordering a significant river system and ravine network (e.g., Edenbridge-Humber Valley and Kingsway South neighbourhoods) running through Toronto (i.e. the Humber River). Clusters of low MHI and low RCC are present in the southern central portion of the study area (Figure 3-3A, cluster iii). This cluster of low MHI - low RCC extends west along historical rail lines and into more heavily populated areas that exhibit lower median incomes (e.g., Dufferin Grove, Kensington-Chinatown, Trinity Bellwoods, PalmerstonLittle Italy, Little Portugal). Bordering this area of low MHI - low RCC to its south is a cluster of CTs that exhibit high MHI and low RCC.

Similar to the analysis of RCC and MHI, a considerable geographic area across Toronto exhibited no significant spatially coincident clusters of PCC and MHI. Where significant clusters of spatially coincident variables are observed, a loose centre-periphery pattern is evident. Two significant clusters of high PCC and high MHI are present on the eastern and western edges of the study area. The eastern most cluster (Figure 3-3B, cluster i) includes several CTs that encompass portions of a large urban park (i.e., Rouge Park), an area that includes historic farmland and large natural areas including forest stands, wetlands, and open meadow (Wilson, 2012). The western most cluster of CTs with high PCC and high MHI (Figure 3-3B, cluster ii) also contains several features of note, specifically a considerable corridor for electricity transfer lines, a large public park, as well as golf courses. Several proximate clusters of low PCC and low MHI were observed in the central southern portion of the study area (Figure 3-3B, cluster iii). Moreover, several CTs within this cluster also correspond to spatial aggregations of low realized canopy and low median income.

When TCC and MHI are examined (Figure 3-3C), there appears to be a considerable influence of the RCC component with strong agreement between clusters defined in Figure 3-3A and Figure 3-3C. This agreement is supported by the strong correlation coefficient observed between RCC and TCC ( $r=0.864 ; p<0.001)$. 


\subsection{Discussion}

Results of the aspatial and spatial approaches used in this study to understand urban tree canopy cover and its relationship with resident wealth converge toward a common conclusion: inequality of access to canopy related to income is present in Toronto. By using a combination of methodological approaches, this research further contributes to our understanding of approaches to investigate the presence of environmental justice within urban centres. In the context of Toronto, findings indicate that the relationship between access to urban tree canopy and $\mathrm{MHI}$ is significant but not linear across space. This observed non-linearity is a function of both historical and contemporary socio-demographic and economic processes manifest across the landscape of the study area.

The central cluster (Figure 3-3A, cluster i) of high RCC and high MHI, for example, is an area of historic affluence. Many of the CTs contained within this cluster have exhibited consistently higher MHI than the central metropolitan area average since the 1970s (see Hulchanski, 2010). Within this geographic area there are several residential areas composed of a higher than average number of single detached dwellings. As an example, of the 2,440 dwellings in the Bridlepath-Sunnybrook-York Mills neighbourhood (located near the centre of Figure 3-3A, cluster i) recorded in the 2006 Canadian Census, 2,205 (or 90\%) were single detached dwellings and 1,565 (or 64\%) of those dwellings were constructed before 1970 (City of Toronto, 2008b). With an average dwelling value of $\$ 1,491,568$ in 2006 (City of Toronto, 2008a), and exhibiting an average forest canopy cover of 55.6\% (City of Toronto: Parks, Forestry, and Recreation, 2013a), it is reasonable to infer that the stability of this neighbourhood over a long period (i.e., older dwellings, lower rates of new construction, consistent socio-demographic characteristics) has contributed to the establishment of a more extensive tree canopy over a long time period. Moreover, this disproportionately high RCC when compared to the city average almost certainly contributes to elevated property values in this area. Although this neighbourhood is an extreme exemplar, portions of other neighbourhoods falling within this cluster exhibit similar characteristics and have been privy to the same historical protection from the pressures of redevelopment.

In contrast, there have been considerable redevelopment and intensification initiatives in the pre-amalgamation municipality of old Toronto that contains the downtown core and older neighbourhoods, with a large number of condominiums being built in the downtown area and traditional central business district (Rosen \& Walks, 2014). As an example, in 2006 the Waterfront Communities area of the city (just south of Figure 3A, cluster iii) has 15,705 dwellings, of which 14,035 (or 89\%) are classified as apartment buildings (a classification that includes 
condominiums) of five stories or more (City of Toronto, 2008c). Of the total number of dwellings, 14570 (over 92\%) were constructed after 1970 and 5,460 (nearly 35\%) were constructed in the period of 2001 to 2006 (City of Toronto, 2008c). Building density above municipal guidelines is being allowed by the municipality, perhaps encouraged, in exchange for increased development fees or an agreement for the developer to provide infrastructure related to these developments (Rosen \& Walks, 2014). However, this increased density is expected to preclude any significant expansion of tree canopy cover in an area already lower in RCC and PCC due to a number of associated barriers to establishing and supporting tree growth such as space constraints for growing, lack of light from building shadows, and lack of soil volume.

This particular example of high-rise residential development along Toronto's waterfront is also of interest due to the deviation from a priori assumptions about the relationship between RCC and $\mathrm{MHI}$. Though the previous discussion has identified factors that likely influence the lack of tree canopy, higher levels of $\mathrm{MHI}$ are not accounted for. The consequence of this reinvestment in the inner city largely through high-rise condominium developments has begun to transform the downtown core from a primarily commercial function to an area of mixed use (Rosen \& Walks, 2014). The demand to live in more "walkable" neighbourhoods with close proximity to employment as well as opportunities for entertainment and leisure has attracted a higher proportion of young professionals with high levels of education and above average household incomes resulting in upward pressure on real estate values and displacing those that rely on affordable housing to other areas of the city (Lehrer and Wieditz, 2009). It is likely that those displaced will end up in areas with lower $\mathrm{MHI}$ and, based on the results of this study, in areas of lower associated RCC thus exacerbating the geographic polarization of UTCC.

Similarly, the presence of clusters of low MHI but high RCC are also interesting anomalies due to their deviation from a priori assumptions about income and tree canopy coverage in contrast to the previous example. Examining socio-demographic change over two decades in several south-eastern Australia neighbourhoods, Luck et al. (2009) demonstrated that in some cases past socio-demographic data better predicted present tree canopy distribution than the more contemporary socio-demographic makeup of that same neighbourhood. This finding indicates it is possible for a neighbourhood to change, either through gentrification or decay, but the longevity of trees may lead to canopy artifacts reflective of past socio-demographic and economic conditions. As a result, these clusters of high canopy-low income are likely to be a legacy of that area prior to experiencing neighbourhood change (Boone et al., 2010; Luck et al., 2009) and likely contribute to the weaker model fits reported in previous studies of tree canopy 
and socio-demographic data (e.g., Heynen \& Lindsey, 2003; Landry \& Chraborty, 2009; Perkins et al., 2004).

In addition to better understanding the processes leading to unequal access by city residents to urban forest canopy, the specific type of clusters identified in the bivariate LISA analysis offer a potential opportunity to reduce inequality through strategically targeted planting efforts. When considering which clusters are important to identifying priorities that address distributional inequalities, of least concern are cluster types representing high amounts of realized canopy (i.e., high-high or high-low). Regardless of whether income is in the lowest quartile or highest quartile, the residents living in these spatial clusters benefit from better access to tree canopy cover, and its associated benefits, than do many other large residential proportions of the study area.

The most prohibitive areas to decrease distributional inequality of access to the benefits of urban trees are related to the spatial clusters representing significantly low values of total tree canopy (realized + potential) and low household income (Figure 3-3C, cluster iii). In addition to having reduced access to RCC, these clusters exhibit less opportunity to expand tree canopy in the future to address unequal access. This challenge can be conceptualized by considering the original classified satellite imagery. If a pixel is not classified as RCC or as an area with the potential to expand canopy, the pixel represents a barrier to planting (e.g., it is classified as water, dwelling, road, or some other impervious surface). With limited pervious surface available to plant new trees, several options to reclaim impervious surface at street level may be considered, through: 1) pavement removal or building demolition; or, 3) sub-surface engineering solutions including suspended pavement systems providing improved soil conditions below impervious surface (Smiley et al. 2006).

Although removal of pavement and demolition has been successful in expanding potential planting areas in a shrinking city with high vacancy rates (Frazier \& Bachi-Sen, 2015), this approach may not be feasible in a growing city like Toronto which has experienced a population growth of 4.5\% from 2006 to 2011 (City of Toronto, 2012), constructed 70,000 new residential units between 2009 and 2013 (City of Toronto, 2014), and is pursuing further intensification (Lehrer et al., 2010). Growing cities that are attempting to maintain or increase density may have to implement smaller scale reclamation of impervious surface at a higher cost; the District of Columbia, for example, invested $\$ 1.22$ million from 2010 to 2012 and reclaimed a total of approximately $7,500 \mathrm{~m}^{2}$ (or $80,303 \mathrm{ft}^{2}$ ) of impervious surface as of 2012 (Thomas, 2012), some of which was earmarked for the planting of trees. 
Over the shorter term, clusters of spatially coincident high PCC and low MHI offer the greatest opportunity for improving access to canopy benefits in urban residential neighbourhoods currently lacking adequate access to trees. The increased availability of pervious surface in these locations for tree planting is less financially burdensome than reclaiming impervious surface or constructing engineered solutions (e.g., suspended pavement). Furthermore, if planted in large areas of pervious surface, mortality may be less than the same number of trees planted in engineered sub-sidewalk growing spaces (Bassuk \& Whitlow, 1988; Lu et al., 2010).

There is, however, the potential for a conundrum: by targeting these high PCC - low MHI locations, a significant sub-region of less affluent city residents may be ignored through an inherent flaw in benefit-cost analysis. Managers applying cost-benefit analysis (CBA) frequently prioritize variables in the decision-making process that can easily be monetized over variables where artificial prices have been applied and have greater associated uncertainty (Ackerman \& Heinzerling, 2002; Hanley \& Barbier, 2009) such as distributional criteria. Because equality of access is more intangible than pollution reduction or temperature mitigation, distributional criteria are prone to be displaced in lieu of efficiency criteria (e.g., maximizing ecosystem services, reducing cost per tree planted). Consequently, urban locations with little pervious surface and low $\mathrm{MHI}$ could be systemically excluded as a priority for future tree planting and, therefore, become more vulnerable to further polarization across income lines if decision makers do not explicitly commit to prioritizing the creation of a standard of access for city residents to tree canopy.

Environmental decision-making that preferences one of three subsystems or spheres of sustainability (i.e., ecological, social, economic) commonly results in trade-offs to one or both of the remaining spheres. To some extent these trade-offs are a consequence of the incompatibility of some underlying assumptions among these three subsystems (McGuire, 2012). Prioritizing tree planting based on one metric within a single sphere of sustainability principles is expected to result in similar outcomes. In other words, making a commitment to improving equality of access to urban trees (i.e., a social principle of sustainability) could result in the reduced aggregate return of economic and ecological benefits with inadequate investment in urban forest management expressed as fixed or shrinking budgets. Planting trees in urban locations with considerably less pervious surface is economically less efficient than planting in locations with higher percentages of pervious space. These economic inefficiencies may be related to increased investment in the short-term (e.g., the reclamation of impervious surface, construction of engineered planting solutions) or from longer term losses from increased mortality related to the more challenging urban growing conditions for trees (Koeser et al., 2013; Lindsey \& Bassuk, 1992; Lu et al. 2010; 
Nowak et al., 2004). Although there are likely to be some opportunities to reduce the cost of planting if coordinated with scheduled reconstruction of roads or sidewalks, there is an inertia embedded in the current urban form that is difficult to overcome, influencing the overall cost per tree planted.

Moreover, there are a number of ecological trade-offs to consider. The first is a direct function of harsh urban growing conditions. Many ecosystem services have a direct relationship to tree size, related in large part to the leaf area of the tree (Givoni, 1991; McPherson, 1992; Peper \& McPherson, 1998). Planting trees in hostile urban growing conditions that includes highly compacted soil reduces the growth rates (Close et al., 1996; Smiley, et al., 2006) and limits the maximum size of planted trees (Bassuk \& Whitlow, 1988; Kozlowski, 1999), though it has been suggested that reduced maximum size is more likely with late successional species (Quigley, 2004). Without adequate soil conditions, trees planted in engineered solutions are more likely to grow at reduced rates, reach a maximum size less than the potential of the species, diminishing the potential leaf area and subsequent collective capacity for these trees to deliver ecosystem services. Moreover, there may be an additional trade-off related to the loss of potential multiplicative effects that emerge from the spatial arrangement of trees. Depending on the target ecosystem service, a fixed number of isolated trees provide a diminished level of that service than if the same number of trees were organized spatially as a stand with contiguous canopy. Thus, if the municipality prioritizes equity in future tree planting initiatives, and focuses primarily on reducing distributional inequalities resulting in the displacement of planting to expand high quality forest patches, some proportion of ecosystem services gained as emergent properties above the collective sum of individuals, will also be lost.

The methodology developed in this study has several limitations. The inclusion of isolated pixels in the analysis will result in an exaggerated area of potential canopy by CT. Because land cover data is derived from sharpened QuickBird imagery, a single isolated pixel represents an area of $0.372 \mathrm{~m}^{2}(0.61 \mathrm{~m} \times 0.61 \mathrm{~m})$, an area inadequate to establish mature trees. Furthermore, these data are aggregated to areal units (i.e., zones) convenient for the analysis but are defined somewhat arbitrarily and are thus subject to the modifiable areal unit problem. Because CT boundaries are defined by using permanent features to maintain a stable population range, these boundaries may artificially truncate underlying socio-demographic patterns and / or vegetation patterns. Several studies (e.g., Jelinski \& Wu, 1996; Fotherington \& Wong, 1991; Oppenshaw \& Taylor, 1979) have demonstrated the unpredictability of statistical outcomes as different zoning schemes were applied to the same base data. Aggregating the data of this study to a different 
system of zoning (e.g., dissemination areas or neighbourhoods) is likely to result in somewhat different analytical outcomes.

Perhaps most important to the discussion of methodological limitations is that the analyses performed in this research subsumes data describing land cover that may be appropriate for planting trees; however, the associated land use designation may not be deemed appropriate for tree canopy expansion. Private land use such as electricity corridors, recreational fields, golf courses, and cemeteries can support mature trees, but in many cases afforestation efforts would interfere with the intended use of the space. Electricity corridors have long tracts of open vegetation; while these areas provide ideal conditions for a number of urban tree species, tree growth is actively suppressed to prevent potential interference with transmission lines. Public land such as parks could yield additional prospects for afforestation; however, urban parks are expected by city residents to provide access to a variety of activities, some of which are in conflict with the presence of trees. Similarly, larger protected areas, though covered with highly pervious surface, represent significant natural heritage sites providing their own ecosystem services and aesthetic values but are likely to be excluded from tree planting efforts due to their special status.

\subsection{Conclusions}

This research presents a novel method of considering the spatial distributional inequalities of the urban forest and provides a methodological framework for use by researchers focusing on environmental justice studies in North American cities. Understanding distributional inequalities related to an environmental good such as the ecological, social, and economic benefits of the urban forest advances the capability of policy makers to address environmental injustice directly through strategic planting efforts. It is important to recognize, however, that making the decision to address one of the subsystems of sustainability, in this case addressing a social principle of sustainability in reducing distributional inequalities, induces the requirement for trade-offs in the remaining ecological and economic spheres. Accepting that trade-offs will occur, however, does not imply that addressing these inequalities should not be a priority. It is important that municipal decision-makers and city planners recognize that cost is not synonymous with value; providing better access to environmental goods such as city trees is not always easy to quantify and even more difficult to monetize. Despite the increased expenditure per tree planted, the aggregate value (economic, environmental and social) of planting a tree in a community underrepresented by this environmental good may be greater than the value to a community that is already well covered with tree canopy. 
While this research focuses on the urban forest as a case study, the methodological approaches used herein could be expanded for use with the evaluation of a number of other environmental amenities. Furthermore, this study has important implications for policy makers by providing a practical method to identify and spatially quantify where inequalities of access to an urban environmental good occur and, in so doing, informing decision makers where to target interventions that can address inequalities of access. 


\section{THE LEGACY OF PAST TREE PLANTING DECISIONS FOR A CITY CONFRONTING EMERALD ASH BORER (AGRILUS PLANIPENNIS) INVASION}

\subsection{Abstract}

Management decisions grounded in ecological understanding are essential to the maintenance of a healthy urban forest. Decisions about where and what tree species to plant have both short and long-term consequences for the future function and resilience of city trees. Through the construction of a theoretical damage index, this study examines the legacy effects of a street tree planting program in a densely populated North American city confronting an invasion of emerald ash borer (Agrilus planipennis). An investigation of spatial autocorrelation for locations of high damage potential across the City of Toronto, Canada was then conducted using Getis-Ord Gi*. Significant spatial clustering of high damage index values affirmed that past urban tree planting practices placing little emphasis on species diversity have created time-lagged consequences of enhanced vulnerability of trees to insect pests. Such consequences are observed at the geographically local scale, but can easily cascade to become multi-scalar in their spatial extent. The theoretical damage potential index developed in this study provides a framework for contextualizing historical urban tree planting decisions where analysis of damage index values for Toronto reinforces the importance of urban forest management that prioritizes proactive tree planting strategies that consider species diversity in the context of planting location.

\subsection{INTRODUCTION}

Widely recognized for providing important ecological, economic, and social benefits to city residents (Dwyer et al., 1992; McPherson, 1992), urban tree cover is a living resource and therefore inherently dynamic (Nowak \& Greenfield, 2012). Beyond the loss of city trees from new development and urban densification (Nowak \& Greenfield, 2012; Sanders, 1984), significant loss of tree cover also results from natural events such as storms (Burley et al., 2008; Sissini et al., 1995; Wiersma et al., 2012) or sustained conditions of drought (Nowak, 1993). The urban forest is also susceptible to unexpected tree loss from diseases and pests that can affect a specific genus or target an individual species (Raupp et al., 2006). With an increasing number of large North American cities like New York and Los Angeles investing in planting programs to protect and enhance their urban forests (Million Trees NYC, 2015; City Plants, 2015), it is important to investigate how city tree management choices driven by short-term considerations (e.g., financial constraints, nursery stock availability, aesthetics) can result in delayed and unexpected consequences that magnify the susceptibility of the urban forest to canopy damage and tree 
mortality. This study considers an example of these consequences that are, in part, a legacy of past planting decisions concerning the street tree resource in Toronto, Canada, which is currently facing sudden and rapid canopy loss resulting from Emerald Ash Borer or "EAB" (Agrilus planipennis), an invasive insect pest.

As one category of tree cover within the broader urban forest, street trees typically constitute a smaller proportion of the total tree biomass when compared with other categories of urban forest such as park, institutional, or private residential trees (Maco \& McPherson, 2002). Despite their exposure to more challenging growing conditions (Bassuk \& Whitlow, 1988) often resulting in retarded growth rates (Grabosky \& Gilman, 2004; Quigley, 2004) and increased mortality of younger trees (Koeser et al., 2013; Lu et al., 2010; Nowak et al. 2004;), several detailed analyses of public trees (or municipal forests) have confirmed that street trees provide greater financial benefits to city dwellers than the costs associated with their planting and maintenance (McPherson et al., 1997; McPherson et al., 2005; McPherson \& Simpson, 2002). New York City street trees are one positive exemplar-the municipal forest has a benefit to cost ratio of 5.60 to 1 , or $\$ 100.2$ million in benefits to city dwellers compared with the $\$ 21.8$ million in program expenditures devoted to street tree planting and maintenance (Peper et al., 2007). At the lower end of the benefit to cost spectrum is Berkley, California where municipal trees deliver $\$ 1.37$ in benefits for every $\$ 1.00$ in expenditures (Maco et al., 2005). Geographic context is an important consideration concerning street tree benefits to costs. Costs are determined by the present state of city's urban forest, the maintenance schedule, as well as any special programs or initiatives the municipality may have implemented. An examination of public trees in five cities by McPherson et al. (2005) found that Berkeley exhibited both the highest per tree benefits of the five city programs examined, however greater attention to reducing conflict between trees and impervious surface resulted in much higher management costs, reducing the overall per tree benefit to cost ratio. The authors suggest, however, that this increased investment is reflective of efforts to decrease mortality and increase the longevity of an urban forest with a very young age distribution and that the benefit to cost ratio will increase appreciably over time as tree maintenance and removal costs decrease and the benefits delivered by maturing trees increase rapidly (McPherson et al., 2005).

As the vast majority of North American street trees are not naturally occurring, the structure of a city's street tree resource is in part resultant from species selection and the planting/replanting rate (stocking rate); both of these choices can have short- and long-term consequences for the urban forest resource and ultimately the resource's potential to deliver 
desirable benefits. More challenging urban growing conditions narrow the selection of species to those more tolerant of urban stresses (Richards, 1983; Whitlow \& Bassuk, 1988). Selecting a tree species less capable of withstanding harsh urban growing conditions increases its probability of mortality, and reduces the average longevity of that species subject to these conditions (Foster \& Blaine, 1978; Richards, 1983; Sanders, 1981). Subsurface infrastructure and overhead conflicts (e.g., electrical wires) as well as proximity to impervious surfaces (e.g., sidewalks and roads) results in chronically inadequate soil quantity and quality, which directly inhibit and prohibit root development and mainstem elongation (Bassuk \& Whitlow, 1988; Lindsey \& Bassuk, 1992). Avoidance of high rates of street tree mortality (Foster \& Blaine, 1978; Lu et al., 2010) and stultified tree growth (Close et al., 1996; Quigley, 2004; Smiley, et al., 2006) are practical and attractive reasons for selecting fast growing tree species that are also more tolerant of urban conditions. Such decision making serves to improve the short-term efficiency of urban tree planting programs.

There are, however, longer-term consequences of narrow species selection, some of which can be magnified based upon decisions related to spatial planting / growing proximity. Preferentially planting many individuals of a single species decreases species diversity and may extend to reduced genetic diversity if very few cultivars of the species are planted. This reduced species and genetic diversity potentially creates conditions for increased susceptibility of city trees to pests or disease (Alvey, 2006; Laćan \& McBride, 2008; Sanders, 1981). The plight of the American elm (Ulmus americana) provides a good cautionary example of not prioritizing tree species diversity. Planted in large numbers along streets in many North American cities due to its fast growth, appearance, and tolerance of a wide range of conditions (Raupp et al., 2006), populations of American Elm have been catastrophically reduced by Dutch elm disease (or "DED”) (Ophiostoma spp.) both in the United States and Canada. Rather than replace this species-specific loss of city trees with a greater diversity of tree species, planting selections were commonly restricted to a small selection of tree species. Planting of cultivars of the Norway maple (Acer platanoides), a non-native species from northern Europe, was a popular choice because of its characteristics that include rapid growth, tolerance of ice and snow, and resistance to a variety of additional urban stresses (Nowak \& Rowntree, 1990). In the last two decades this tree species has been classified as invasive, especially in understory forest environments where it is naturalized and may exhibit allelopathic properties (Martin, 1999; Wyckoff \& Webb, 1996). This species is of particular concern for cities like Toronto with large natural ravine systems, vulnerable to its competitive advantages that include early leaf out, shade tolerance and high fecundity. 
Another genus of tree species that frequently manifests in high concentrations within North American cities is ash (Fraxinus spp.). Prior to being a common choice for replacement of American elms lost to DED (Poland \& McCullough, 2006) ash had become a common shade tree due to the "Marshall Seedless" cultivar of the green ash (Fraxinus pennsylvanica) introduced in the early 1940s (MacFarlane \& Meyer, 2005). The resulting popularity and increased spatial concentration of ash in some cities has recently resulted in a new problem not anticipated at the time of planting -susceptibility to EAB. Originally identified in Detroit, Michigan in 2002 (Cappaert et al., 2005; MacFarlane \& Meyer, 2005), this insect native to Asia has spread from Detroit to twenty-two US states (Siegert et al. 2010) and two Canadian provinces (Poland \& McCullough, 2006; Siegert et al. 2010). EAB is considered to be a significant threat to the urban forest for a number of reasons. While ash species are considered to be more resistant to the pressures of the urban environment than many broadleaf tree species, they still experience exposer to urban stressors and their growing environment is similarly constrained when compared with other city tree species.

Despite their tolerance of harsh conditions, there are still many individual ash trees whose vigour is compromised by chronic exposure to urban stressors. Several recent studies have demonstrated that stressed ash trees tend to be preferentially colonized by EAB (McCullough et al., 2009; Siegert et al., 2010). Moreover, low genetic diversity among urban ash tree plantings and the lack of a co-evolutionary pathway to develop some resistance to $E A B$ (i.e., EAB is nonnative) means even healthy individuals are at risk of infestation (Sydnor et al., 2007; Siegert et al., 2010). Once infested with $E A B$, the death of a tree occurs within three to four years for a large ash tree (Poland \& McCullough, 2006). With the potential to migrate up to $20 \mathrm{~km}$ per year (Prasad et al., 2010), when established in the urban forest of a city, EAB can disperse very quickly and has the potential to extirpate ash trees throughout the tree canopy. In many eastern North American cities, extirpation of the genus Fraxinus from the urban tree canopy seems most likely given the mixed success of containment strategies applied in locations where EAB infestations have been identified (Herms \& McCullough, 2014).

\subsection{Study Site}

The study area for this research is the City of Toronto, Ontario, Canada. With a population of 2.8 million people (most recent Canadian census), Toronto is now the fourth largest city in North America by population (O'Toole, 2013). The city's current political boundaries are the result of the amalgamation of six contiguous municipalities, which occurred in 1998 (Schwartz, 2004). 
Pre-amalgamation, these independent municipalities had their own planning departments, each of which had its own objectives and priorities that have resulted in considerable spatial heterogeneity of urban form. Among the variability in planning priorities was the provision and maintenance of green space and, immediately relevant to this research, planning and investment in street tree programs. It is reasonable to infer that each of these former Toronto municipalities shows some variability in how reliant street tree programs have been on ash (Fraxinus spp.) in their planting selections. While ash is commonly encountered in every city ward across amalgamated Toronto (see Error! Reference source not found.), there does appear to be areas of higher ash concentrations (spatial clustering), particularly in Scarborough and Old Toronto.

Toronto was chosen as the context for this study for a number of reasons. With 10.2 million trees and a structural value of $\$ 7.1$ billion (Nowak et al., 2013), Toronto's urban forest is comparable to that of other large North American cities such as New York (5.2 million trees, structural value of $\$ 5.2$ billion; see Nowak et al., 2007) and Los Angeles (6 million trees, structural value of $\$ 12.4$ billion dollars; see Nowak et al., 2011). Furthermore, Toronto's street tree population exhibits relatively low species richness and an associated high abundance of a small number of species, most of which have been selected based upon short-term economic considerations (i.e., fast growing, tolerant of urban conditions). Of the 530,190 street trees inventoried in Toronto, $21.1 \%$ are a cultivar of Norway maple; $7.2 \%$ are Gleditsia spp. (e.g., Gleditsia triacanthos or honey locust); 5.2\% (27,693 individuals) are ash (Fraxinus spp.) With $33.5 \%$ of the street tree population by number of trees, and an even greater proportion of leaf area, composed of three species (City of Toronto, Parks, Forestry and Recreation, Urban Forestry, 2012), Toronto's municipal forest is especially vulnerable to threats in the form of insect pests and pathogens.

Empirically, the study location offers the opportunity to examine the consequences of past tree planting decisions across a large urban forest with an established EAB infestation. At the time of this writing, high levels of ash decline and mortality from EAB are observable within Toronto's street tree population. While Toronto is attempting to delay infestation in as many as 13,000 trees (mostly along streets and in parks) through injection of insecticide in "high value trees" (Paterson, 2011), recent estimates indicate that as many as 860,000 ash trees (across all land cover categories) could be lost, representing just over $2 \%$ of the leaf area of Toronto's tree canopy, or the equivalent of $\$ 570$ million in structural value (City of Toronto, Parks, Forestry and Recreation, Urban Forestry, 2013). This loss of canopy is expected to coincide with the early stages of Toronto's renewed commitment to expanding tree canopy (from approximately $27 \%$ at 
present to $40 \%$ over four to five decades) (City of Toronto, Parks, Forestry and Recreation, Urban Forestry, 2013).
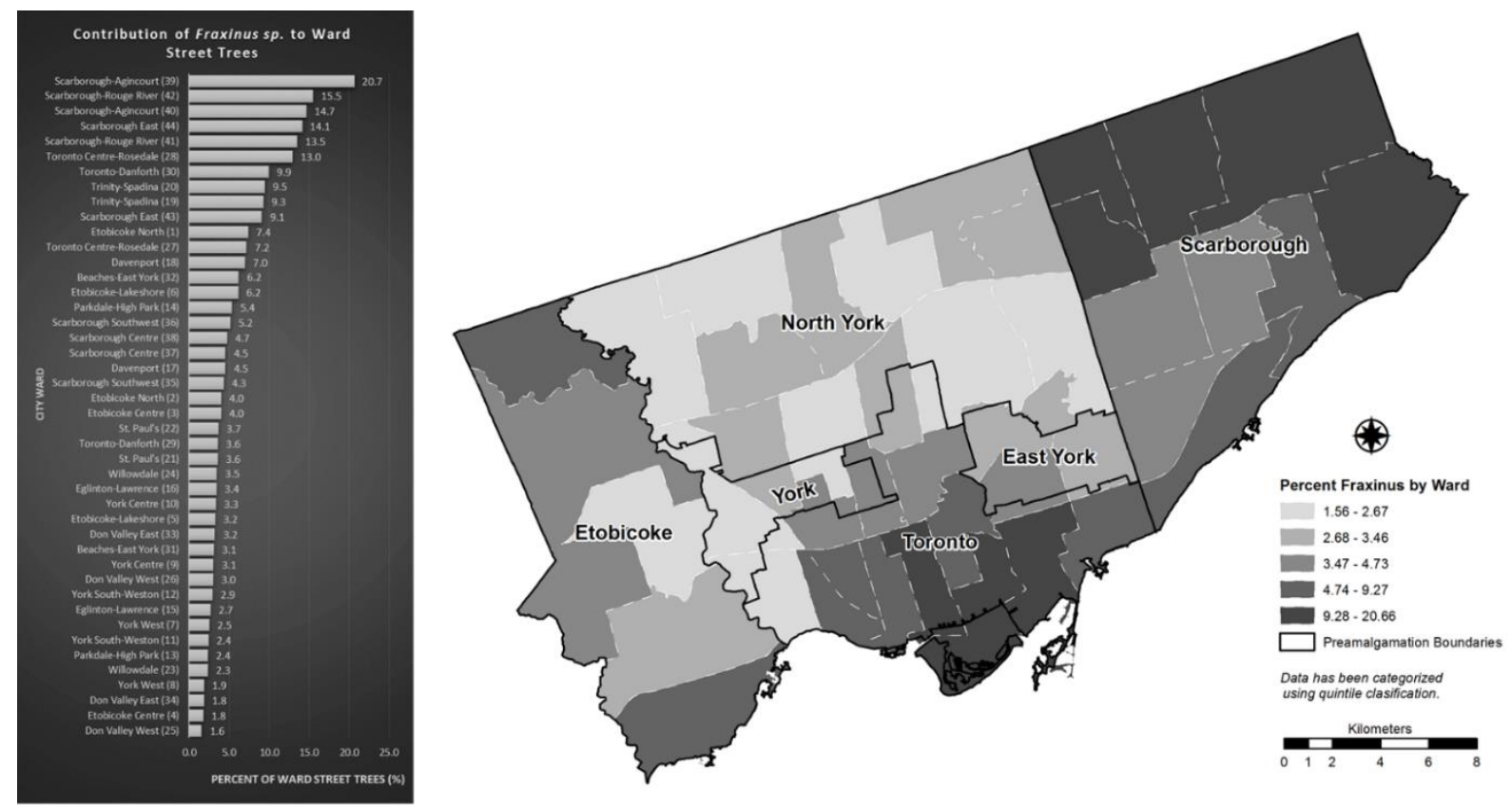

Figure 4-1: Proportion of street tree stems that are species of the genus Fraxinus by city ward for Toronto, Canada (2012)

While the impact of EAB on Toronto's urban forest cover, and associated lost benefits, has been quantified from an aspatial perspective (i.e., structurally and monetarily), there is considerable value in identifying and describing spatially how the municipal forest is likely to be impacted by EAB. In this study, a damage potential index was constructed to provide a spatially explicit framework to evaluate the consequences of past tree planting decisions, particularly the ecological, economic, and social trade-offs that result from those original management considerations. By understanding the time-lagged consequences of past planting decisions, and how they manifest across urban space, important input to proactive approaches of future urban tree planting decisions is possible. Constructing a theoretical metric to identify high-risk locations for $E A B$ infestation and tree mortality can contribute to developing strategic planting objectives, including where to prioritize ash replacement. Ideally, a theoretical damage potential metric would be developed from a complete inventory of trees that includes those growing on public and private land. Toronto, similar to most cities, does not have a full inventory of all of its trees, but it does have a complete inventory of street trees. This inventory provides an opportunity to construct a preliminary model to identify, on a local scale, where the street tree resource is likely to be damaged most by EAB. While derived from a street tree inventory, the methodology developed 
in this study allows for the subsequent inclusion of additional tree datasets, allowing for a more comprehensive understanding of the threat posed by EAB. Finally, this research documents an approach that is transferrable to other geographic settings and to other tree genera that may be vulnerable to current or future threats posed by insects or disease.

\subsection{Methodology}

\subsubsection{Datasets}

At the time of analyses, current cadastral data for the City of Toronto was not publically available as a complete dataset. A property boundaries feature dataset containing 476,904 individual parcels was created by Ryerson University's Urban Forest Research \& Ecological Disturbance (UFRED) Group by merging 922 AutoCAD tiles originally developed for the purpose of emergency service response. While the City of Toronto has recently released a property boundary dataset for the municipality, preliminary examination of it has revealed that it is missing several parcels contained in the UFRED created dataset. The Toronto street tree inventory was obtained through the Open Toronto portal (City of Toronto Parks Forestry and Recreation, Urban Forestry, 2012). A total of 530,190 trees composed of approximately 185 species in 65 genera were represented by points and georeferenced to parcel centres rather than at discrete coordinates. The following attributes were available for each tree: property address, common name, scientific name, diameter at breast height, and a position code to differentiate multiple trees present on a lot. Street centerlines were obtained from DMTI Spatial Inc. Census tract (or "CT") boundaries for the 2006 Census were obtained from Statistics Canada.

\subsubsection{Damage Potential Index}

In order to produce a spatial distribution of the theoretical damage index, the data were aggregated to a common zonation or analytical frame. Translating the data to a common analytical frame allowed for the standardization of data from spatially implicit forms to spatially explicit forms, which permits better comparison between and among locations. Although an argument could be made for an analysis that used an arbitrary grid with quadrants of equal size, most planning and policy decisions target only quasi-regular shaped geographic areas that are based on socio-demographic or political boundaries such as dissemination areas, CTs, neighbourhoods, and wards. Furthermore, the impact on the street tree resource may disproportionately affect some groups of residents over others (e.g., by income or ethnicity). As a result, CTs were chosen as the common frame for analysis to allow comparability between 
locations throughout the city, while at the same time maintaining the ability to conduct future analysis that includes socio-demographic variables.

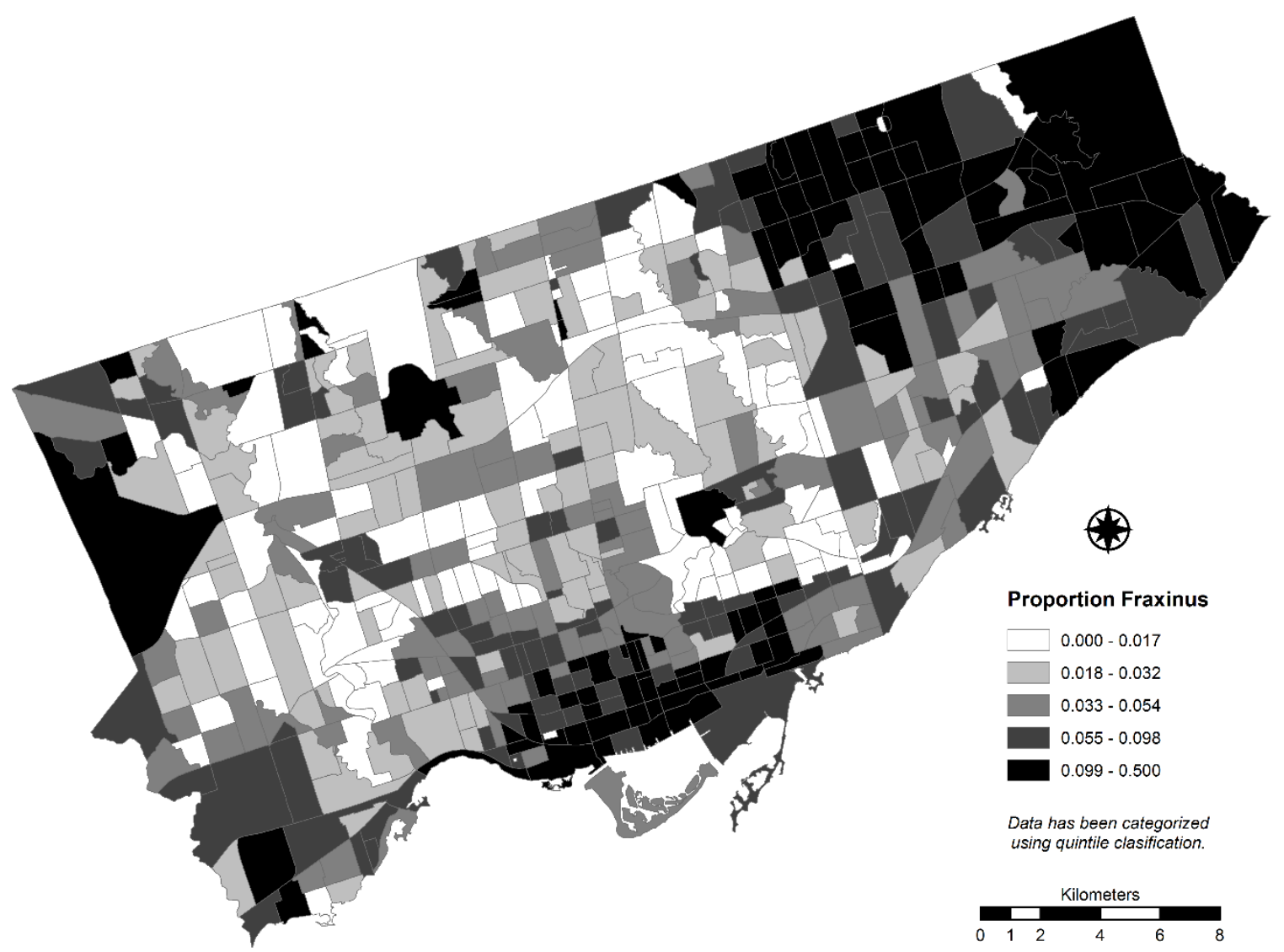

Figure 4-2: The proportion of street trees that belong to the Fraxinus genus calculated for each census tract for Toronto, Canada (2012).

EAB damage to the street tree resource in any CT is expected to be a function of several variables. The first is the frequency of individual trees belonging to the genus Fraxinus as a function of the total number of street trees (relative abundance) (Figure 4-2). The greater the proportion of tree canopy area contributed by ash trees, the higher the aggregate or "global" damage to the tree canopy is expected within a CT. It is In this context "global" is intended to contribute to understanding the potential overall magnitude of the damage, but provides little insight concerning the localized (street level) effects to tree canopy (e.g., the loss of clusters of ash individuals opening large gaps in the tree canopy). It is important to note that a measure of ash leaf area represents a superior choice in calculating the proposed index. These data, however, was not available for the target study area and stem density was necessary to apply as a proxy measure to represent the frequency of ash species. 


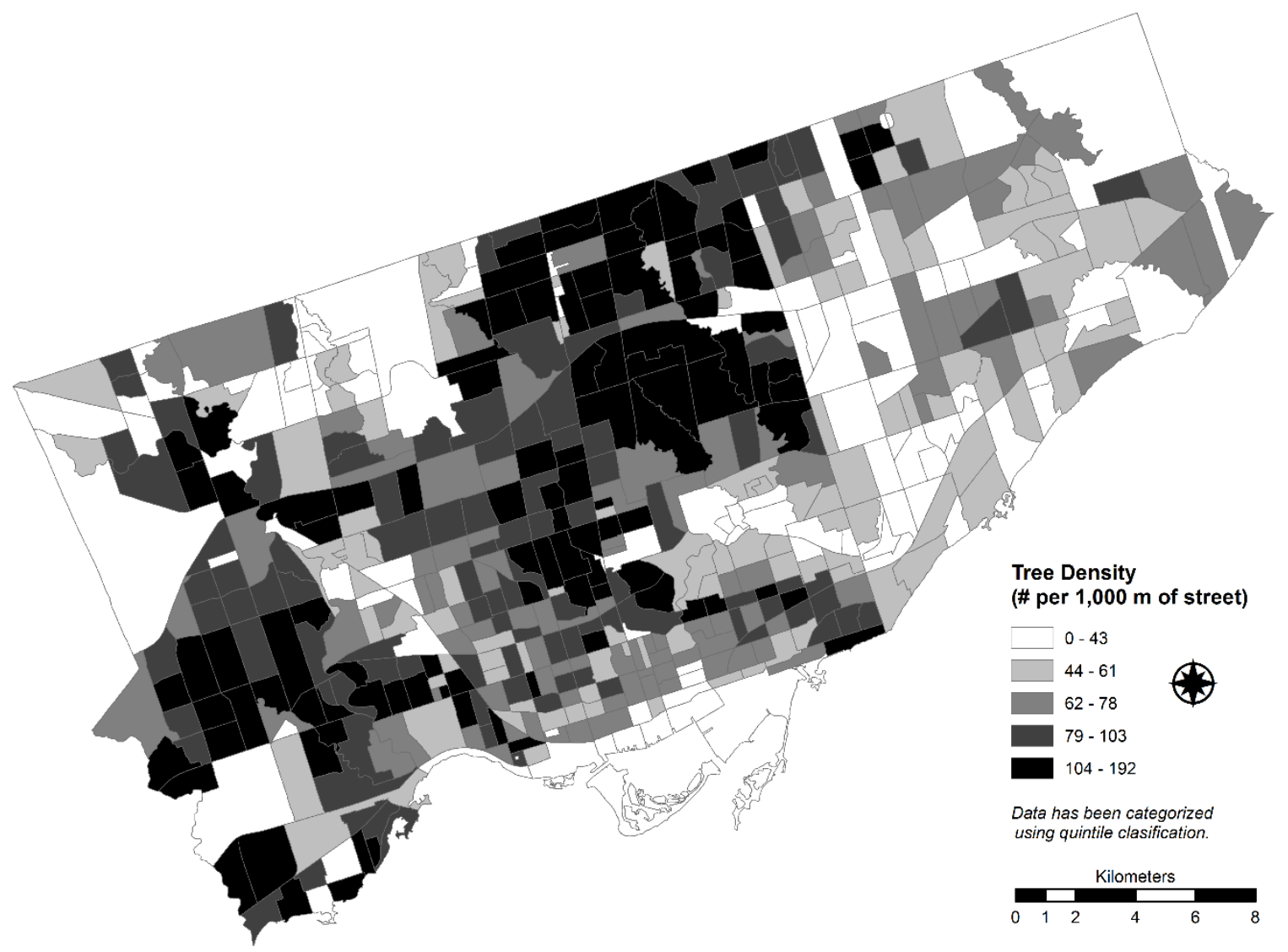

Figure 4-3: Street tree stem density standardized as a function of the street network density and calculated for each census tract for Toronto, Canada (2012).

Similarly, the magnitude of potential EAB damage is also a function of an interaction of both the overall street tree density (Figure 4-3) and the relative proportion of ash leaf area making up that street tree canopy within a CT. Where there is a high-density of street tree canopy and a large proportion of ash trees contributing to that canopy, there will be a greater magnitude of canopy loss. Therefore, the count of street trees within a CT is not adequate alone for comparison between CTs due to the irregular sizes and shapes of tracts. Therefore, a density of street trees was calculated to facilitate this comparison. If a complete inventory of all trees was available, a simple density of trees by unit area would be adequate. In contrast, trees in this dataset are linked directly to the street network within each CT and, therefore, a different standardization process is necessary. For each CT, the number of street trees per 1,000 metres of street length was calculated. Primary roadways were excluded from the standardization process as trees growing along major expressways and their associated access ramps are uncommon in Toronto. 


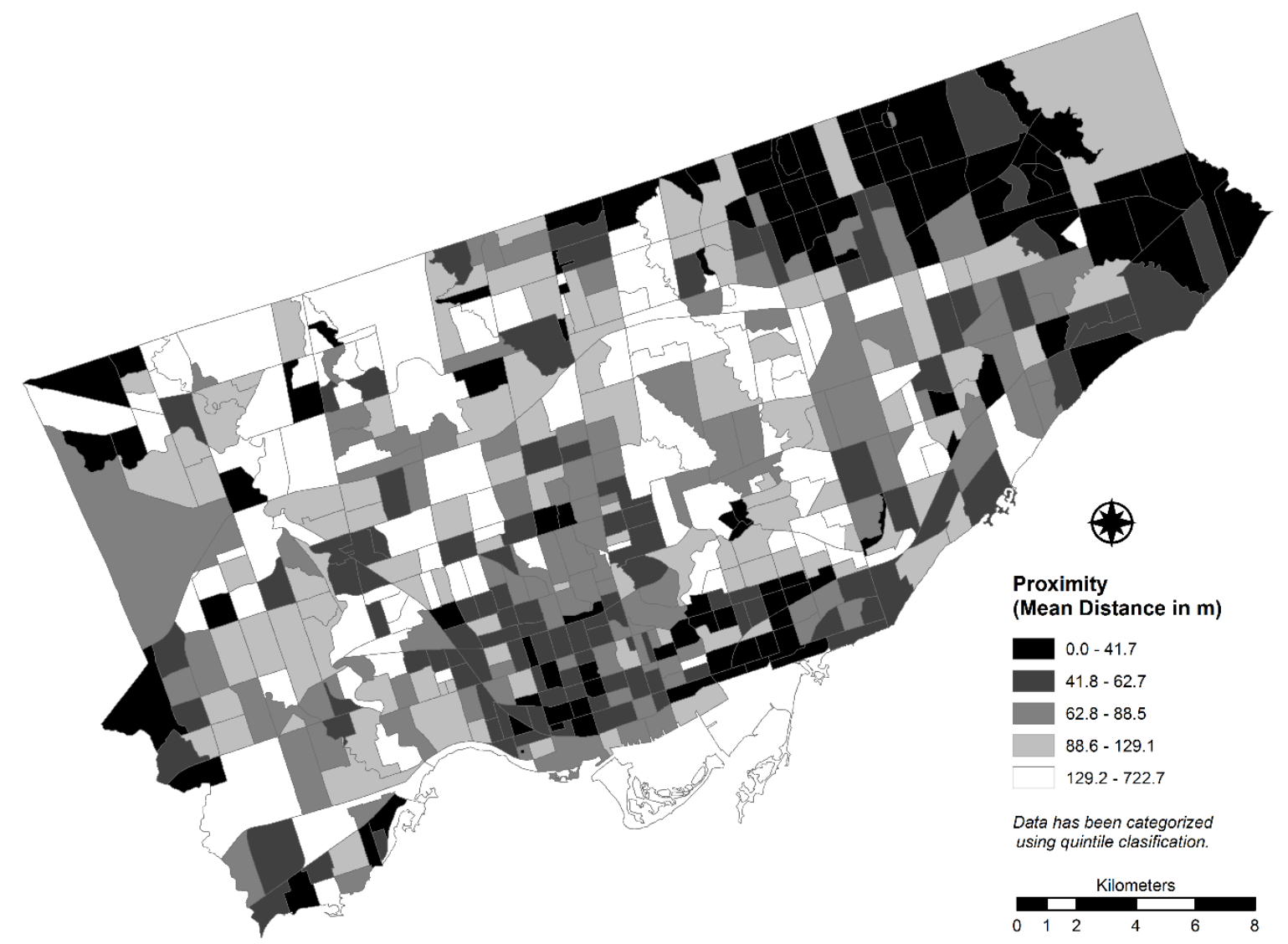

Figure 4-4: Average proximity of street trees that are ash species calculated for each census tract for Toronto, Canada (2012).

Finally, the potential for additional localized damage due to the planting arrangement of street trees must be considered. If there are clusters of ash trees in close proximity, mortality of those trees from EAB infestation may result in significant holes appearing in the tree canopy. If the same number of trees are planted at larger distances between individuals with other tree species interspersed between ash plantings, the extent of gaps in the tree canopy is expected to be less extensive. Because discrete coordinate locations were not available, lot boundaries were used as a proxy to calculate the mean distance between ash trees for each CT (Figure 4-4). As mean distance increases (i.e., mean proximity decreases), localized damage is expected to decrease as the affected ash individuals are more dispersed. As mean distance decreases (i.e., mean proximity increases), individuals in the CT are more likely to be grouped more closely and the potential for localized damage increases.

Therefore, the potential damage in a CT is a function of the interaction of the spatial density of street trees and the relative proportion of ash trees, which in turn is augmented by the 
mean distance between those individuals. This damage potential index (DPI) is operationalized in Equation 4-1.

$$
\text { Damage Potential Index }(D P I)=\frac{(\text { Spatial Density }) \times(\text { Relative Proportion of Fraxinus })}{\text { Mean Distance Between Fraxinus Individuals }}
$$

Where

Spatial Density = Number of street trees per kilometer of street within the zone

Relative Proportion of Ash Species $=$ Proportion of individual street trees in the defined zone that are ash

Mean Distance Between Individual Sum of the distances from each lot containing one or more ash trees Ash Species $=$ divided by the total number of lots containing ash species

The numerator denotes an estimation of global damage; as the value of the numerator increases the potential for overall damage to the municipal forest increases. The denominator represents a modifier for localized structural damage and represents an inverse relationship. Holding the numerator constant (e.g., two CTs with the same street tree density and relative proportion of ash), as the mean distance between ash trees becomes larger there is a reduction in the calculated DPI. As the mean distance between ash trees becomes smaller, there is an increase in the calculated DPI. Examining the input variable ranges for maximum and minimum values, the theoretical maximum DPI value possible for this distribution is 19.2 based on the observed spatial density maximum of 192.2, the relative proportion of ash species maximum of 0.5 , and the minimum mean distance between individual ash species of 5 metres.

Descriptive statistics for the DPI output revealed a distribution of index values with extreme skew (skewness $=+4.103$ ). Consequently the DPI was re-expressed through a log base 10 transformation (assume base 10 for any subsequent reference to log) to better approximate normality and to meet the assumptions necessary for application of spatial statistics. The spatial distribution of re-expressed DPI values was then evaluated for clustering of extreme values using a local indicator of spatial autocorrelation or LISA (Anselin, 1995; Getis \& Ord, 1992). For this analysis the Getis-Ord $\mathrm{Gi}^{*}$ statistic was chosen because of its ability to detect spatial clusters representing locations that deviate from the overall variable average. These clusters are commonly referred to as significant "hotspots" (i.e., similar high values above the distribution mean) and "cold spots" (i.e., very low values below the distribution mean) in the presence of global spatial autocorrelation (Getis \& Ord, 2001; Ord \& Getis, 1995). The identification of significant 
clusters of high magnitude DPI values expands the spatial extent of investigation beyond individual CTs to identify broader, more regional geographic areas containing ash trees that are likely to become infested with EAB. The presence of these clusters may indicate a multi-scalar impact of local planting decisions; in other words, choices made at the local scale results in local vulnerability to $E A B$, but may propagate and result in vulnerability at a wider geographic scale.

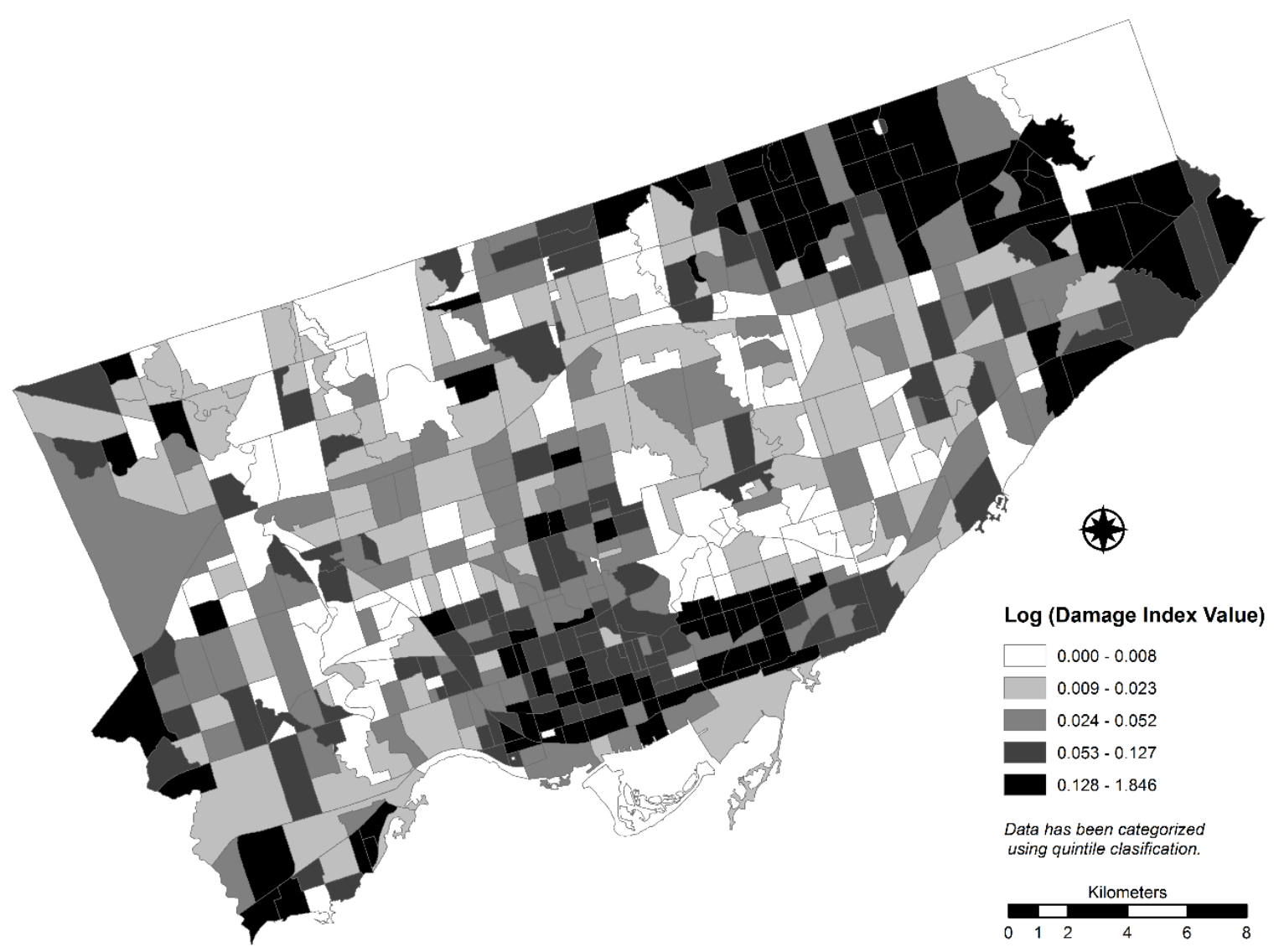

Figure 4-5: Spatial distribution of theoretical damage potential index values calculated for census tracts. Increasing damage to the street tree resource is expected as index values increase.

\subsection{Results}

Prior to transformation, DPI values calculated for study area CTs range from 0 to 1.85 (see Error! Reference source not found.), with higher values indicating higher damage potential due to EAB. The spatial distribution of log-transformed DPI values by CT is presented in Figure 4-6. Though the spatial distributions of the original values and log transformed values are similar, the scale of the transformed variable is more difficult to interpret. Because many observed DPI values are positive but less than 1 , a log function results in a negative value as an output. Though 
this outcome is not expected to appreciably affect the results of the LISA cluster analysis, the interpretability of this re=expression may be problematic for application in a policy setting.

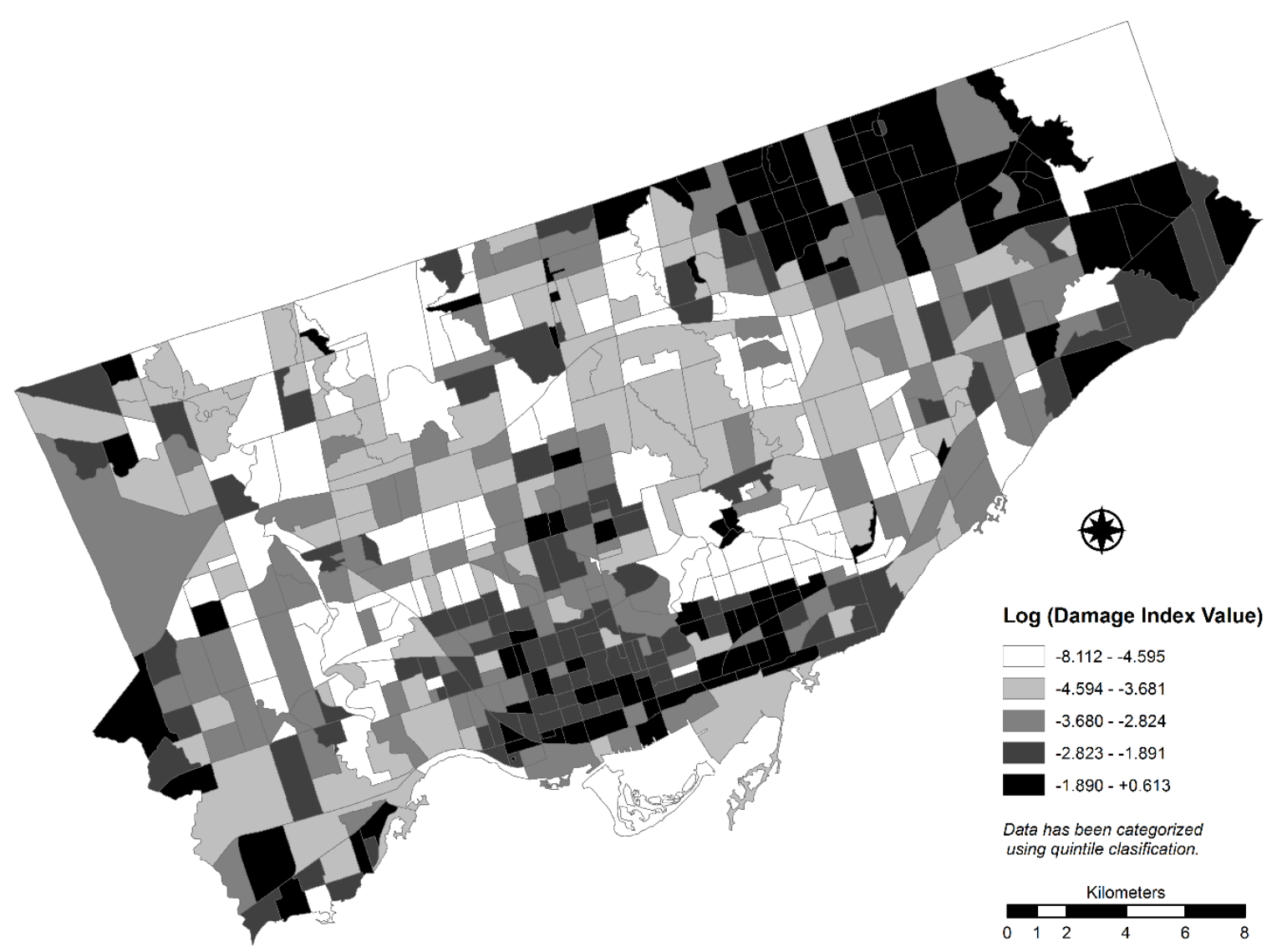

Figure 4-6: Spatial distribution of log-transformed theoretical damage potential index values calculated for census tracts for Toronto, Canada (2012). Regardless of sign, increased damage to the street tree resource is expected as values increase.

The second notable cluster of elevated DPI values is located in the northeastern portion of the study area and is contained within the pre-amalgamation municipality of Scarborough. This large contiguous group of CTs exhibits similar street tree characteristics to the previously discussed cluster observed in the downtown core-greater proportions of ash trees as well as closer mean proximity values between individuals. 


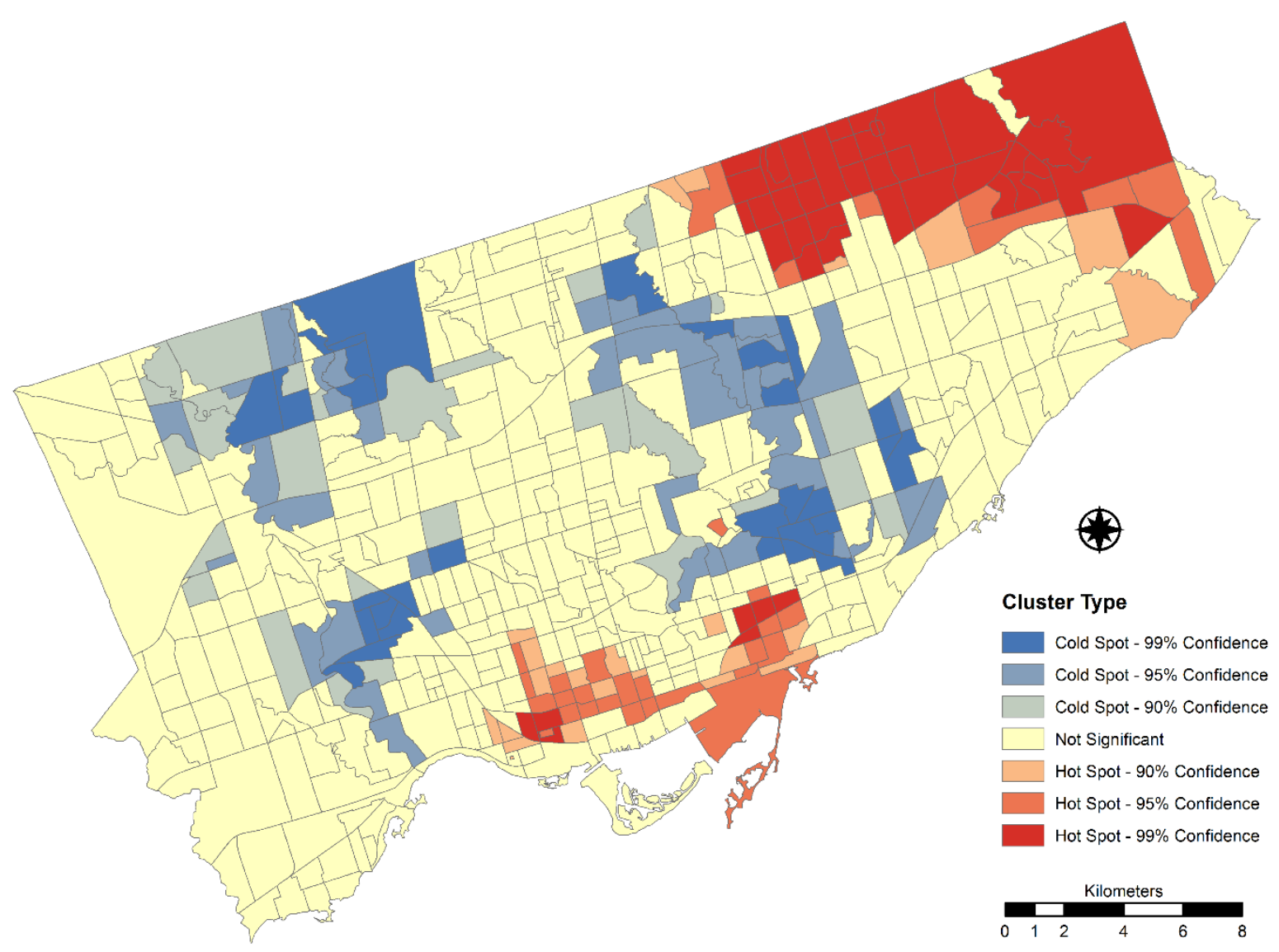

Figure 4-7: Getis-Ord local Gi* cluster analysis of the log transformed theoretical damage potential index values calculated for each census tract for Toronto, Canada (2012). Hotspots and cold spots represent clusters of transformed index values significantly higher and lower than the distribution mean.

\subsection{Discussion}

Results of this analysis indicate that past management decisions can have an important influence on the multi-scale vulnerability of city trees, in this case susceptibility to an invasive insect pest. In addition to individual CTs being more vulnerable to potential EAB damage, the presence of broader clusters of adjacent (neighbouring) CTs with higher DPI values suggests past planting patterns have inadvertently left much larger geographic coverages of street trees at risk to canopy damage. Even with the assumption that all ash trees will be lost to $E A B$, if the same number of individual trees were more dispersed (i.e., greater distances between individuals), localized structural damage to the canopy is likely to be lessened. More specifically, the gaps in the canopy from lost ash trees are expected to be larger when individuals are planted in close proximity than if the same number of individuals were separated by several individuals of other species with no vulnerability to the threat (Gandhi \& Herms, 2010). The importance of canopy 
density in providing improved ecosystem service delivery such as summer temperature moderation (see Chapter 2) and air filtration (Givoni, 1991) has been demonstrated (see Chapter 2) and it is reasonable to expect other ecosystem services may exhibit a similar positive relationship with canopy density.

Furthermore, there are social and economic losses related to urban tree decline and mortality. For some low-income city dwellers, public trees (i.e., street and park trees) represent their primary access to nature and the plethora of benefits associated with such access; many of these residents do not have the resources to purchase and maintain their own private trees (Heynen et al., 2006). Findings from the present study confirm that the amalgamated City of Toronto will be disproportionately affected by the damage to city trees caused by $\mathrm{EAB}$. If these areas of high potential damage coincide with areas more reliant on street trees for access to greenspace, social issues related to distributional inequality are likely to result (see Chapter 3 ). However, even if very limited distributional inequality of access emerges as a result of ash tree mortality, if dying ash trees lost to the EAB are not replaced, the benefits once delivered by said trees will be lost to the affected neighbourhood and to the city as a whole. Considerable public funds are invested in street tree planting and maintenance; where EAB-caused tree mortality is prevalent this investment represents, to some extent, sunk costs. However, it can also be argued that those sunk costs may not be as high as the original investment if benefits provided by those trees are considered. Prior to succumbing to EAB it can be reasonably argued that enough ecological, economic, and social benefits provided by these individuals in aggregate accrued that, in part, provides an offset of the initial investment and maintenance costs associated with ash trees.

In Toronto, a specific commitment has been made to replace lost ash trees as a part of the strategic plan to expand the urban tree canopy from approximately $27 \%$ at present to $40 \%$ over four to five decades (City of Toronto Parks Forestry and Recreation, Urban Forestry, 2013). This commitment to canopy expansion, in the face of a relatively sudden $2 \%$ loss of tree canopy by leaf area resulting from EAB mortality, most certainly will slow the rate of tree canopy expansion over the short term. Though Toronto is expecting the tree loss resulting from EAB will begin to subside by 2017 (Doyle, 2015), planned plantings of 105,000 trees in 2015 and 2016, and an additional 110,587 in 2107 will not adequately compensate for the canopy loss occurring over that same time period. Moreover, if priority is focused on mitigating this EAB caused tree loss, other planting priorities may be compromised due to opportunity costs. Resources dedicated to managing $E A B$ infestations, and replacing lost ash trees, are resources that cannot be 
committed to other planting objectives such as decreasing the polarization of access to tree canopy (see Chapter 3) or maximizing the efficiency of important ecosystem services (see Chapter 2).

Understanding the trade-offs resulting from past planting decisions is critical to informing future management practices, specifically adapting methods towards more proactive tree planting and maintenance efforts in Toronto as well as in other North American cities. Replacing ash trees that are casualties of EAB with a single species, or even a single genus, has the potential to result in new and, yet unknown urban forest vulnerabilities. Ensuring diversity in the form of species richness is one of the most important decisions that can serve to buffer against future urban forest vulnerability to insect pests or disease. Nevertheless, the reason that large aggregations of CTs are susceptible to higher magnitude damage from EAB remains connected to the difficulty associated with establishing alternate tree species that are tolerant of harsh urban growing conditions. Therefore, achieving a more resilient urban forest canopy requires not only planting proactively from the perspective of species diversity to avoid potential crises similar to $E A B$, but is also dependent upon the will to improve difficult growing conditions for city trees so as to increase the probability of survival and to extend average longevity for a wider range of tree species (e.g., shared rooting zones or engineered solutions such as suspended pavement designs). Assuming a fixed budget for urban forest management that includes both planting and maintenance activities, a shift from more reactive planting (i.e., replacing dead trees with new ones in the same growing conditions and hoping for a different result) to proactive planting (i.e., improving the survival of young trees and focussing on approaches to enhance their longevity) implies less trees are likely to be planted per year in lieu of improving subsurface soil conditions and improved maintenance of existing trees.

A shift towards more proactive planting is complicated by the political nature of tree planting and the power relationships that exist between established municipal departments and elected officials. Tree planting is a highly visible activity and the number of trees planted in a year is a metric easily interpretable by the electorate. During the most recent municipal election in Toronto the new mayor made a campaign pledge to plant 3.8 million trees by 2025 (Dale, 2014). It is uncertain whether this commitment was made due to a belief that the benefits provided by the urban tree canopy are a critical natural capital resource or whether this commitment was to portray a well-defined contrasting vision to his predecessor who viewed tree planting and maintenance as an unnecessary expenditure of public tax dollars. Though recently amended, the Urban Forestry Financial Plan with projected plantings totalling 1,066,787 trees by 2023 (Doyle, 
2015) has not been modified to the extent that the mayor's campaign pledge can reasonably be met. It is foreseeable that a recommendation by urban forestry managers to spend more per tree in order to improve probability of survival and longevity of those trees is likely to be politically unfavourable and be difficult to adopt once presented to city council.

In addition to providing a framework for considering the consequences of past planting decisions and informing future planting efforts for street tree resources, the DPI developed in this research can be enhanced as additional datasets become available to better describe the entirety of urban forest. Adding a new dataset that represents an additional subpopulation of the urban forest (e.g., tree cover in city parks) will not affect how the proportion of ash trees or the mean distance to the next ash individual are calculated, there would simply be more individuals to include in a DPI calculation. Adding new datasets or expanding the inputs to a complete inventory would require a modification of the density variable in the numerator. Despite this requirement, tree density can easily be modified from a measure of trees per linear distance to a measure of trees per area, ideally a measure of leaf area coverage per area. Because tree benefits increase with leaf area (usually correlated with tree maturity) (McPherson, 1992; Peper \& McPherson, 2003), a greater benefit to cost ratio is typically possible with fewer larger trees than is associated with a greater number of younger trees. Moreover, when expressed as leaf area per unit of geographic area, the DPI would better reflect the magnitude of potential damage to the local stand structure than using stem density. Data describing leaf area by tree species was not available for this study and, therefore, it was necessary to use select stem density to represent ash tree density. As a consequence the nature of the relationship (whether linear or multiplicative) between $\mathrm{DPI}$ and realized damage to the canopy cannot effectively be evaluated at this time.

It is important to note that although the methodology is expandable as new data become available, because this DPI was developed using a street tree inventory, the results of the analyses should not be extrapolated categorically beyond that of the street tree resource. As well, there are potential data limitations related to the dynamic nature of the urban forest that include some uncertainty concerning tree condition and whether the dataset may include trees that have died since the time of inventory. Furthermore, this analysis was not designed to predict how EAB will spread throughout the study area. Developing a model that could predict both the spatial and temporal dimensions of EAB infestation, and resulting damage, requires data that were not available for Toronto. In addition to a complete inventory (or an estimation from a sampling program), more complete information regarding where the EAB infection originated; the location 
of first satellite colonies that spread from the origin of infestation; and, the time from infestation to new colony establishment are all required for such a spatio-temoral model.

\subsection{CONCLUSIONS}

Construction of the DPI in this research serves as an important framework for understanding how past urban tree planting decisions can create unanticipated consequences as a result of insect pests or pathogens, beyond the immediate example of EAB. A narrow tree species selection and the resulting decrease in diversity, influenced in part by short-term economic considerations, has led to high concentrations of ash trees in parts of Toronto. Subsequently, an uneven distribution of locations with a greater likelihood of tree mortality and associated loss of tree canopy has developed over time. These planting decisions have caused an exacerbation of the EAB impact that is multi-scalar, present at both the local level (i.e., the CT level) and at a meso-scale (i.e., across multiple contiguous CTs) in some parts of the study area.

Like many North American cities confronting EAB infestations, Toronto has made a commitment to replacing trees that succumb to this insect pest. The findings of this study underscore the need for decision-makers to understand the longer-term consequences of the tradeoffs made at the time of planting (i.e., species selection and geographic placement) and point toward the requirement for a systemic change to decision making that moves beyond the more customary, reactive approach of replacing dead or dying trees to one of tree planting and management that is proactive and with a long-term vision of ensuring a resilient future urban forest. Replacing one species or genus with another on a one-to-one basis does not address the risks to the urban forest stemming from low species diversity, genetic diversity, and the increased stress from urban pressures contributing to the current EAB problem. Achieving improved diversity and reducing these urban stressors will require greater attention to significantly enhancing growing conditions (i.e., improving soil volume and quality), which is likely to require increased investment per tree in the short-term. Increased short-term investment will yield returns in the form of longer-term benefits delivered by trees of a more mature stature having greater leaf area).

The framework used when developing the DPI in this research has broader applicability than evaluating Toronto's street tree resource. Within the context of the study area, the DPI can be expanded to include additional datasets as they become available to encompass a larger proportion (or the entirety) of the urban forest. Furthermore, there is wider applicability for urban forest managers-this framework can effectively be transferred for application to other tree 
species that may be vulnerable to other insect pests such as Anoplophora glabripennis (Asian Long-horned Beetle) and Lymantria dispar dispar (Gypsy Moth), or be used in vulnerability assessments of tree pathogens such as Ophiostoma spp. (Dutch Elm Disease). 


\section{INTEGRATING SUSTAINABILITY SUBSYSTEMS WITH URBAN TREE PLANTING DECISIONS}

The contribution of this dissertation is twofold. In addition to advancing the understanding of important relationships within each of the three sustainability subsystems (economy, society, ecology), it provides valuable insights into how these subsystems can be integrated within urban tree planting decision-making. This final chapter discusses connections between the findings reported in the three studies (chapters 2 through 4) and makes several broader conclusions about urban tree planting within the context of EDM. This chapter also identifies opportunities for future research. Furthermore, a preliminary example is presented to illustrate how methods developed in this research can be used to inform the integration of sustainability subsystems into the decision-making process, specifically concerning future urban forest management decisions. Though the variables chosen to operationalize the individual sustainability subsystem are highly specific and topical to the study area, the broader approach to the research is transferrable to other geographic settings.

\subsection{INDIVIDUAL STUDIES, BUT COMMON THEMES}

Each study presented in Chapter 2 through 4 implicitly and explicitly examines the importance of different structural aspects of the urban forest. Chapter 2 demonstrates the importance of urban tree canopy cover (UTCC) closure in providing an ecosystem service important to city dwellers (i.e., summer cooling or, more specifically, mitigation of surface temperature rise) and also identifies significant differences in how access to tree canopy is geographically distributed amongst different household income groups. The evaluation of different tree canopy classes introduces a new dimension when considering ecosystem service delivery provided by the urban forest and also raises the question of who has access to these benefits.

Distributional inequalities of UTCCC, from the perspective of household income, are identified in Chapter 3. This study employs novel methods, infrequently applied in both urban forest and environmental justice research to explore the presence of unequal access to UTCC. As well, this research also extends beyond the demonstration of distributional inequalities to include a discussion of some of the potential processes that may be contributing to the presence of these inequalities.

The vulnerability of the urban forest to damage resulting from structure deficiencies such as minimal species diversity is explored in Chapter 4. This research demonstrates how urban 
forest structure-specifically species richness, genetic diversity, and the related spatial distribution of these trees-can increase the vulnerability of the urban forest to damage from unexpected insect pests or pathogens. While the relationship between diversity and risk has been established in other settings, it has been seldom used is an effort to evaluate the impact of past tree planting management decisions.

Although independent analyses, each chapter in this dissertation addresses prominent lines of inquiry within the urban forestry and sustainability literature that are united by three themes. The first of these themes is the considerable importance of growing conditions in influencing short-term urban forest management decisions that lead to long-term consequences within one or more of the various sustainability subsystems. As discussed in earlier chapters, areas with significant impervious surface are difficult places to establish and grow trees, reducing access to canopy for many lower income households (i.e., poor social outcome) as demonstrated in Chapter 3. The lack of canopy and increased exposure to impervious surface also leads to poor ecological and social outcomes, with higher mean surface temperatures (as shown in Chapter 2) likely to be experienced for those lower income households (refer to Chapter 3). Furthermore, as discussed in Chapter 4, these difficult growing conditions can lead to a smaller suite of tree species comprising local urban forest patches, specifically because these species (e.g., ash spp.) were specifically chosen for their tolerance of more challenging growing conditions. The result is a poor ecological and economic outcome as parts of the urban forest are more susceptible to pests and diseases like $E A B$ and now require considerable resources to mitigate widespread tree losses.

The second theme emerging from this research is the importance of moving to a more proactive and multi-criteria approach to urban forest management decisions. As has been suggested in all three studies, a focus on single decision-making metrics fosters the potential for poor, even perverse outcomes. As discussed in Chapter 2, a focus on maximizing the efficiency of an ecosystem service like temperature mitigation requires increasing the present stock of highdensity and closed tree canopy. This approach would add trees to areas with higher percentages of canopy and eschew areas already lacking canopy, thus exacerbating existing distributional inequalities (see Chapter 3). Conversely, a focus on reducing distributional inequalities observed in Chapter 3, or increasing diversity to reduce the potential for damage identified in Chapter 4, requires more attention to improving growing conditions to reduce potential tree mortality and improve longevity, a more expensive approach for planting programs. Though the longer term benefits from larger, healthier, and longer living trees will improve, this improvement is not likely 
to equate to the total benefits provided by the same number of trees in more favourable growing settings. These potential outcomes highlight the importance of applying a multi-criteria approach to decision making in urban forest management, rather than focusing on single ecological, social, or economic metrics.

Finally, there is an important conceptual thread connecting each of the preceding chapters related to the role of time in urban forestry analysis and conceptualizations of sustainability. Medium to large trees require a considerable length of time to reach maturity and, when in adequate conditions, have lived for a number of decades. The time required from the planting and establishment of trees to their reaching maturity translates into a considerable lag-effect from the time of management decision(s) to an observed effect or forest structure modification. Understanding these legacy effects has important implications to advancing understanding of underlying determinants of urban forest structure. For example, economic restructuring and urban transformation can occur at a time scale that is a fraction of the lifespan of individual trees. Processes related to this transformation result in local socio-demographic change whilst leaving urban vegetation intact in some circumstances, appearing as outliers when analyzed statistically for relationships between UTCC and other types of data (see Chapter 3).

As a result, when examining single spatio-temporal snapshots of urban canopy cover it is important to consider that it may be difficult to identify some of the underlying processes influencing UTCC if they are occurring at considerably different temporal scales. This observation supports the need for additional research focusing on urban vegetation change over several decades to better understand what processes contribute to distributional inequalities related to UTCC and to identify the potential presence of environmental injustice related to access to this natural capital resource. It is also important to note that many of the decisions that have led to the present urban forest structure predate the concepts that are providing the framework for this research. In other words, decisions from several decades ago that have inadvertently lead to unsustainable outcomes, cannot be fairly criticized. Past decision-makers cannot be held accountable for not adhering to sustainability principles when the fundamental concepts had not been popularized, and the value of the urban forest to city dwellers had yet to be systematically quantified.

Further understanding of these common themes spanning the individual studies contributes to urban forest management in a number of ways. Theoretically this work has identified new avenues for empirical research to better understand processes that influence urban forest structure both within and across sustainability subsystems. Methodologically, this research 
has demonstrated that approaches such as the use of bivariate LISA, established in other disciplines but somewhat novel to urban forestry, can assist in pursuing these new avenues of research. From the perspective of policy, these themes clearly demonstrate the importance of considering all sustainability subsystems in the decision-making process, if the urban forest as a natural capital resource is to be protected, enhanced, made more resilient, and equitably distributed. However, to operationalize the promise of this dissertation, future work is needed.

\subsection{DIRECTIONS FOR FUTURE WORK}

There are several directions for future research emerging from this dissertation. The relationship between UTCC and UHI explored in Chapter 2 identified the potential importance of urban forest stand characteristics to provide more efficient temperature mitigation beyond simple coverage metrics at the sub-city level (e.g., DA or CT). Confirming these relationships through the use of landscape metrics and multiple effects statistical models can provide a contribution to urban forest theory by adding to the present understanding of the importance of urban forest structure that has not yet been significantly explored. This line of inquiry also has the potential to contribute to urban forest management methodology through the introduction of new data and approaches that can be adapted for other subtopic areas. Finally, quantifying the importance of stand structure provides empirical evidence that can inform policy decisions, particularly strategic urban forest management plans.

In Chapter 3, distributional inequalities in access to UTCC, related to household income, were identified and provide additional directions for future research. Of particular interest is the rational derivation of a minimum standard for UTCC. Developing this metric is particularly important for two reasons. Firstly, a standard metric for the North American context would allow an expansion of environmental justice studies focussed on the urban forest beyond examinations of distributional inequalities to questions of whether there is the presence of injustice. Furthermore, defining minimum standards for urban forest structure and access can contribute to policy development in cases such as Toronto's where defined equity of access as a strategic urban forest management objective has been difficult because of an inability to identify an appropriate metric, or set of metrics, other than simply focussing on "areas with less tree canopy" (City of Toronto, Parks, Forestry and Recreation, Urban Forestry, 2013, pg. 9).

Further research is also required in a number of areas prior to the implementation of a system for prioritization of tree planting. To achieve an operational system of prioritization, additional empirical, contextual, and methodological studies are required. For example, the three 
studies operationalizing sustainability subsystems in Chapters 2 to 4 were undertaken using the CT level as the unit of analysis. Though a strong choice to ensure valid statistical outcomes for this research, it remains uncertain whether this analytical scale is the most appropriate for management of the urban forest.

Furthermore, and similar to the heterogeneity of urban form discussed in earlier chapters, there is very likely to be heterogeneity in planting priorities depending on the spatial scale of interest (e.g., neighbourhood, ward, region, or municipality) and from the stakeholder perspective (e.g., resident, volunteer group, urban forest manager, municipal councillor, etc.). As such, any methods used in a system to prioritize where to plant trees must be flexible and adaptable. Though the empirical data that acts as inputs to any decision-making system may remain constant, different analytical outcomes must be possible depending on the scale of focus and the identity of the decision-maker(s). In other words, the intent of the example to be presented is not to be prescriptive, but rather to allow for a range of alternatives to be evaluated from the same database.

One potential approach to prioritizing plantable space is to employ overlay analysis in a geographic information system (or GIS) as a method of accomplishing multi-criteria decision analysis (or MCDA). All of the individual research studies contributing to this work applied geospatial methods, with space or location considered as a part of the analysis. This platform also acts as an appropriate mechanism to integrate data from the different sustainability subsystems into a single output at different scales. To accomplish this integration, an example variable (or derivative) from each study representing one of the three sustainability subsystems was converted to a common ordinal scale (for more detailed methodology see Appendix A-1). Using raster overlay, four different weighted overlays for the pre-amalgamation municipality of Old Toronto were produced and presented in Figure 5-1. The first output panel (Figure 5-1A) represents an equal weighting of all three sustainability subsystem criteria (i.e., 33.33\% ecological $+33.33 \%$ social $+33.33 \%$ economic). An ecological weighting is presented in Figure 5-1B, with higher value placed on areas identified as belonging to clusters of high mean surface temperatures (i.e., $60 \%$ ecological $+20 \%$ social $+20 \%$ economic). The third output (Figure $5-1 \mathrm{C}$ ) represents a heavier weight towards prioritizing distributional inequalities, (i.e., $20 \%$ ecological + $60 \%$ social $+20 \%$ economic). The final panel output (Figure $5-1 \mathrm{D})$ represents a heavier weight the prioritizing the economic dimension, (i.e., $20 \%$ ecological $+20 \%$ social $+60 \%$ economic). On the surface it may appear that increasing the weighting of social or economic considerations above ecological considerations is taking a weak approach to sustainability. Regardless of how 
the weighting is assigned, an outcome consistent with a strong sustainability approach is achieved. These weightings simply represent different potential approaches to protecting and enhancing the existing natural capital resource (i.e., the urban forest).
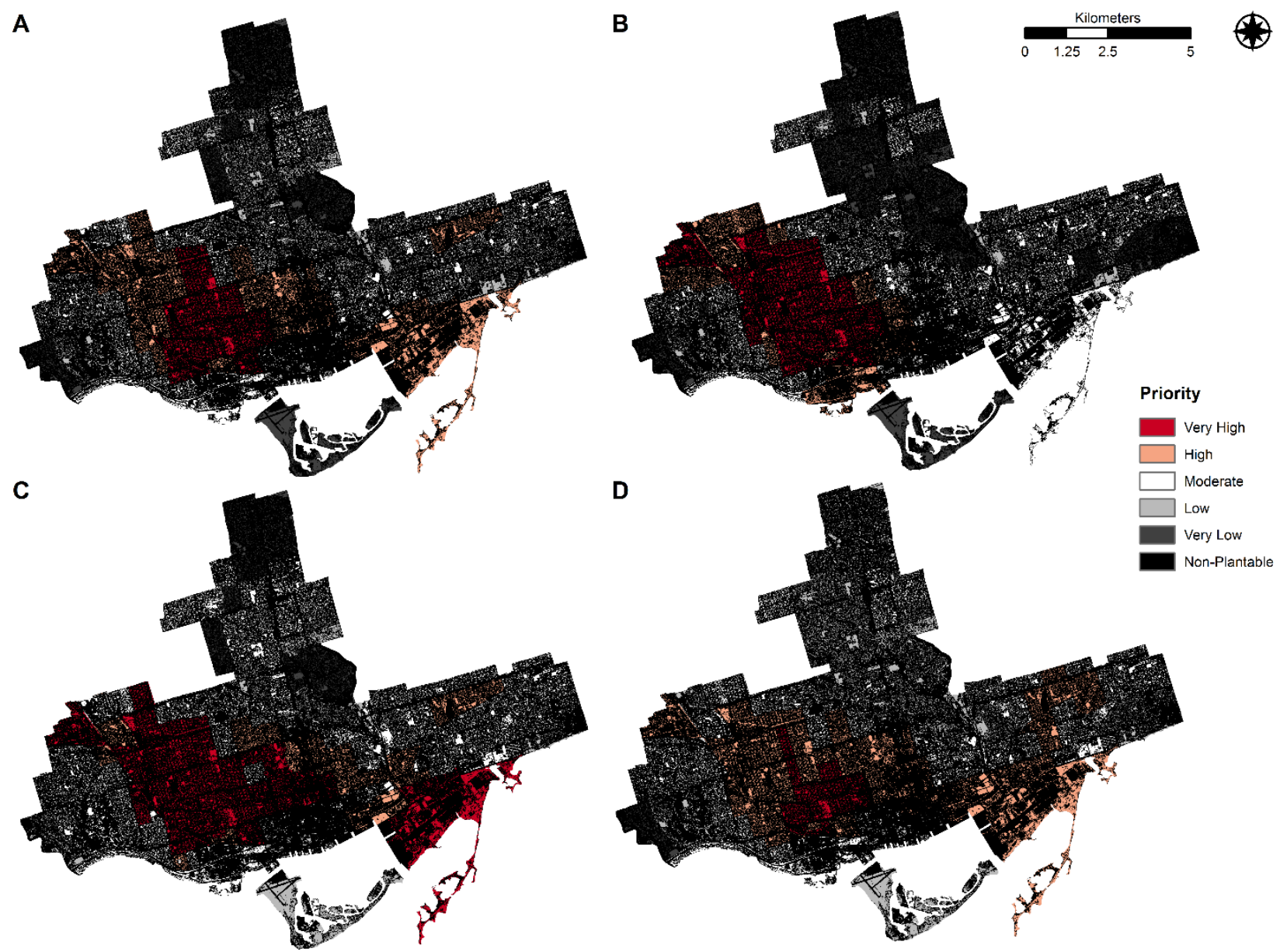

Figure 5-1: Parallel outcomes of weighted raster overlay to prioritize plantable space for pre-amalgamation Toronto, Canada, including (A) an equal balance option, (B) an ecologically weighted option, $(C)$ a socially weighted option, and $(D)$ an economically weighted option.

A benefit of using a common system to quantify each variable is the outputs fall within the same range of values. Thus weighting each input as a fraction or proportion with the sum of all proportions equal to 1 allows direct comparability of the different outputs. A visual comparison of these different overlay schemes confirmed that the distributional patterns of prioritization scores do indeed change to reflect changes in subsystem weighting. Of particular note in this example is the area of high priority plantable space in the central-west portion of the study area, identified as high priority regardless of the chosen weighting system applied. This high priority score across 
all three sustainability subsystems highlights potential negative local synergistic effects depending on conditions.

Most certainly this example has been simplified; an applied prioritization system requires an expanded suite of variables informed by context-specific empirical studies. What is clear, however, is that this proposed approach has considerable potential. Although the input data to this weighted overlay analysis was unchanged for each parallel scenario, the flexibility to adjust subsystem weightings to reflect hypothetical stakeholder perspectives allows for different alternatives to be expressed based on those values. As a result, this simplified system can be easily expanded and adapted to accommodate additional input variables. Moreover, this approach can be applied in other geographic contexts beyond Toronto. Though a strong proof of concept, there is a need to advance understanding in a range of relationships and processes within each sustainability subsystem. Concomitantly, there is a need to investigate how these processes and relationships vary with different geographies and identify the potential for generalization. Finally, there are a number of approaches to MCDA that vary in underlying assumptions and methods of variable valuation. Further studies are required that examine these different approaches and evaluate which are better suited to integrate data from all three sustainability subsystems; are adaptable enough to respond to contextual variability (e.g., a rapidly growing city like Toronto versus a contracting industrial city like Buffalo, New York); and are flexible enough to reflect changing stakeholder perspectives and variable analytical scales. 


\section{APPENDICES}

\section{Appendix A - Raster overlay methodology to produce Figure 5-1}

The following is an outline of the methodology used to prepare the weighted overlay scenarios for prioritization of tree planting by sustainability subsystems presented in Figure 5-1. For each subsystem, a variable or derivative from each of Chapters 2 through 4 was chosen as a representative of each subsystem. In each case, the chosen variable was converted from a vector data model to raster, and assigned an ordinal scale common to all variables for comparability of parallel outcomes. Final outputs were produced through raster overlay using the raster calculator in ArcGIS 10.2.2 where priority scores at pixel location $\left(x_{i}, y_{i}\right)$ are calculated using the following generalized formula:

$$
\text { Pixel Priority Score }=\left(C_{1} V_{\text {ecol }}+C_{2} V_{\text {social }}+C_{3} V_{\text {econ }}\right)(P)
$$

Where,

$C_{n}=$ Proportional weighting of the subsystem variable $\left(C_{1}+C_{2}+C_{3}\right.$ must total 1)

$V_{\text {ecol }}=$ Ecological subsystem variable score at location $\left(x_{i}, y_{i}\right)$

$V_{\text {soci }}=$ Social subsystem variable score at location $\left(x_{i}, y_{i}\right)$

$V_{\text {econ }}=$ Economic subsystem score at location $\left(x_{i}, y_{i}\right)$

$P=$ Binary variable at location $\left(x_{i}, y_{i}\right)$ representing plantable $(1)$, or non-plantable $(0)$

\section{Ecological Subsystem: Surface Temperature Clusters}

To represent the need for ecological services, mean surface temperature at the census tract level (see Chapter 2) was analyzed using Getis-Ord Local Gi* a local indicator of spatial autocorrelation (LISA). The data were reclassified based on the standardized z-score resulting from this analysis using known critical values from the statistical normal distribution (i.e., -2.53, $1.96,-1.65,+1.65,+1.96,+2.53)$. In this example, regions of high surface temperature are high priority targets. Because this type of LISA identifies clusters of similar values (i.e., hotspots of high values and cold spots of low values), this variable was reclassified in ascending order from lowest to highest priority (see Table A-1 for detailed reclassification info about this variable and subsequent variables).

\section{Social Subsystem: Total Tree Canopy Cover - Median Household Income Cluster Type}

Output of the original Local Moran's I LISA analysis (see Chapter 3) provides the basis for the social subsystem variable, specifically the total tree canopy cover - median household income 
analysis. This output was nominal and so the reclassification is based on a normative evaluation of which cluster type should receive highest priority, in this case those lacking access to total tree canopy cover, and which should receive the lowest priority (see Table A-1). For this example the highest priority was given to statistically significant clusters of census tracts exhibiting low TCC low MHI, then low TCC - high MHI, followed by Non-Significant clusters, high TCC - low MHI, and high TCC - high $\mathrm{MHI}$.

\section{Economic Subsystem: Damage Potential Clusters}

To represent the economic subsystem, output from the Getis-Ord Local Gi* analysis (see Chapter 4) was selected. Similar to the ecological variable, this dataset was reclassified based on the standardized z-score resulting from this analysis using known critical values from the statistical normal distribution (i.e., $-2.53,-1.96,-1.65,+1.65,+1.96,+2.53$ ). In this example, clusters of high index variables are targeted as these high values represent locations of greater potential for emerald ash borer damage. Because this type of LISA identifies clusters of similar values (i.e., hotspots of high values and cold spots of low values), this variable was reclassified in ascending order from lowest highest priority (see Table A-1).

Table A-1: Summary of reclassification scheme applied to convert example sustainability subsystem variables to a standard ordinal system in preparation for weighted raster overlay operations.

\begin{tabular}{|c|c|c|c|}
\hline & \multicolumn{3}{|c|}{ Original Values } \\
\hline Reclassified Value & Ecological (Z-Score) & Social (Nominal) & Economic (Z-Score) \\
\hline 100 & $<-2.53$ & & $<-2.53$ \\
\hline 200 & -2.53 to -1.96 & & -2.53 to -1.96 \\
\hline 300 & -1.96 to -1.65 & High TCC - High MHI & -1.96 to -1.65 \\
\hline 400 & -1.65 to 1.65 & High TCC - Low MHI & -1.65 to 1.65 \\
\hline 500 & 1.65 to 1.96 & Not Significant & 1.65 to 1.96 \\
\hline 600 & 1.96 to 2.53 & Low TCC - High MHI & 1.96 to 2.53 \\
\hline 700 & $>2.53$ & Low TCC - Low MHI & $>2.53$ \\
\hline
\end{tabular}


Appendix B - Full page map figures from Chapters 2 to 5

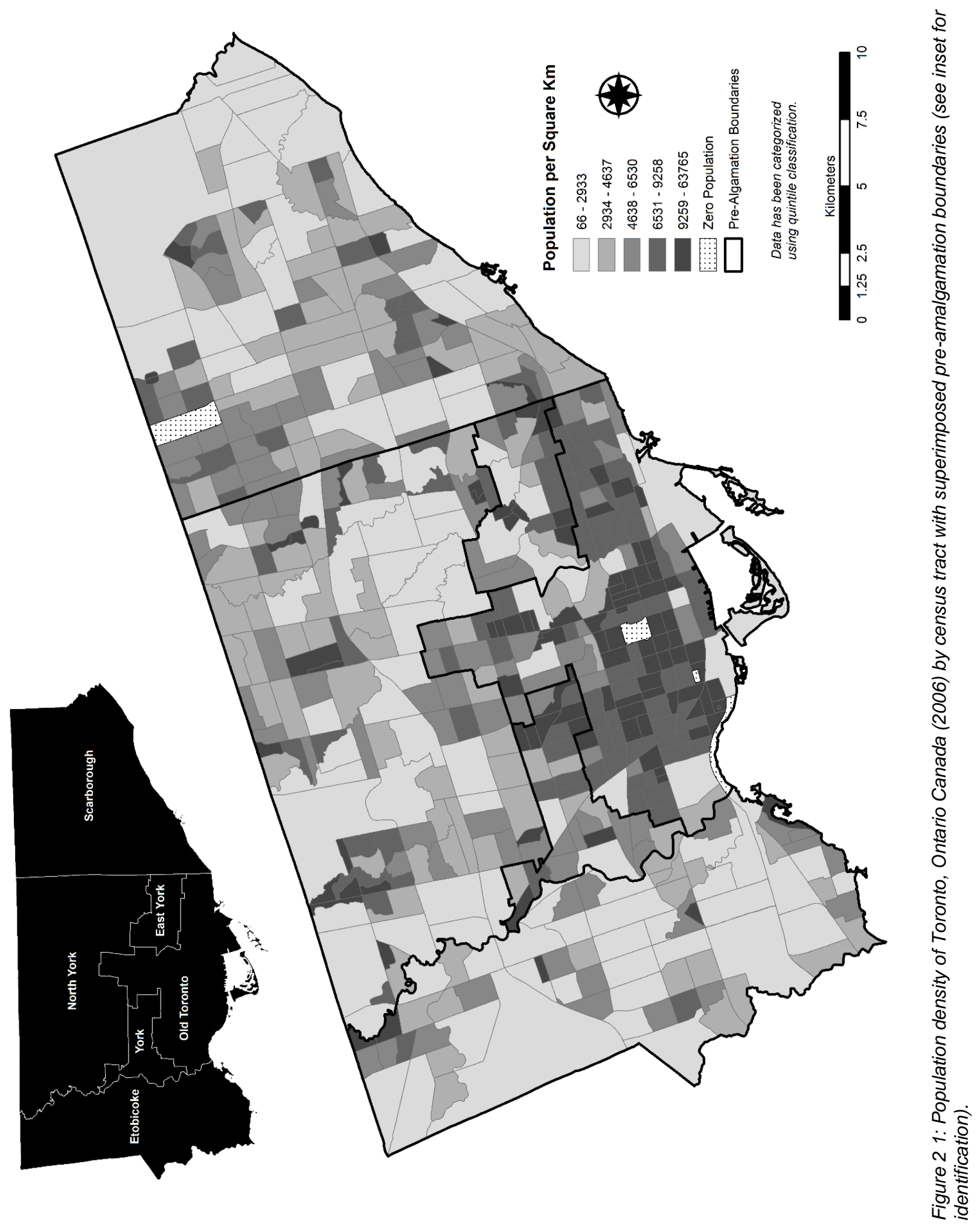


A.

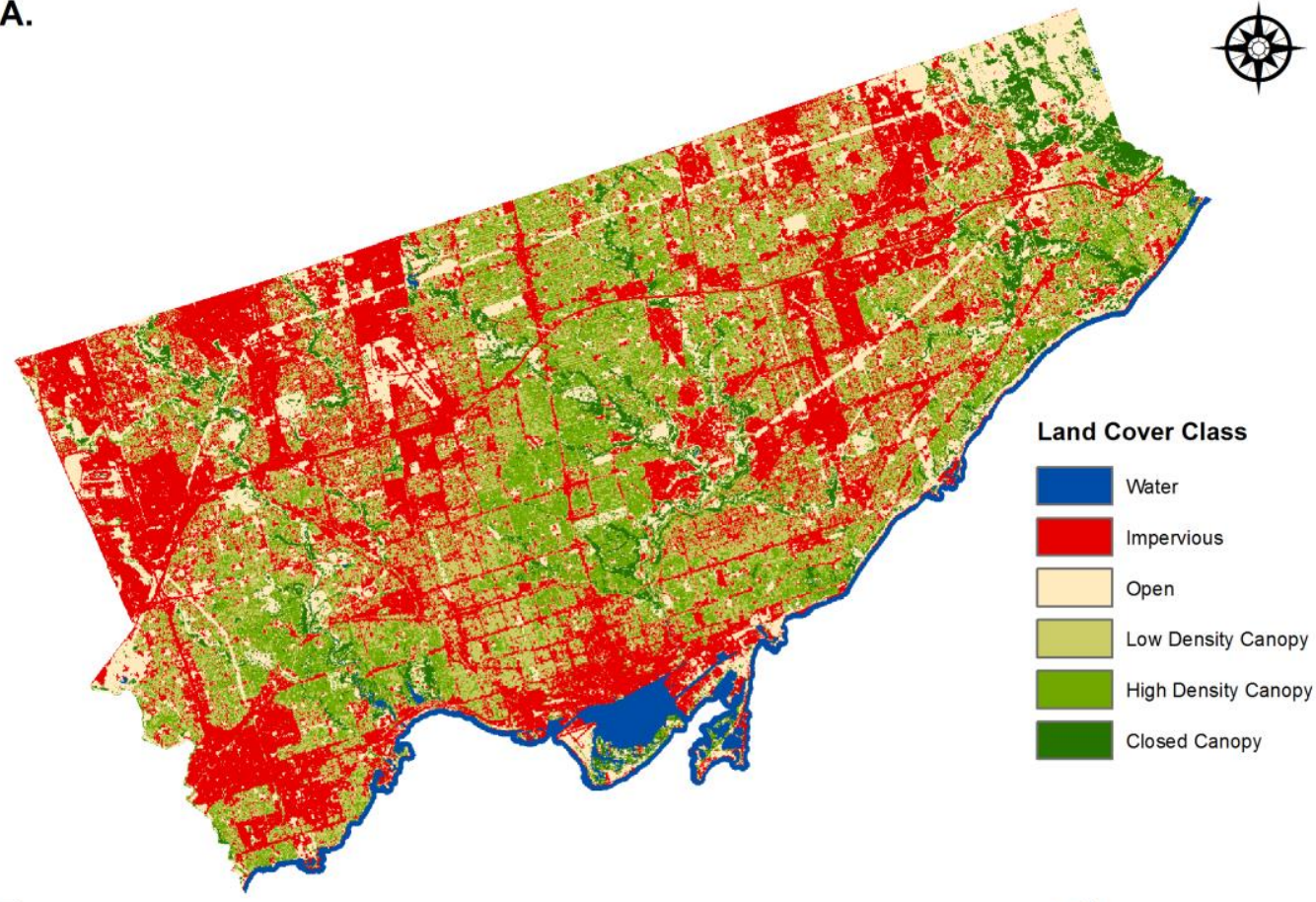

B.

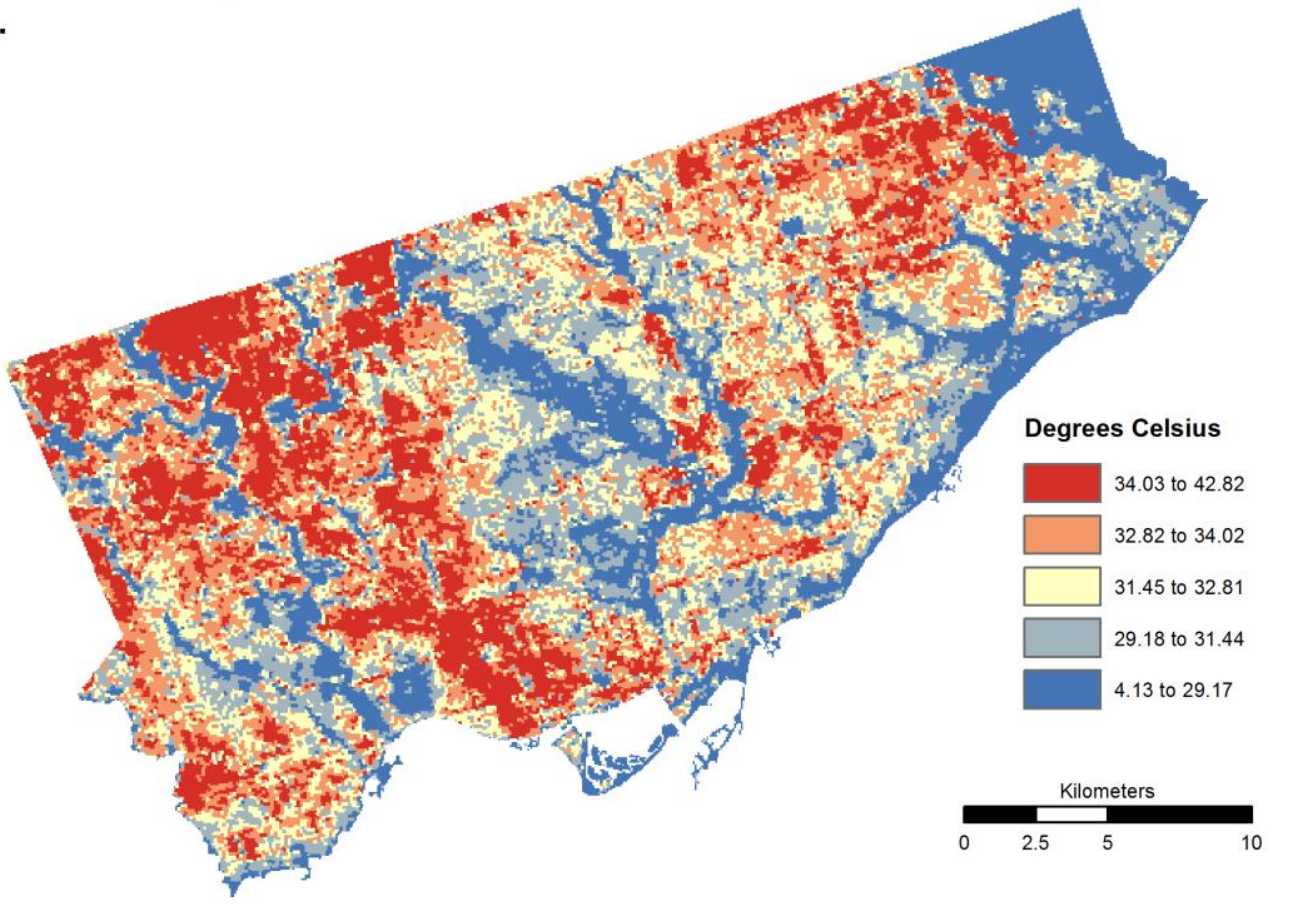

Figure 2-2: Classified land-cover data ( $A$ ) and surface temperature data (B) derived from 2005 Landsat TM5 imagery for amalgamated City of Toronto, Canada (2005). 


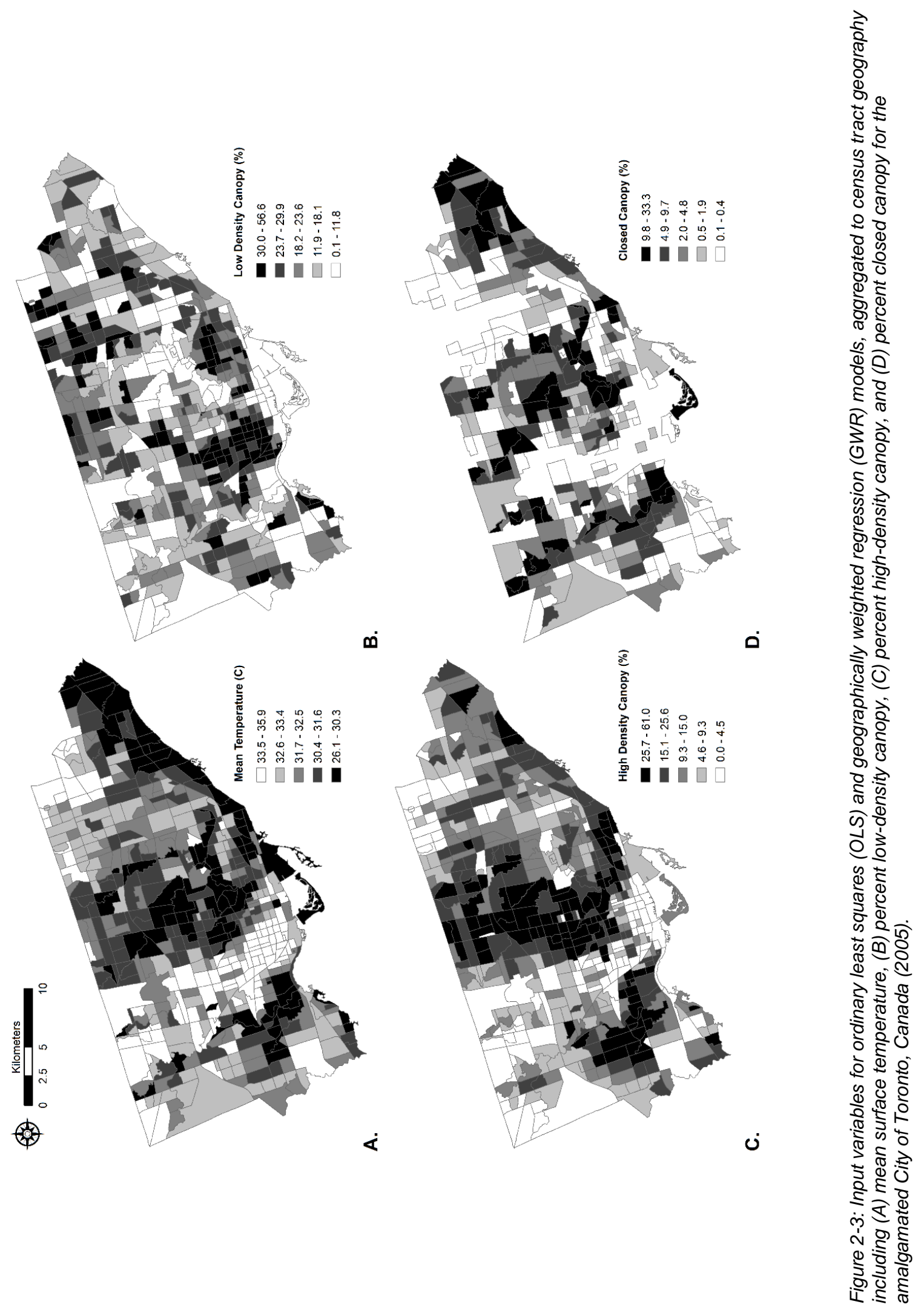




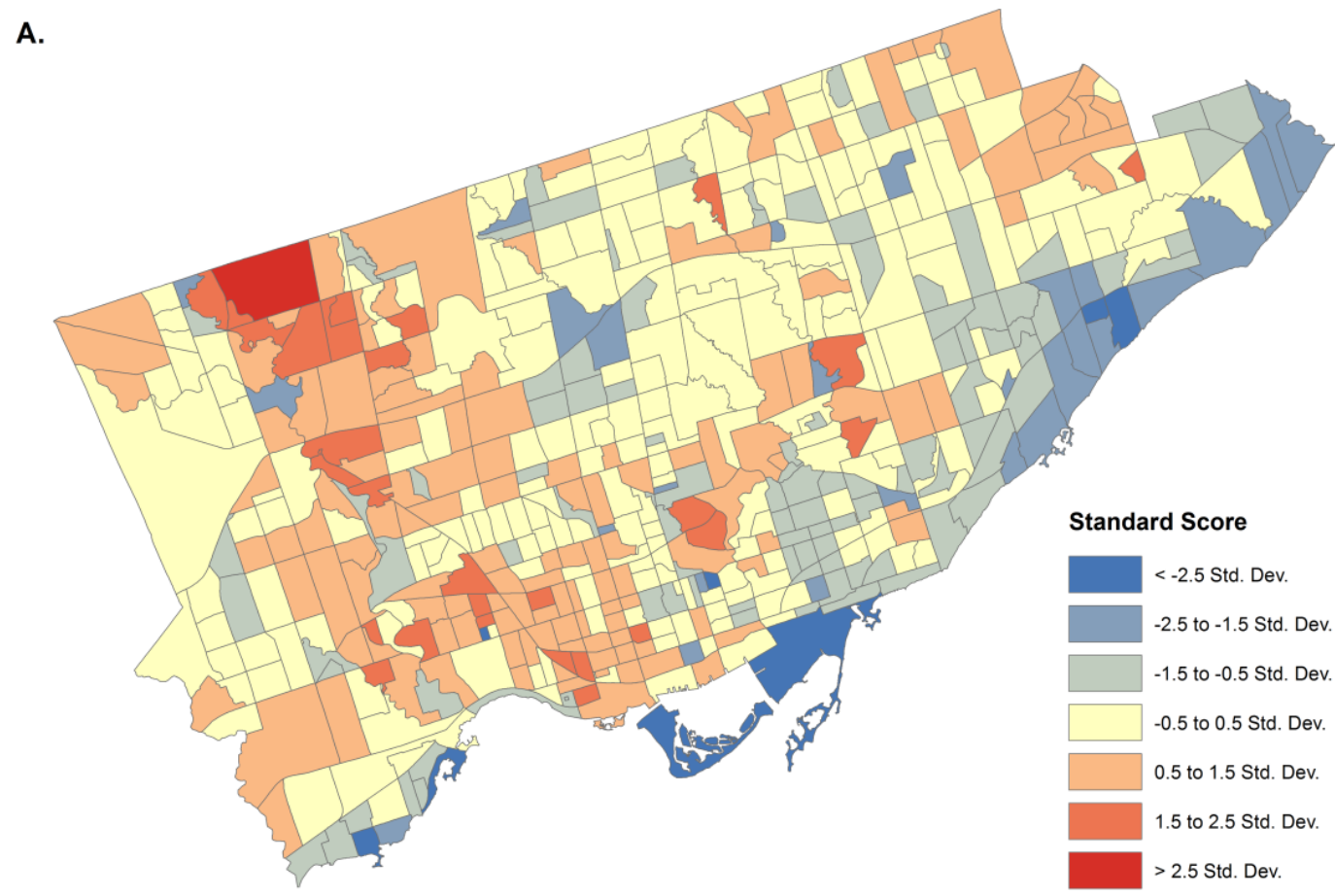

B.

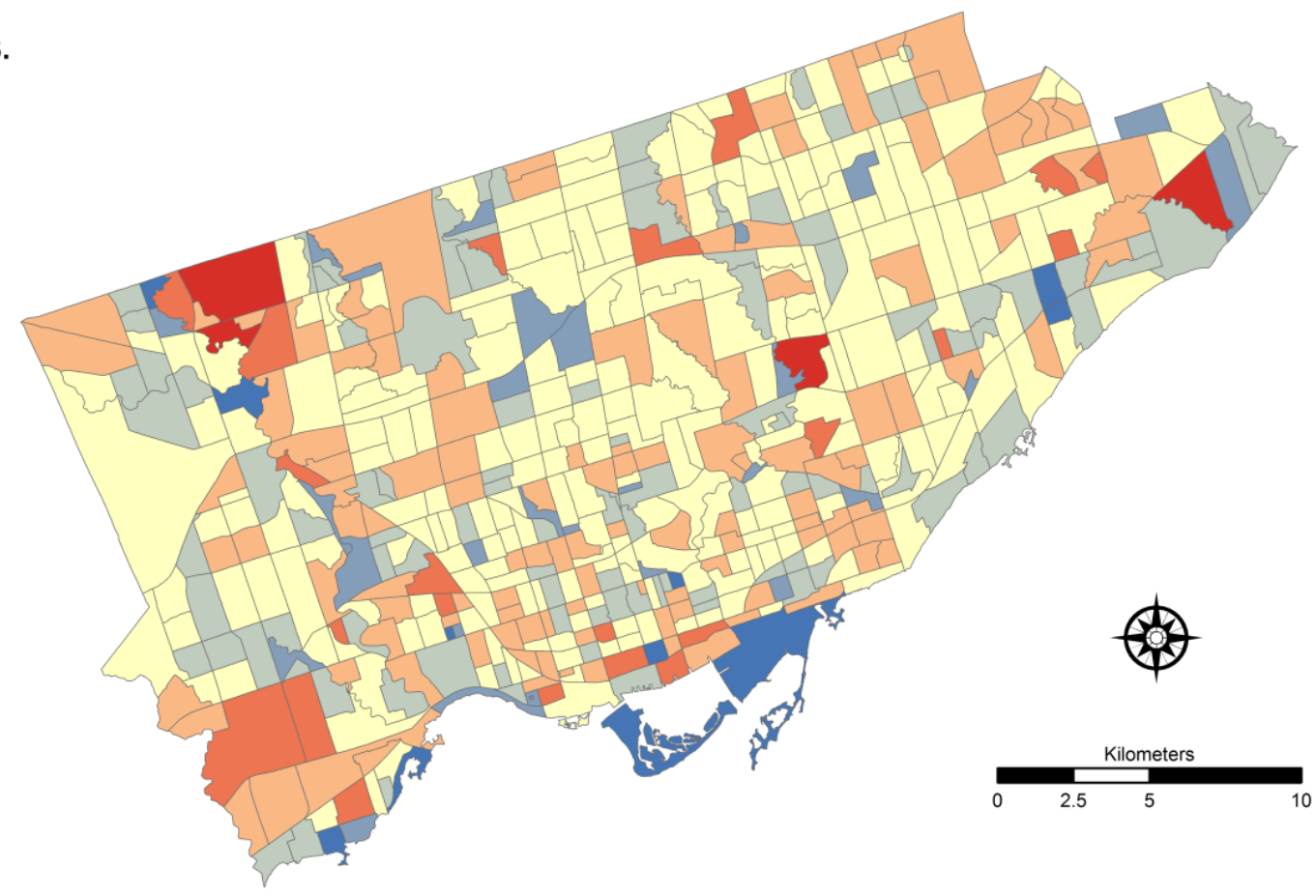

Figure 2-4: Distribution of standardized residuals by census tract for the (A) ordinary least squares (OLS) regression model and $(B)$ the geographically weighted regression (GWR) model used to evaluate regression model specification for the relationship between mean surface temperature and canopy in Toronto, Canada (2005). 


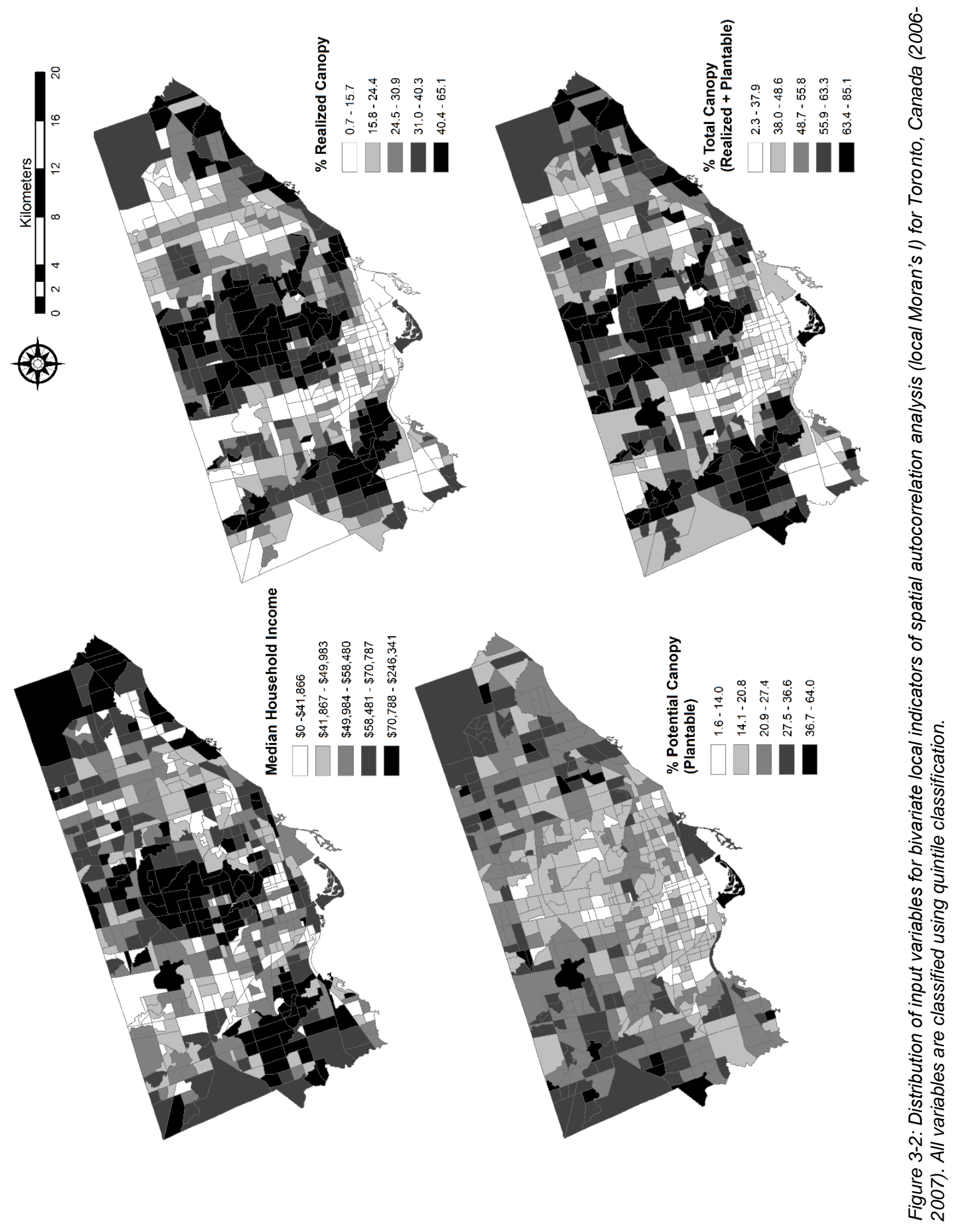




\section{A. RCC - MHI}

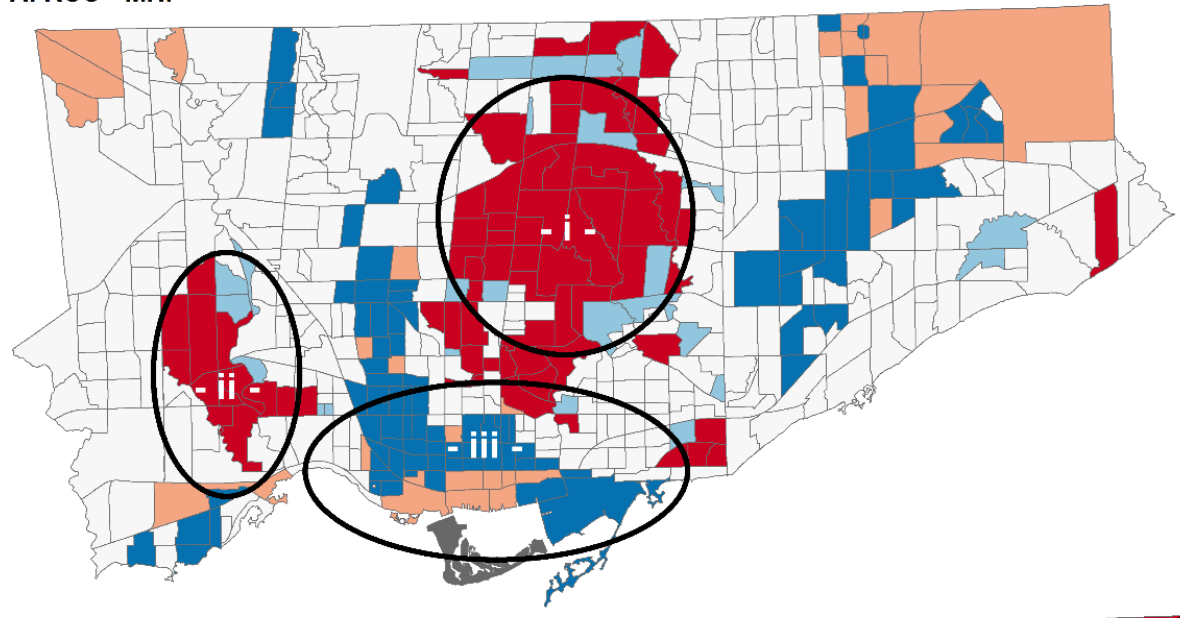

B. PCC - MHI

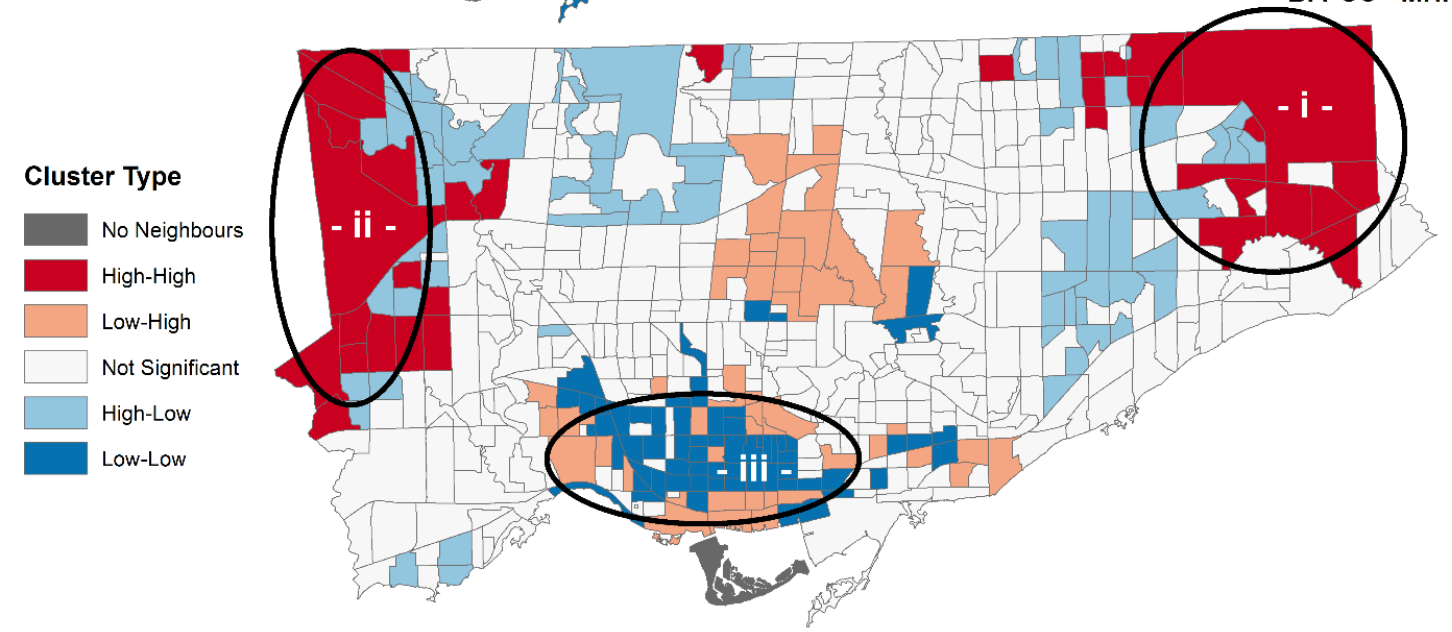

C. TCC - MHI

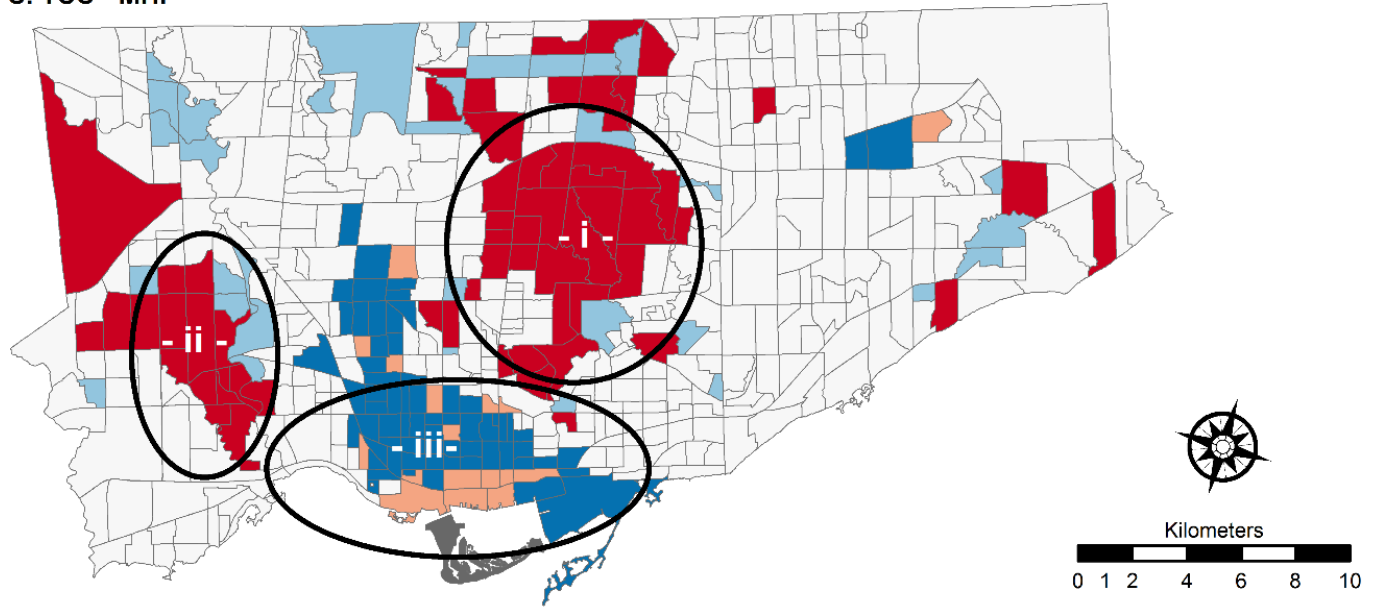

Figure 3-3: Results of bivariate local indicator of spatial autocorrelation analysis examining the relationship by census tract between $(A)$ percent realized canopy cover and median household income, (B) percent potential canopy cover and median household income, and $(C)$ percent total canopy cover and median household income for Toronto, Canada (2006-2007). 


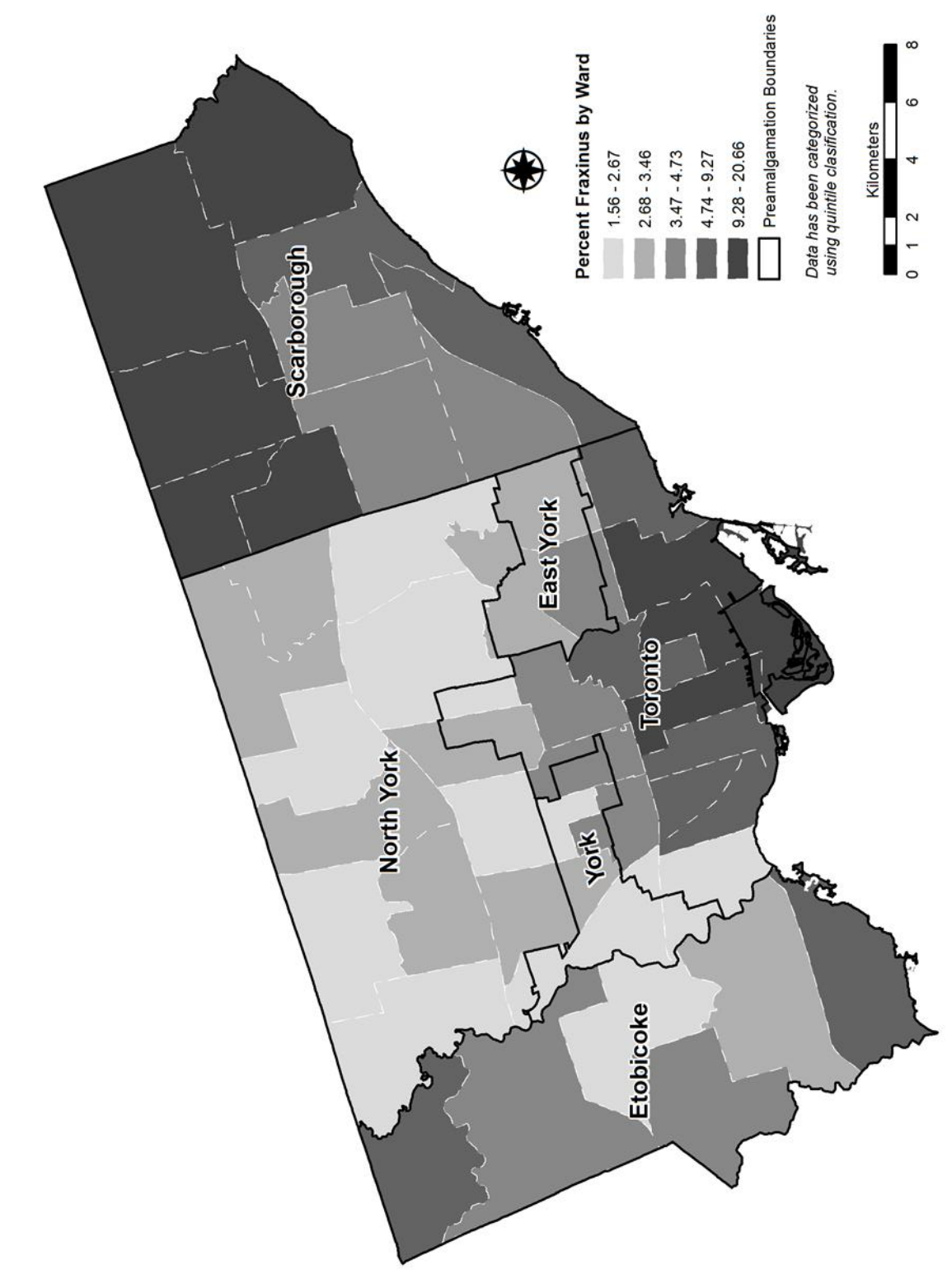

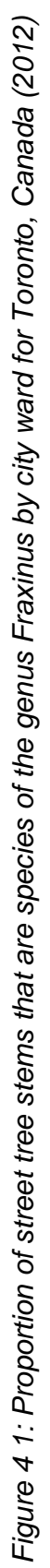




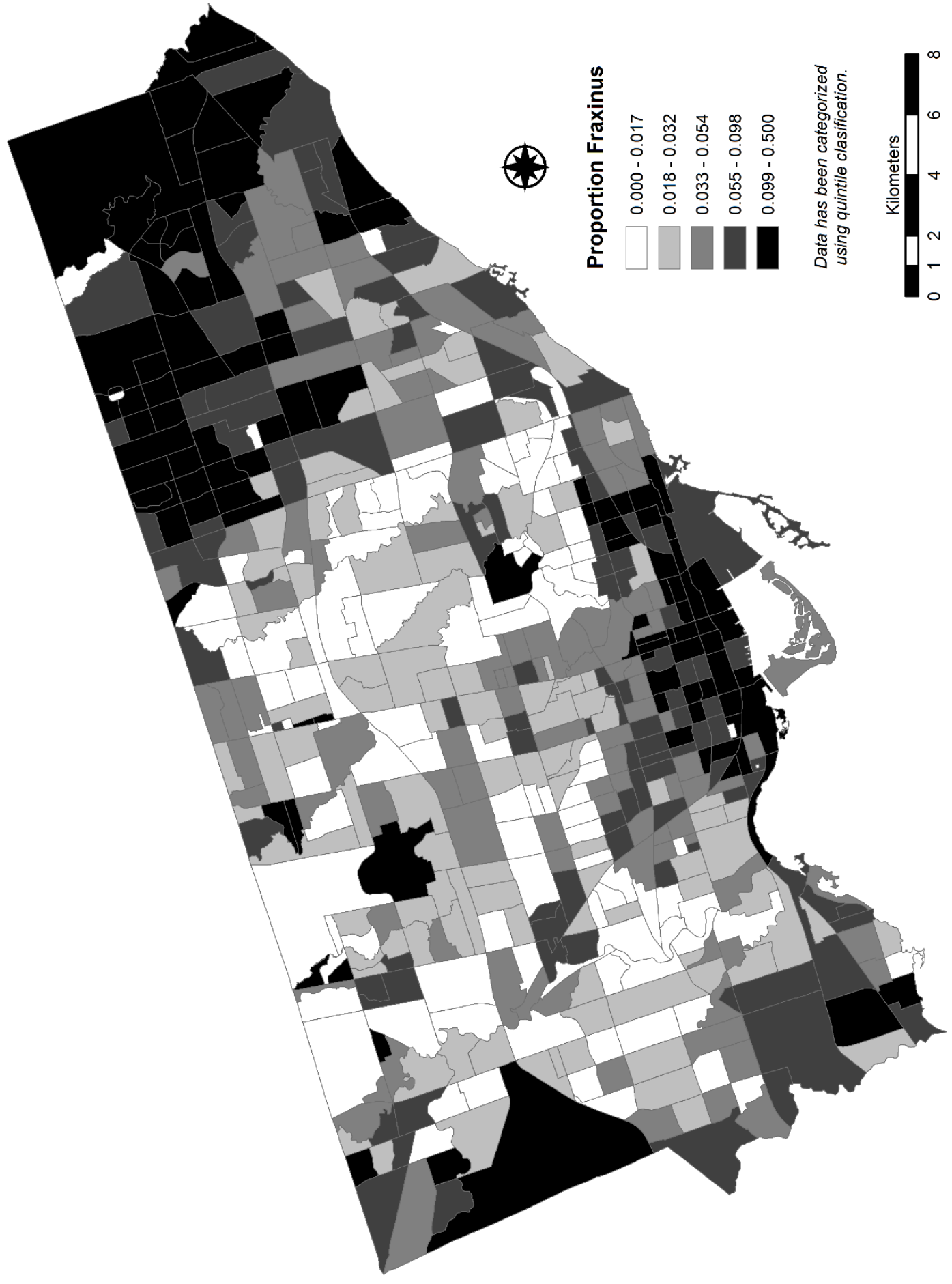

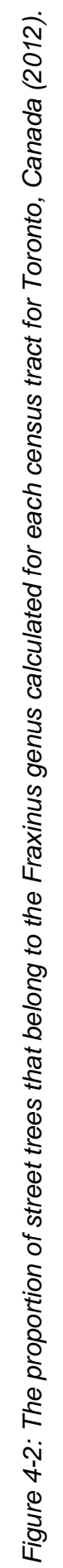




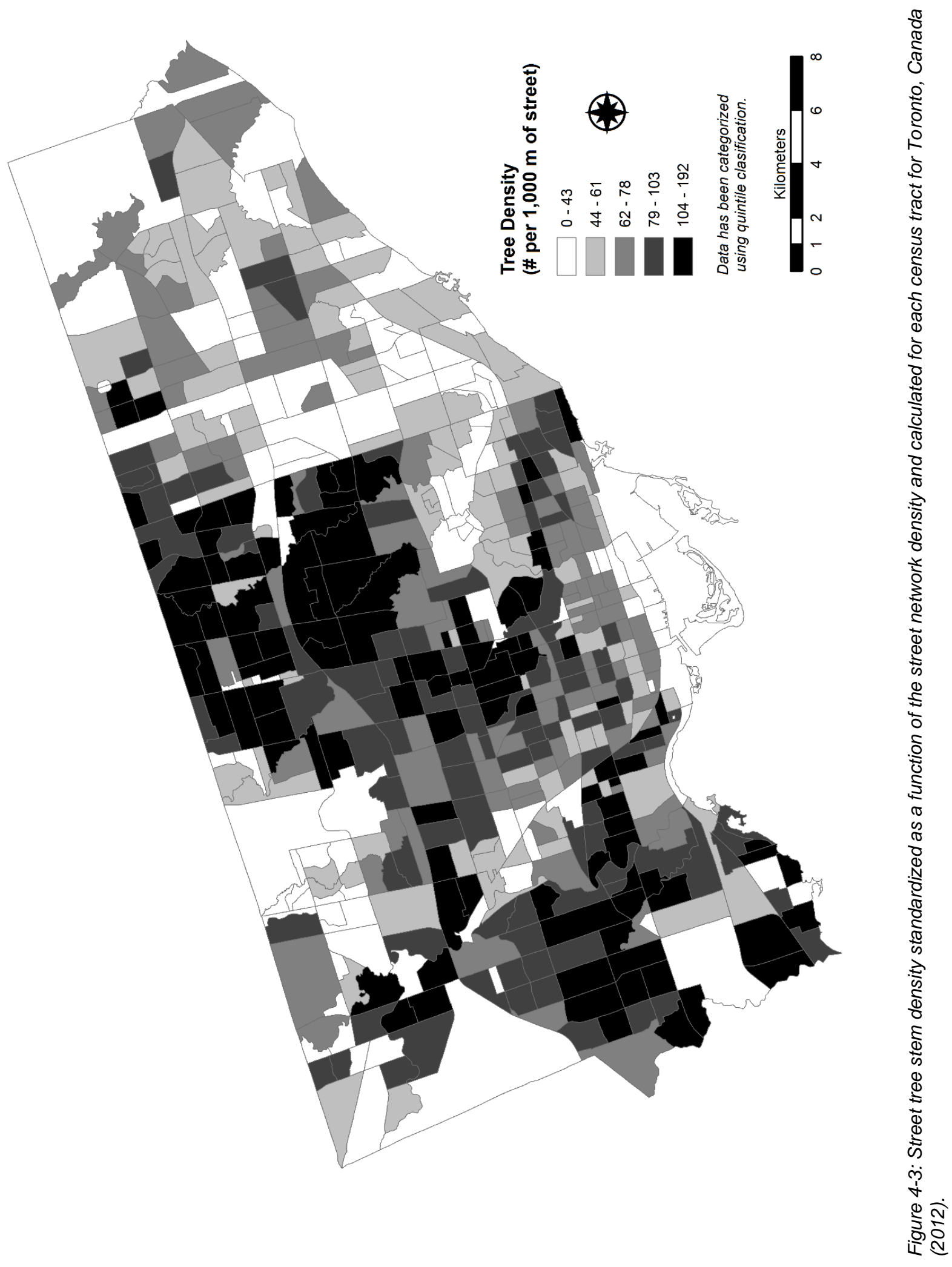




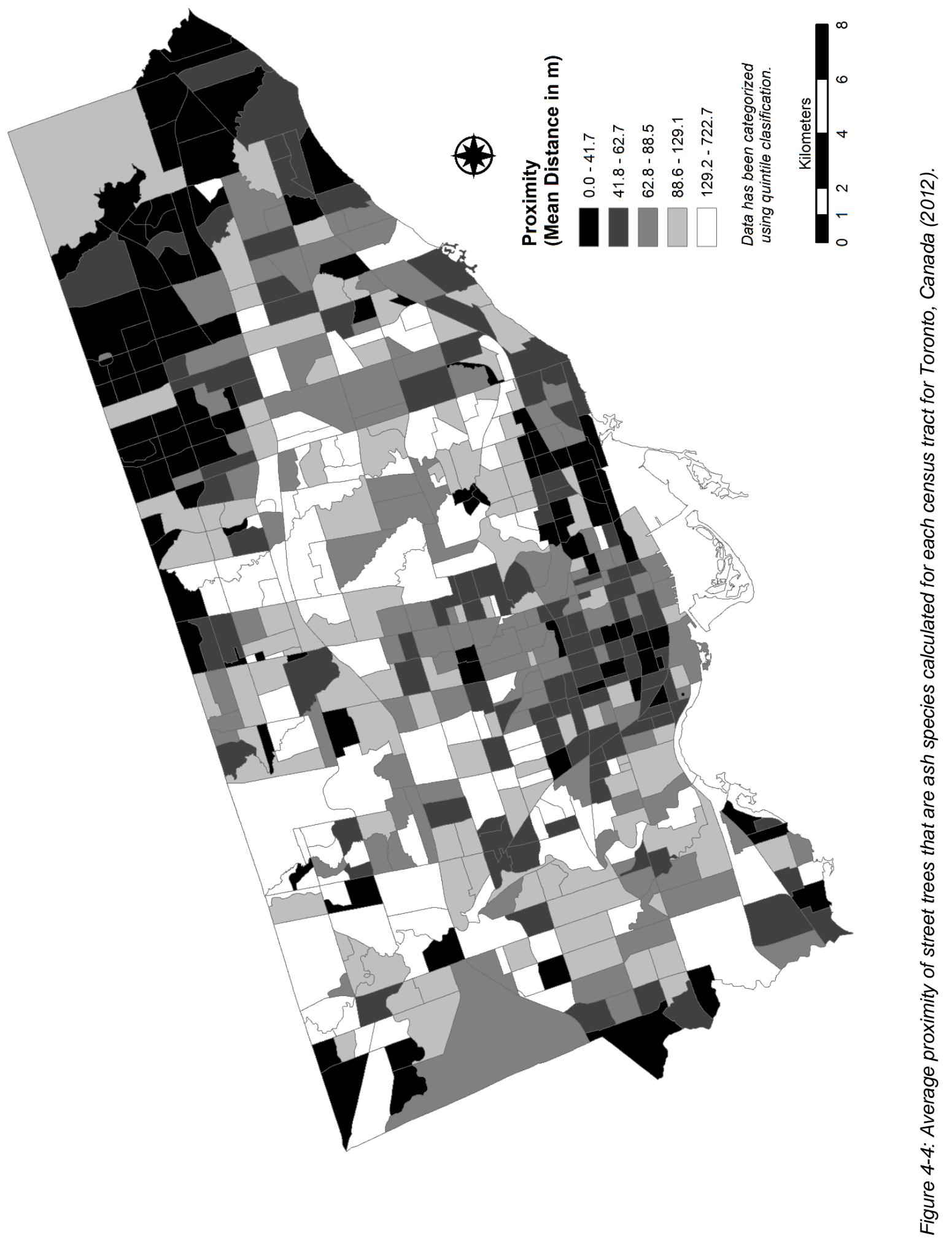




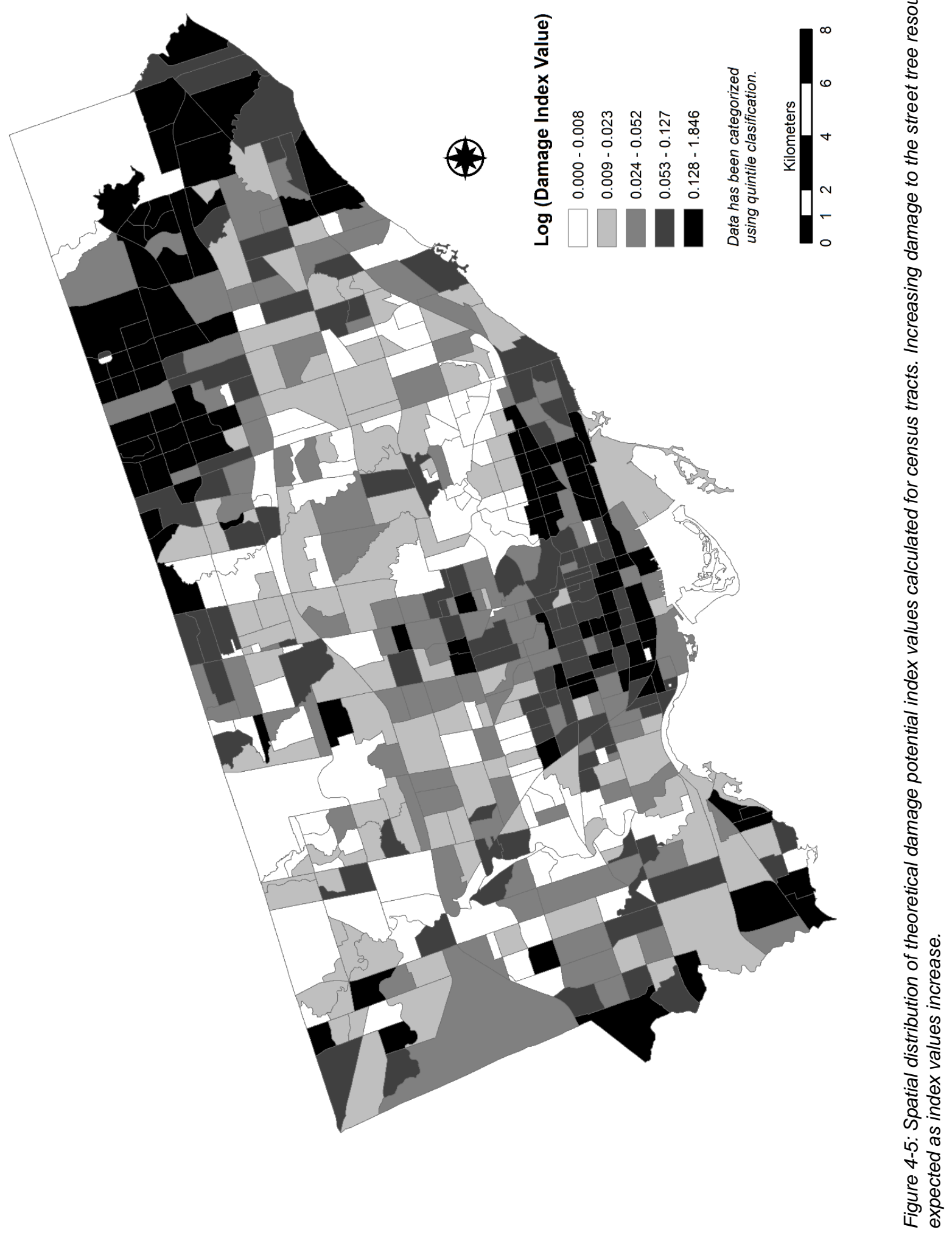



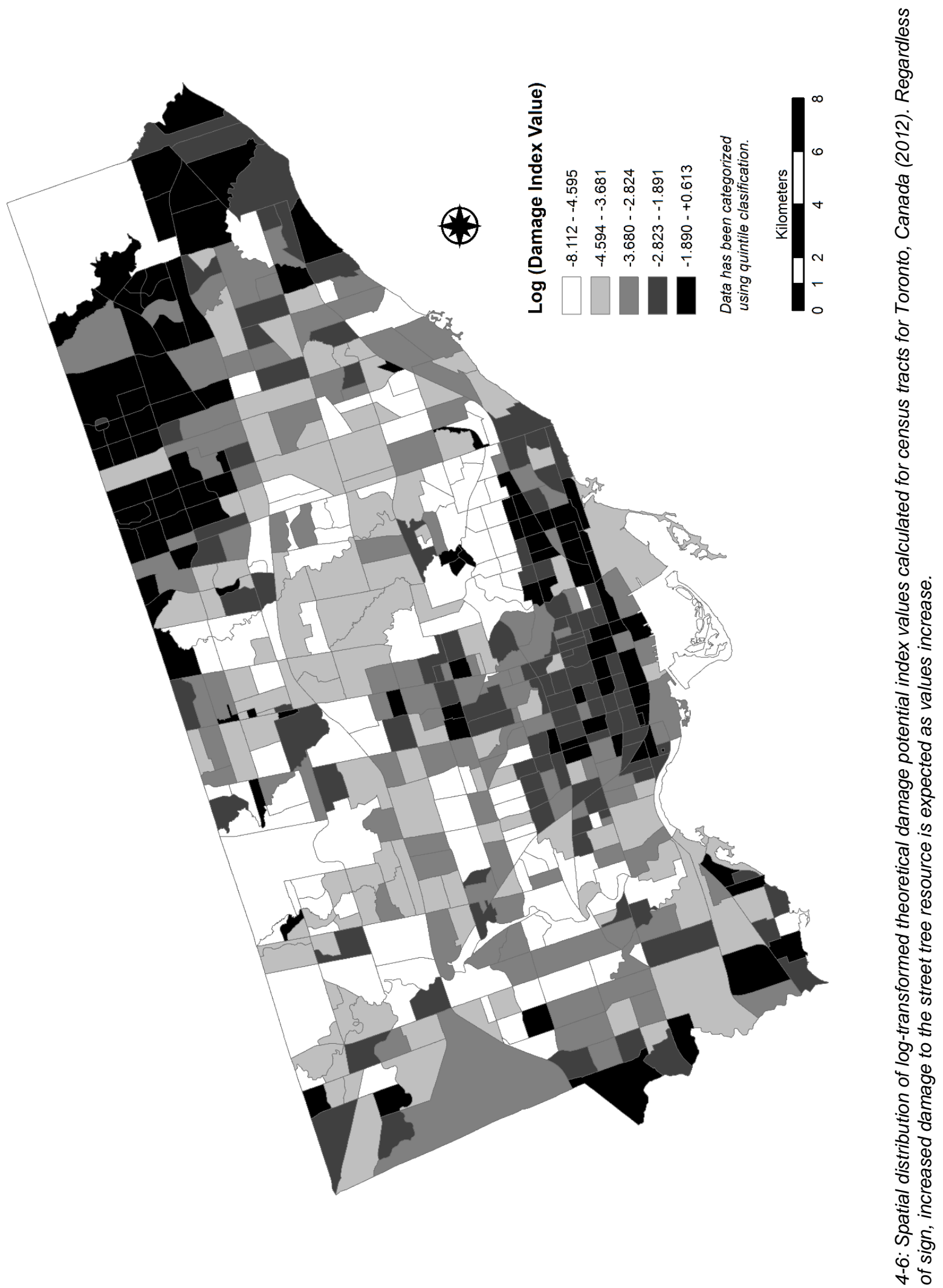


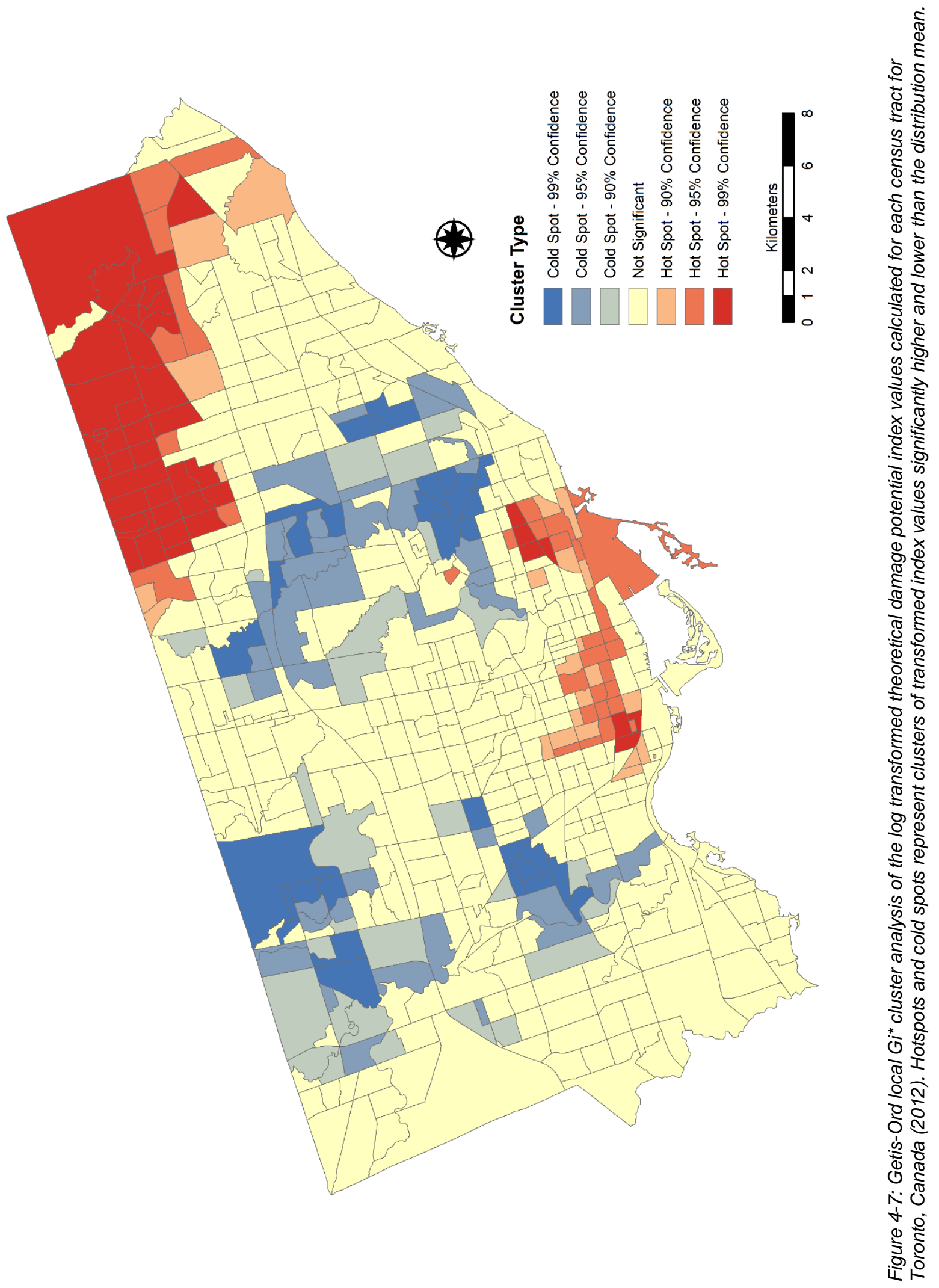




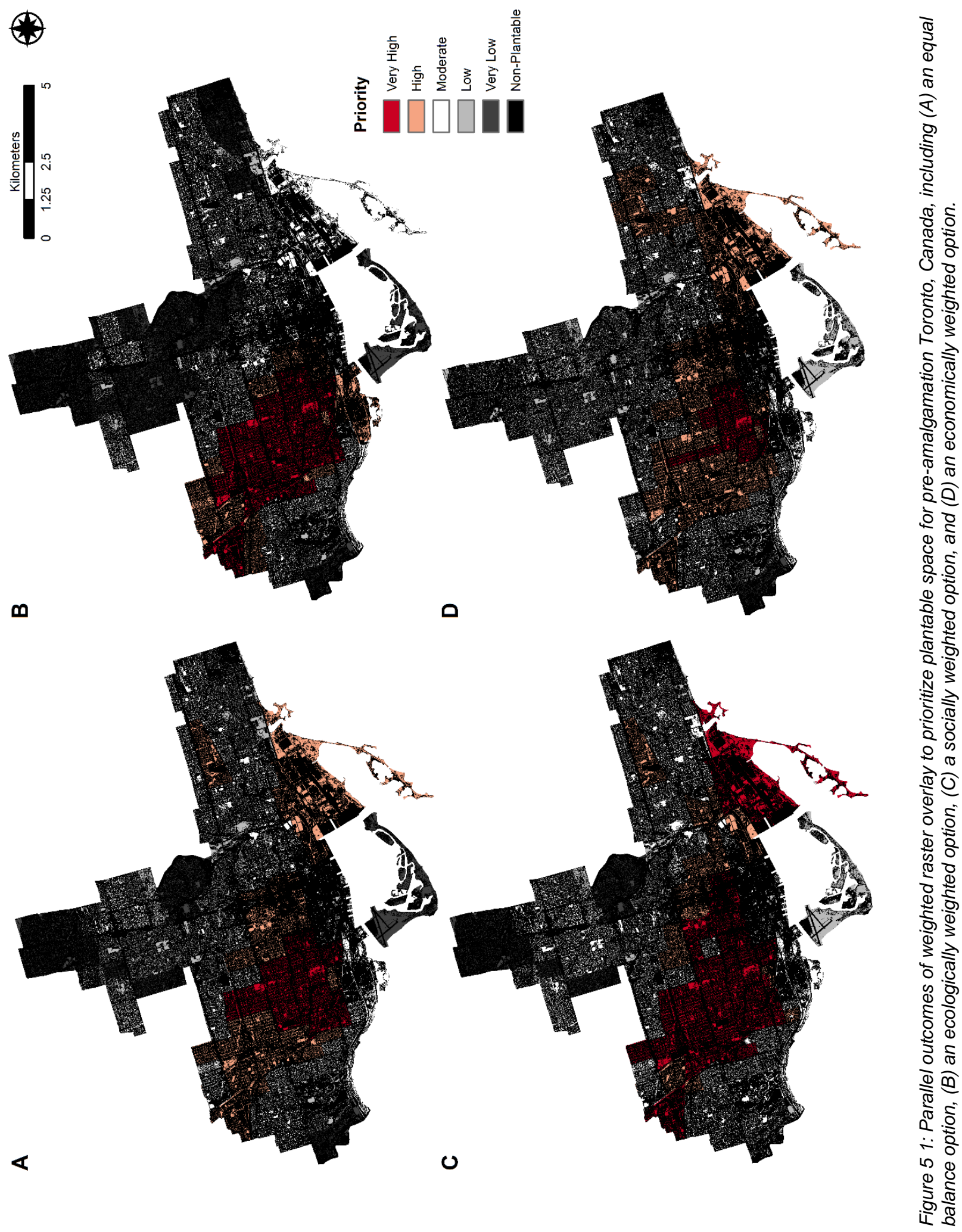




\section{REFERENCES}

Ackerman, F., \& Heinzerling, L. (2002). Pricing the priceless: Cost-benefit analysis of environmental protection. University of Pennsylvania Law Review, 150(5), 1553-1584.

Agyeman, J., \& Evans, B. (2004). 'Just sustainability': The emerging discourse of environmental justice in Britain? The Geographical Journal, 170(2), 155-164. doi:10.1111/j.00167398.2004.00117.x

Akbari, $\mathrm{H}$. (2002). Shade trees reduce building energy use and $\mathrm{CO}_{2}$ emissions from power plants. Environmental Pollution, 116(Supplement 1), S119-S126.

Akbari, H., Pomerantz, M., \& Taha, H. (2001). Cool surfaces and shade trees to reduce energy use and improve air quality in urban areas. Solar Energy, 70(3), 295-310.

Alig, R. J., Kline, J. D., \& Lichtenstein, M. (2004). Urbanization on the US landscape: Looking ahead in the 21st century. Landscape and Urban Planning, 69(2-3), 219-234.

Alvey, A. A. (2006). Promoting and preserving biodiversity in the urban forest. Urban Forestry \& Urban Greening, 5(4), 195-201.

Anderson, L. M., \& Cordell, H. K. (1988). Influence of trees on residential property values in Athens, Georgia (U.S.A.): A survey based on actual sales prices. Landscape and Urban Planning, 15(1-2), 153-164.

Anselin, L. (1995). Local indicators of spatial association-LISA. Geographical Analysis, 27(2), 93-115.

Anselin, L., Syabri, I., \& Smirnov, O. (2002). Visualizing multivariate spatial correlation with dynamically linked windows (Discussion Paper No. REAL 02-T-8). Retrieved from The Regional Economics Applications Laboratory (REAL) website: http://www.real.illinois.edu/d-paper/02/02-t-8.pdf

Arnfield, A. J. (2003). Two decades of urban climate research: A review of turbulence, exchanges of energy and water, and the urban heat island. International Journal of Climatology, 23(1), 1-26. doi:10.1002/joc.859

Bassuk, N., \& Whitlow, T. (1988). Environmental stress in street trees. Arboricultural Journal, 12(2), 195-201.

Beckett, K. P., Freer-Smith, P. H., \& Taylor, G. (1998). Urban woodlands: Their role in reducing the effects of particulate pollution. Environmental Pollution, 99(3), 347-360. doi:10.1016/S0269-7491(98)00016-5

Beckett, K. P., Freer-Smith, P. H., \& Taylor, G. (2000). Particulate pollution capture by urban trees: Effect of species and windspeed. Global Change Biology, 6(8), 995-1003.

Bell, D. (2004). Environmental justice and Rawls' difference principle. Environmental Ethics, 26(3), 287-306.

Berland, A., \& Hopton, M. E. (2014). Comparing street tree assemblages and associated stormwater benefits among communities in metropolitan Cincinnati, Ohio, USA. Urban Forestry \& Urban Greening, 13(4), 734-741. 
Berland, A., Schwarz, K., Herrmann, D. L., \& Hopton, M. E. (2015). How environmental justice patterns are shaped by place: Terrain and tree canopy in Cincinnati, Ohio, USA. Cities and the Environment (CATE), 8(1), 1.

Boone, C., Cadenasso, M., Grove, J. M., Schwarz, K., \& Buckley, G. (2010). Landscape, vegetation characteristics, and group identity in an urban and suburban watershed: Why the 60s matter. Urban Ecosystems, 13(3), 255-271.

Bosselmann, P., Arens, E., Dunker, K., \& Wright, R. (1995). Urban form and climate: Case study, Toronto. Journal of the American Planning Association, 61(2), 226-239. doi:10.1080/01944369508975635

Botkin, D. B., \& Beveridge, C. E. (1997). Cities as environments. Urban Ecosystems, 1(1), 3-19.

Burley, S., Robinson, S. L., \& Lundholm, J. T. (2008). Post-hurricane vegetation recovery in an urban forest. Landscape and Urban Planning, 85(2), 111-122.

Campbell, J. B., \& Wynne, R. H. (2011). Introduction to remote sensing (5th ed.). New York, NY: Guilford Press.

Cappaert, D., McCullough, D. G., Poland, T. M., \& Siegert, N. W. (2005). Emerald ash borer in North America: A research and regulatory challenge. American Entomologist, 51(3), 152-165.

Changnon, S. A., \& Jones, D. (1972). Review of the influences of the Great Lakes on weather. Water Resourcs Research, 8(2), 360-371.

Ching-hua, H., Sasidharan, V., Elmendorf, W., Willits, F. K., \& et al. (2005). Gender and ethnic variations in urban park preferences, visitation, and perceived benefits. Journal of Leisure Research, 37(3), 281-306.

City of Toronto. (2012). 2011 census: Population and dwelling counts. (Backgrounder). Toronto: City of Toronto. (Toronto Demographics)

City of Toronto. (2014). Profile Toronto: How does the city grow (July 2014 ed.). Toronto: City of Toronto. Retrieved from http://www1.toronto.ca/Grow/grow-july2014.pdf

City of Toronto Parks Forestry and Recreation, Urban Forestry. (2012). Street tree data [Feature Dataset, Shapefile]. Retrieved from

http://www1 .toronto.ca/wps/portal/contentonly?vgnextoid=5af95104c26f3310 VgnVCM10 00003dd60f89RCRD\&vgnextchannel=1a66e03bb8d1e310VgnVCM10000071d60f89RC $\underline{\mathrm{RD}}$

City of Toronto Parks Forestry and Recreation, Urban Forestry. (2013a). Every tree counts: A portrait of Toronto's urban forest. Toronto, ON: City of Toronto. Retrieved from http://www1.toronto.ca/City\%200f\%20Toronto/Parks\%20Forestry\%20\&\%20Recreation/ Urban\%20Forestry/Files/pdf/E/every tree counts.pdf

City of Toronto Parks Forestry and Recreation, Urban Forestry. (2013b). Sustaining \& expanding the urban forest: Toronto's strategic forest management plan. Toronto, ON: City of Toronto.

City of Toronto, Social Development, Finance and Administration Division. (2008a). Social profile \#3 - income \& poverty: Bridle Path-Sunnybrook-York Mills (41). Toronto, ON: City of Toronto. Retrieved from

http://www1.toronto.ca/wps/portal/contentonly?vgnextoid=ae3285d32acd1410VgnVCM1 
0000071d60f89RCRD\&vgnextchannel=1e68f40f9aae0410VgnVCM10000071d60f89RC $\underline{\mathrm{RD}}$

City of Toronto, Social Development, Finance and Administration Division. (2008b). Social profile \#3 - neighbourhoods families \& dwellings: Bridle Path-Sunnybrook-York Mills (41). Toronto, ON: City of Toronto. Retrieved from http://www1.toronto.ca/wps/portal/contentonly?vgnextoid=ae3285d32acd1410 VgnVCM1 0000071d60f89RCRD\&vgnextchannel=1e68f40f9aae0410VgnVCM10000071d60f89RC $\underline{\mathrm{RD}}$

City of Toronto, Social Development, Finance and Administration Division. (2008). Social profile \#3 - Neighbourhoods Families \& dwellings: Waterfront communities-the island (77).

Toronto, ON: City of Toronto. Retrieved from http://www1.toronto.ca/wps/portal/contentonly?vgnextoid=ae3285d32acd1410 VgnVCM1 0000071d60f89RCRD\&vgnextchannel=1e68f40f9aae0410VgnVCM10000071d60f89RC $\underline{\mathrm{RD}}$

City Plants. (2015). About city plants. Retrieved May 30, 2015, from http://www.cityplants.org/index.php/about-us-1/about-city-plants

Clark, J. R., Matheny, N. P., Cross, G., \& Wake, V. (1997). A model of urban forest sustainability. Journal of Arboriculture, 23(1), 17-30.

Close, R. E., Nguyen, P. V., \& Kielbaso, J. J. (1996). Urban vs. natural sugar maple growth: I. stress symptoms and phenology in relation to site characteristics. Journal of Arboriculture, 22(3), 144-150.

Conway, T. M., \& Bourne, K. S. (2013). A comparison of neighborhood characteristics related to canopy cover, stem density and species richness in an urban forest Elsevier. doi:10.1016/.landurbplan.2013.01.005

Conway, T. M., Shakeel, T., \& Atallah, J. (2011). Community groups and urban forestry activity: Drivers of uneven canopy cover? Landscape and Urban Planning, 101(4), 321-329. doi:10.1016/.landurbplan.2011.02.037

Costanza, R., \& Daly, H. E. (1992). Natural capital and sustainable development. Conservation Biology, 6(1), 37-46.

Dale, D. (2014, April 22). Mayoral candidate john tory proposes doubling Toronto's tree-planting budget. Toronto Star, Retrieved from http://www.thestar.com/news/city hall/toronto2014election/2014/04/22/mayoral candidat e john tory proposes doubling torontos treeplanting budget.html

Daly, H. E. (1990). Toward some operational principles of sustainable development. Ecological Economics, 2(1), 1-6.

de Groot, R. S., Wilson, M. A., \& Boumans, R. M. J. (2002). A typology for the classification, description and valuation of ecosystem functions, goods and services. Ecological Economics, 41(3), 393-408.

Dietz, S., \& Neumayer, E. (2007). Weak and strong sustainability in the SEEA: Concepts and measurement. Ecological Economics, 61(4), 617-626.

Dockery, D. W., Pope, C. A., Xu, X., Spengler, J. D., Ware, J. H., Fay, M. E., et al. (1993). An association between air pollution and mortality in six U.S. cities. N England Journal of Medicine, 329(24), 1753-1759. doi:10.1056/NEJM199312093292401 
Donovan, G. H., \& Butry, D. T. (2009). The value of shade: Estimating the effect of urban trees on summertime electricity use. Energy \& Buildings, 41(6), 662-668.

doi:10.1016/j.enbuild.2009.01.002

Doyle, J. (2015). 2015 Operating budget briefing note: Tree planting program (Briefing Note No. BN \# 9 - Feb 13). Toronto, ON: City of Toronto.

Dwyer, J. F., McPherson, E. G., Schroeder, H. W., \& Rowntree, R. A. (1992). Assessing the benefits and costs of the urban forest. Journal of Arboriculture, 18(5), 227-234.

Escobedo, F. J., \& Nowak, D. J. (2009). Spatial heterogeneity and air pollution removal by an urban forest. Landscape and Urban Planning, 90(3-4), 102-110. doi:10.1016/j.landurbplan.2008.10.021

Farber, S. C., Costanza, R., \& Wilson, M. A. (2002). Economic and ecological concepts for valuing ecosystem services. Ecological Economics, 41(3), 375-392.

Federer, C. A. (1976). Trees modify the urban microclimate. Journal of Arboriculture, 2(7), 121127.

Foster, R. S., \& Blaine, J. (1978). Urban tree survival: Trees in the sidewalk. Journal of Arboriculture, 4(1), 14-17.

Fotheringham, A. S., \& Wong, D. W. S. (1991). The modifiable areal unit problem in multivariate statistical analysis. Environment and Planning A, 23(7), 1025-1044. doi:10.1068/a231025

Frazier, A. E., \& Bagchi-Sen, S. (2015). Developing open space networks in shrinking cities. Applied Geography, 59, 1-9. doi:10.1016/j.apgeog.2015.02.010

Frazier, A. E., \& Wang, L. (2011). Characterizing spatial patterns of invasive species using subpixel classifications. Remote Sensing of Environment, 115(8), 1997-2007.

Gallo, K. P., Mcnab, A. L., Karl, T. R., Brown, J. F., Hood, J. J., \& Tarpley, J. D. (1993). The use of NOAA AVHRR data for assessment of the urban heat island effect. Journal of Applied Meteorology, 32(5), 899-908.

Getis, A., \& Ord, J. K. (1992). The analysis of spatial association by use of distance statistics. Geographical Analysis, 24(3), 189-206.

Gandhi, K. J., \& Herms, D. A. (2010). Direct and indirect effects of alien insect herbivores on ecological processes and interactions in forests of eastern North America. Biological Invasions, 12(2), 389-405.

Gibson, R. B. (2006). Beyond the pillars: Sustainability assessment as a framework for effective integration of social, economic and ecological considerations in significant decisionmaking. Journal of Environmental Assessment Policy and Management, 8(3), 259-280.

Givoni, B. (1991). Impact of planted areas on urban environmental quality: A review. Atmospheric Environment Part B, Urban Atmosphere, 25(3), 289-299. doi:10.1016/09571272(91)90001-U

Goodland, R. (1995). The concept of environmental sustainability. Annual Review of Ecology and Systematics, 26(1995), 1-24.

Goodland, R., \& Daly, H. (1996). Environmental sustainability: Universal and nonnegotiable. Ecological Applications, 6(4), 1002-1017. 
Grabosky, J., \& Gilman, E. (2004). Measurement and prediction of tree growth reduction from tree planting space design in established parking lots. Journal of Arboriculture, 30(3), 154-164.

Grahn, P., \& Stigsdotter, U. A. (2003). Landscape planning and stress. Urban Forestry \& Urban Greening, 2(1), 1-18.

Greene, C. S., Millward, A. A., \& Ceh, B. (2011). Who is likely to plant a tree? The use of public socio-demographic data to characterize client participants in a private urban forestation program. Urban Forestry \& Urban Greening, 10(1), 29-38.

doi:10.1016/j.ufug.2010.11.004

Grimmond, S. (2007). Urbanization and global environmental change: Local effects of urban warming. Geographical Journal, 173(1), 83-88. doi:10.1111/j.1475-4959.2007.232_3.x

Grove, J. M., Cadenasso, M. L., Burch Jr., W. R., Pickett, S. T. A., Schwarz, K., O'Neil-Dunne, J., et al. (2006). Data and methods comparing social structure and vegetation structure of urban neighborhoods in Baltimore, Maryland. Society \& Natural Resources, 19(2), 117-136. doi:10.1080/08941920500394501

Hanley, N., \& Barbier, E. (2009). Pricing nature: Cost-benefit analysis and environmental policy. Northampton, MA: Edward Elgar.

Hansmann, R., Mieg, H. A., \& Frischknecht, P. (2012). Principal sustainability components: Empirical analysis of synergies between the three pillars of sustainability. International Journal of Sustainable Development \& World Ecology, 19(5), 451-459.

Hart, M., \& Sailor, D. (2009). Quantifying the influence of land-use and surface characteristics on spatial variability in the urban heat island. Theoretical and Applied Climatology, 95(34), 397-406. doi:10.1007/s00704-008-0017-5

Heisler, G. M. (1986). Effects of individual trees on the solar radiation climate of small buildings. Urban Ecology, 9(3-4), 337-359.

Herms, D. A., \& McCullough, D. G. (2014). Emerald ash borer invasion of North America: History, biology, ecology, impacts, and management. Annual Review of Entomology, 59(2014), 13-30.

Herzog, T. R., \& Chernick, K. K. (2000). Tranquility and danger in urban and natural settings. Journal of Environmental Psychology, 20(1), 29-39. doi:10.1006/jevp.1999.0151

Heynen, N. C. (2003). The scalar production of injustice within the urban forest. Antipode, 35(5), 980-998.

Heynen, N., \& Lindsey, G. (2003). Correlates of urban forest canopy cover. Public Works Management \& Policy, 8(1), 33-47. doi:10.1177/1087724X03008001004

Heynen, N., Perkins, H. A., \& Roy, P. (2006). The political ecology of uneven urban green space: The impact of political economy on race and ethnicity in producing environmental inequality in Milwaukee. Urban Affairs Review, 42(1), 3-25.

doi: $10.1177 / 1078087406290729$

Huang, W., Kan, H., \& Kovats, S. (2010). The impact of the 2003 heat wave on mortality in Shanghai, China. Science of the Total Environment, 408(11), 2418-2420.

doi:10.1016/j.scitotenv.2010.02.009 
Hulchanski, J. D. (2010). In J. David Hulchanski. (Ed.), The three cities within Toronto income polarization among Toronto's neighbourhoods, 1970-2005 / Toronto, ON: Cities Centre, University of Toronto, 2010.

Imhoff, M. L., Zhang, P., Wolfe, R. E., \& Bounoua, L. (2010). Remote sensing of the urban heat island effect across biomes in the continental USA. Remote Sensing of Environment, 114(3), 504-513.

Iverson, L. R., \& Cook, E. A. (2000). Urban forest cover of the Chicago region and its relation to household density and income. Urban Ecosystems, 4(2), 105-124.

Jelinski, D., \& Wu, J. (1996). The modifiable areal unit problem and implications for landscape ecology. Landscape Ecology, 11(3), 129-140. doi:10.1007/BF02447512

Jenerette, G. D., Harlan, S. L., Brazel, A., Jones, N., Larsen, L., \& Stefanov, W. L. (2007). Regional relationships between surface temperature, vegetation, and human settlement in a rapidly urbanizing ecosystem. Landscape Ecology, 22(3), 353-365. doi:10.1007/s10980-006-9032-z

Jensen, J. R., 2005. Introductory Digital Image Processing: A Remote Sensing Perspective. $3^{\text {rd }}$ ed. Upper Saddle River, NJ: Pearson Prentice Hall.

Jim, C. Y., \& Chen, W. Y. (2008). Assessing the ecosystem service of air pollutant removal by urban trees in Guangzhou (China). Journal of Environmental Management, 88(4), 665676. doi:10.1016/j.jenvman.2007.03.035

Johnston, P., Everard, M., Santillo, D., \& Robert, K. (2007). Reclaiming the definition of sustainability. Environmental Science and Pollution Research, 14(1), 60-66.

Kardan, O., Gozdyra, P., Misic, B., Moola, F., Palmer, L. J., Paus, T., \& Berman, M. G. (2015). Neighborhood greenspace and health in a large urban center. Scientific Reports, 5 (11610), 1-14. doi: http://doi.org/10.1038/srep11610

Kauth, R., and Thomas, G., (1976). The tasseled Cap - A graphic description of the spectraltemporal development of agricultural crops as seen by Landsat. In Proceedings of the Symposium on Machine Processing of Remotely Sensed Data (West Lafayette, Indiana: Laboratory for Applications of Remote Sensing, Purdue University).

Kershaw, S., \& Millward, A. (2012). A spatio-temporal index for heat vulnerability assessment. Environmental Monitoring and Assessment, 184(12), 7329-7342. doi:10.1007/s10661-011-2502-z

Keshava, N., \& Mustard, J. F. (2002). Spectral unmixing. Signal Processing Magazine, IEEE, 19(1), 44-57.

Kiker, G. A., Bridges, T. S., Varghese, A., Seager, T. P., \& Linkov, I. (2005). Application of multicriteria decision analysis in environmental decision making. Integrated Environmental Assessment and Management, 1(2), 95-108.

Kirnbauer, M. C., Kenney, W. A., Churchill, C. J., \& Baetz, B. W. (2009). A prototype decision support system for sustainable urban tree planting programs. Urban Forestry \& Urban Greening, 8(1), 3-19.

Klinenberg, E. (2012). Heat wave: A social autopsy of disaster in Chicago. Chicago, IL: University of Chicago Press. 
Koeser, A., Hauer, R., Norris, K., \& Krouse, R. (2013). Factors influencing long-term street tree survival in Milwaukee, WI, USA. Urban Forestry \& Urban Greening, 12(4), 562-568. doi:http://dx.doi.org/10.1016/j.ufug.2013.05.006

Konijnendijk, C. C., Ricard, R. M., Kenney, A., \& Randrup, T. B. (2006). Defining urban forestryA comparative perspective of North America and Europe. Urban Forestry \& Urban Greening, 4(3), 93-103.

Kozlowski, T. T. (1999). Soil compaction and growth of woody plants. Scandinavian Journal of Forest Research, 14(6), 596-619. doi:10.1080/02827589908540825

Künzli, N., McConnell, R., Bates, D., \& Bastain, T. (2003). Breathless in Los Angeles: The exhausting search for clean air. American Journal of Public Health, 93(9), 1494.

Laćan, I., \& McBride, J. R. (2008). Pest vulnerability matrix (PVM): A graphic model for assessing the interaction between tree species diversity and urban forest susceptibility to insects and diseases. Urban Forestry \& Urban Greening, 7(4), 291-300.

Landry, S., \& Chakraborty, J. (2009). Street trees and equity: Evaluating the spatial distribution of an urban amenity. Environment and Planning A, 41(11), 2651-2670.

Law, B. E., Cescatti, A., \& Baldocchi, D. D. (2001). Leaf area distribution and radiative transfer in open-canopy forests: Implications for mass and energy exchange. Tree Physiology, 21(12-13), 777-787. doi:10.1093/treephys/21.12-13.777

Lehrer, U., Keil, R., \& Kipfer, S. (2010). Reurbanization in Toronto: Condominium boom and social housing revitalization. disP-The Planning Review, 46(180), 81-90.

Lehrer, U., \& Wieditz, T. (2009). Condominium development and gentrification: The relationship between policies, building activities and socio-economic development in Toronto. Canadian Journal of Urban Research, 18(1), 140-161.

Lillesand, T. M., Kiefer, R. W., \& Chipman, J. W. (2007). Remote sensing and image interpretation (6th ed.). New York, NY: John Wiley and Sons.

Lindsey, P., \& Bassuk, N. (1992). Redesigning the urban forest from the ground below: A new approach to specifying adequate soil volumes for street trees. Arboricultural Journal, 16(1), 25-39.

Locke, D. H., Grove, J. M., Lu, J. W. T., Troy, A., O'Neil-Dunne, J., \& Beck, B. D. (2010). Prioritizing preferable locations for increasing urban tree canopy in New York City. Cities and the Environment, 3(1), 4.

Lohr, V. I., Pearson-Mims, C. H., Tarnai, J., \& Dillman, D. A. (2004). How urban residents rate and rank the benefits and problems associated with trees in cities. Journal of Arboriculture, 30(1), 28-35.

Lu, D., \& Weng, Q. (2006). Use of impervious surface in urban land-use classification. Remote Sensing of Environment, 102(1), 146-160. doi:10.1016/j.rse.2006.02.010

Lu, J. W. T., Svendsen, E. S., Campbell, L. K., Greenfield, J., Braden, J., King, K. L., et al. (2010). Biological, social, and urban design factors affecting young street tree mortality in New York City. Cities and the Environment, 3(1), 1-15. 
Luck, G., Smallbone, L., \& O'Brien, R. (2009). Socio-economics and vegetation change in urban ecosystems: Patterns in space and time. Ecosystems, 12(4), 604-620.

doi:10.1007/s10021-009-9244-6

MacFarlane, D. W., \& Meyer, S. P. (2005). Characteristics and distribution of potential ash tree hosts for emerald ash borer. Forest Ecology and Management, 213(1-3), 15-24.

MacLachlan, I., \& Sawada, R. (1997). Measures of income inequality and social polarization in Canadian metropolitan areas. Canadian Geographer, 41(4), 377-397.

Maco, S. E., \& McPherson, E. G. (2002). Assessing canopy cover over streets and sidewalks in street tree populations. Journal of Arboriculture, 28(6), 270-276.

Maco, S. E., McPherson, E. G., Simpson, J. R., Peper, P. J., \& Xiao, Q. (2005). City of Berkeley, California municipal tree resource analysis. Center for Urban Forest Research, USDA Forest Service, Pacific Southwest Research Station, Berkeley, CA.

Maloley, M. J. (2010). Thermal remote sensing of urban heat island effects: Greater Toronto area (Open File No. 6283). Geological Survey of Canada. Retrieved from http://ftp2.cits.rncan.gc.ca/pub/geott/ess pubs/263/263392/of 6283.pdf

Martin, P. H. (1999). Norway maple (Acer platanoides) invasion of a natural forest stand: Understory consequence and regeneration pattern. Biological Invasions, 1(2-3), 215222.

McBride, J. R., \& Jacobs, D. F. (1986). Presettlement forest structure as a factor in urban forest development. Urban Ecology, 9(3-4), 245-266.

McCarthy, M. P., Best, M. J., \& Betts, R. A. (2010). Climate change in cities due to global warming and urban effects. Geophysical Research Letters, 37(9), n/a. doi:http://dx.doi.org.ezproxy.lib.ryerson.ca/10.1029/2010GL042845

McCullough, D. G., Poland, T. M., \& Cappaert, D. (2009). Attraction of the emerald ash borer to ash trees stressed by girdling, herbicide treatment, or wounding. Canadian Journal of Forest Research, 39(7), 1331-1345.

McGuire, C. J. (2012). Environmental decision-making in context: A toolbox. New York, NY: CRC Press.

McPherson E. G. (1984). Energy-conserving site design. Washington DC: American Society of Landscape Architects.

McPherson, E. G. (1992). Accounting for benefits and costs of urban greenspace. Landscape and Urban Planning, 22(1), 41-51.

McPherson, E. G., Herrington, L. P., \& Heisler, G. M. (1988). Impacts of vegetation on residential heating and cooling. Energy and Buildings, 12(1), 41-51. doi:10.1016/03787788(88)90054-0

McPherson, E. G., Nowak, D., Heisler, G., Grimmond, S., Souch, C., Grant, R., \& Rowntree, R. (1997). Quantifying urban forest structure, function, and value: The Chicago urban forest climate project. Urban Ecosystems, 1(1), 49-61.

McPherson, E. G., Scott, K. I., \& Simpson, J. R. (1998). Estimating cost effectiveness of residential yard trees for improving air quality in Sacramento, California, using existing models. Atmospheric Environment, 32(1), 75-84. doi:10.1016/S1352-2310(97)00180-5 
McPherson, E. G., \& Simpson, J. R. (2002). A comparison of municipal forest benefits and costs in Modesto and Santa Monica, California, USA. Urban Forestry \& Urban Greening, 1(2), 61-74.

McPherson, E. G., \& Simpson, J. R. (2003). Potential energy savings in buildings by an urban tree planting programme in California. Urban Forestry \& Urban Greening, 2(2), 73-86.

McPherson, G., Simpson, J. R., Peper, P. J., Maco, S. E., \& Xiao, Q. (2005). Municipal forest benefits and costs in five US cities. Journal of Forestry, 103(8), 411-411-416.

McPherson, E. G., Simpson, J. R., Peper, P. J., \& Xiao, Q. (1999). Benefit-cost analysis, of Modesto's municipal urban forest. Journal of Arboriculture, 25(5), 235.

McPherson, E. G., Simpson, J. R., Xiao, Q., \& Wu, C. (2011). Million trees Los Angeles canopy cover and benefit assessment. Landscape and Urban Planning, 99(1), 40-50. doi: 10.1016/..landurbplan.2010.08.011

Meehl, G. A., \& Tebaldi, C. (2004). More intense, more frequent, and longer lasting heat waves in the 21st century. Science, 305(5686), 994-997. doi:10.1126/science.1098704

Million Trees NYC. (2015). Million trees NYC: About; Retrieved May 15, 2015, from http://www.milliontreesnyc.org/html/about/about.shtml

Millward, A. A., Piwowar, J. M., \& Howarth, P. J. (2006). Time-series analysis of mediumresolution, multisensor satellite data for identifying landscape change. Photogrammetric Engineering \& Remote Sensing, 72(6), 653-663.

Millward, A. A. (2011). Urbanisation viewed through a geostatistical lens applied to remotesensing data. Area, 43(1), 53-66.

Millward, A. A., \& Sabir, S. (2011). Benefits of a forested urban park: What is the value of Allan Gardens to the city of Toronto, Canada? Landscape and Urban Planning, 100(3), 177188.

Millward, A. A., Torchia, M., Laursen, A. E., \& Rothman, L. D. (2014). Vegetation placement for summer built surface temperature moderation in an urban microclimate. Environmental management, 53(6), 1043-1057.

Müeller, F., \& Nielsen, S. N. (2009). Emergent properties. In S. E. Jorgensen (Ed.), Ecosystem ecology (pp. 91-98). Burlington, MA: Academic Press.

Newman, P. (2006). The environmental impact of cities. Environment \& Urbanization, 18(2), 275-295. doi:10.1177/0956247806069599

Nowak, D. J. (1993). Historical vegetation change in Oakland and its implications for urban forest management. Journal of Arboriculture, 19(5), 313-319.

Nowak, D. J. (1994). Air pollution removal by Chicago's urban forest. In E. G. McPherson, D. J. Nowak \& R. A. Rowntree (Eds.), Chicago's urban forest ecosystem: Results of the Chicago urban forest climate project (USDA forest service gen. tech. rep. NE-18). Radnor, PA: US Department of Agriculture, Forest Service.

Nowak, D. J., Civerolo, K. L., Trivikrama Rao, S., Gopal, S., Luley, C. J., \& E. Crane, D. (2000). A modeling study of the impact of urban trees on ozone. Atmospheric Environment, 34(10), 1601-1613. 
Nowak, D. J., \& Crane, D. E. (2002). Carbon storage and sequestration by urban trees in the USA. Environmental Pollution, 116(3), 381-389. doi:10.1016/S0269-7491(01)00214-7

Nowak, D. J., Crane, D. E., \& Stevens, J. C. (2006). Air pollution removal by urban trees and shrubs in the United States. Urban Forestry \& Urban Greening, 4(3), 115-123. doi:10.1016/j.ufug.2006.01.007

Nowak, D. J., \& Greenfield, E. J. (2012). Tree and impervious cover change in U.S. cities. Urban Forestry \& Urban Greening, 11(1), 21-30. doi:10.1016/j.ufug.2011.11.005

Nowak, D. J., \& Greenfield, E. J. (2012). Tree and impervious cover in the United States. Landscape and Urban Planning, 107(1), 21-30. doi:http://dx.doi.org/10.1016/i.landurbplan.2012.04.005

Nowak, D. J., Hoehn III, R. E., Bodine, A. R., Greenfield, E. J., Ellis, A., Endreny, T. A., et al. (2013). Assessing urban forest effects and values: Toronto's urban forest (Research Bulletin No. NRS-79). Newtown Square, PA: U.S. Forest Service.

Nowak, D. J., Hoehn III, R. E., Crane, D. E., Stevens, J. C., \& Walton, J. T. (2007). Assessing urban forest effects and values: New York City's urban forest (Research Bulletin No. NRS-9). Newtown Square, PA: U.S. Forest Service.

Nowak, D. J., Hoehn III, R. E., Crane, D. E., Weller, L., \& Davila, A. (2011). Assessing urban forest effects and values: Los Angeles' urban forest (Research Bulletin No. NRS-47). Newtown Square, PA: U.S. Forest Service.

Nowak, D. J., Kuroda, M., \& Crane, D. E. (2004). Tree mortality rates and tree population projections in Baltimore, Maryland, USA. Urban Forestry \& Urban Greening, 2(3), 139147.

Nowak, D. J., Noble, M. H., Sisinni, S. M., \& Dwyer, J. F. (2001). People and trees: Assessing the US urban forest resource. Journal of Forestry, 99(3), 37-42.

Nowak, D. J., \& Rowntree, R. A. (1990). History and range of Norway maple. Journal of Arboriculture, 16(11), 291-296.

Nowak, D. J., Stein, S. M., Randler, P. B., Greenfield, E. J., Comas, S. J., Carr, M. A., \& Alig, R. J. (2010). Sustaining America's urban trees and forests: A forests on the edge report. (General Technical Report No. NRS-62). Newton Square, PA: United States Department of Agriculture, Forest Service.

Nowak, D. J., \& Walton, J. T. (2005). Projected urban growth (2000-2050) and its estimated impact on the US forest resource. Journal of Forestry, 103(8), 383-389.

O'Toole, M. (2013, March 6). Toronto overtakes Chicago as fourth-largest city in North America. National Post. Retrieved from http://news. nationalpost.com/toronto/toronto-overtakeschicago-as-fourth-largest-city-in-north-america

Odum, E. P., \& Barrett, G. W. (2005). Fundamentals of ecology (5th ed.) Toronto, ON: Thomson Brooks/Cole.

Oke, T. R., \& Maxwell, G. B. (1975). Urban heat island dynamics in Montreal and Vancouver. Atmospheric Environment (1967), 9(2), 191-200. doi:10.1016/00046981(75)90067-0 
Openshaw, S., \& Taylor, P. J. (1979). A million or so correlation coefficients: Three experiments on the modifiable areal unit problem. In N. Wrigley (Ed.), Statistical applications in the spatial sciences (pp. 127-144). London: Pion.

Ord, J. K., \& Getis, A. (1995). Local spatial autocorrelation statistics: Distributional issues and an application. Geographical Analysis, 27(4), 286-306.

Patterson, B. (2011). Strategy for the management of the emerald ash borer (Staff Report No. PE02-032811-AFS\#12934). Toronto, ON: City of Toronto.

Peper, P. J., \& McPherson, E. G. (1998). Comparison of five methods for estimating leaf area index of open-grown deciduous trees. Journal of Arboriculture, 24, 98-111.

Peper, P. J., \& McPherson, E. G. (2003). Evaluation of four methods for estimating leaf area of isolated trees. Urban Forestry \& Urban Greening, 2(1), 19-29. doi:http://dx.doi.org/10.1078/1618-8667-00020

Peper, P. J., McPherson, E. G., Simpson, J. R., Gardner, S. L., Vargas, K. E., Xiao, Q., et al. (2007). New York City, New York: Municipal forest resource analysis Center for Urban Forest Research, USDA Forest Service, Pacific Southwest Research Station New York.

Perkins, H. A., Heynen, N., \& Wilson, J. (2004). Inequitable access to urban reforestation: The impact of urban political economy on housing tenure and urban forests. Cities, 21(4), 291-299.

Phinn, S., Stanford, M., Scarth, P., Murray, A. T., \& Shyy, P. T. (2002). Monitoring the composition of urban environments based on the vegetation-impervious surface-soil (VIS) model by subpixel analysis techniques. International Journal of Remote Sensing, 23(20), 4131-4153. doi:10.1080/01431160110114998

Poland, T. M., \& McCullough, D. G. (2006). Emerald ash borer: Invasion of the urban forest and the threat to North America's ash resource. Journal of Forestry, 104(3), 118-124.

Prasad, A., Iverson, L., Peters, M., Bossenbroek, J., Matthews, S., Davis Sydnor, T., et al. (2010). Modeling the invasive emerald ash borer risk of spread using a spatially explicit cellular model. Landscape Ecology, 25(3), 353-369.

Prol-Ledesma, R., Uribe-Alcantara, E., \& Diaz-Molina, O. (2002). Use of cartographic data and Landsat TM images to determine land use change in the vicinity of Mexico City. International Journal of Remote Sensing, 23(9), 1927-1933. doi:10.1080/01431160110087985

Quigley, M. F. (2004). Street trees and rural conspecifics: Will long-lived trees reach full size in urban conditions? Urban Ecosystems, 7(1), 29-39.

doi:10.1023/B:UECO.0000020170.58404.e9

Raupp, M. J., Cumming, A. B., \& Raupp, E. C. (2006). Street tree diversity in eastern North America and its potential for tree loss to exotic borers. Arboriculture and Urban Forestry, 32(6), 297.

Rees, W. (1995). Achieving sustainability: Reform or transformation? Journal of Planning Literature, 9(4), 343-361.

Rees, W., \& Wackernagel, M. (1996). Urban ecological footprints: Why cities cannot be sustainable--and why they are a key to sustainability. Environmental Impact Assessment Review, 16(4-6), 223-248. 
Richards, N. A. (1983). Diversity and stability in a street tree population. Urban Ecology, 7(2), 159-171. doi:10.1016/0304-4009(83)90034-7

Rogerson, P. (2006). Statistical methods for geography: A student guide (2nd ed.). London, UK: SAGE.

Roseland, M. (2012). Toward sustainable communities: Solutions for citizens and their governments (4th ed.). Gabriola Island, BC: New Society Publishers.

Rosen, G., \& Walks, A. (2014). Castles in Toronto's sky: Condo-ism as urban transformation. Journal of Urban Affairs, In Press, n/a-n/a. doi:10.1111/juaf.12140

Rowntree, R. A. (1984). Forest canopy cover and land use in four eastern United States cities. Urban Ecology, 8(1-2), 55-67. doi:10.1016/0304-4009(84)90006-8

Rowntree, R. A., \& Nowak, D. J. (1991). Quantifying the role of urban forests in removing atmospheric carbon dioxide. Journal of Arboriculture, 17(10), 269-275.

Rosenzweig C, Solecki W.D., Slosberg R. (2006) Mitigating New York City's heat island with urban forestry, living roofs, and light surfaces. A report to the New York State Energy Research and Development Authority. Retrieved from http://www.giss.nasa.gov/research/news/20060130/103341.pdf

Roth, M., Oke, T. R., \& Emery, W. j. (1989). Satellite-derived urban heat islands from three coastal cities and the utilization of such data in urban climatology. International Journal of Remote Sensing, 10(11), 1699-1720. doi:10.1080/01431168908904002

Sander, H., Polasky, S., \& Haight, R. G. (2010). The value of urban tree cover: A hedonic property price model in Ramsey and Dakota counties, Minnesota, USA. Ecological Economics, 69(8), 1646-1656.

Sanders, R. A. (1981). Diversity in the street trees of Syracuse, New York. Urban Ecology, 5(1), 33-43.

Sanders, R. A. (1984). Some determinants of urban forest structure. Urban Ecology, 8(1), 1327. doi:10.1016/0304-4009(84)90004-4

Sanders, R. A. (1986). Urban vegetation impacts on the hydrology of Dayton, Ohio. Urban Ecology, 9(3-4), 361-376.

Sarnat, J. A., Schwartz, J., \& Suh, H. H. (2001). Fine particulate air pollution and mortality in 20 U.S. cities. The New England Journal of Medicine, 344(16), 1253-1254. doi:10.1056/NEJM200104193441614

Satterthwaite, D. (1997). Sustainable cities or cities that contribute to sustainable development? Urban Studies, 34(10), 1667-1691. doi:10.1080/0042098975394

Sawka, M., Millward, A. A., Mckay, J., \& Sarkovich, M. (2013). Growing summer energy conservation through residential tree planting. Landscape and Urban Planning, 113(2013), 1-9. http://doi.org/10.1016/j.landurbplan.2013.01.006

Schwartz, H. (2004). The relevance of Toronto's new governmental structure for the 21st century. Canadian Journal of Regional Science, 27(1), 99-120.

Sieghardt, M., Mursch-Radlgruber, E., Paoletti, E., Couenberg, E., Dimitrakopoulus, A., Rego, F., et al. (2005). The abiotic urban environment: Impact of urban growing conditions on urban vegetation. In C. Konijnendijk, K. Nilsson, T. Randrup \& J. Schipperijn 
(Eds.), Urban forests and trees: A reference book (pp. 281-323). New York, NY: Springer Berlin Heidelberg.

Siegert, N. W., McCullough, D. G., Williams, D. W., Fraser, I., Poland, T. M., \& Pierce, S. J. (2010). Dispersal of Agrilus planipennis (coleoptera: Buprestidae) from discrete epicenters in two outlier sites. Environmental Entomology, 39(2), 253-265. doi:10.1603/EN09029

Sisinni, S., Zipperer, W., \& Pleninger, A. (1995). Impacts from a major ice storm: Street-tree damage in Rochester, New York. Journal of Arboriculture, 21(3), 156-167.

Smiley, E. T., Calfee, L., Fraedrich, B. R., \& Smiley, E. J. (2006). Comparison of structural and noncompacted soils for trees surrounded by pavement. Arboriculture \& Urban Forestry, 32(4), 164-169.

Sreetheran, M., \& Konijnendijk van den Bosch, C. C. (2014). A socio-ecological exploration of fear of crime in urban green spaces - A systematic review. Urban Forestry \& Urban Greening, 13(1), 1-18. doi:10.1016/j.ufug.2013.11.006

Stone, B., \& Rodgers, M. O. (2001). Urban form and thermal efficiency: How the design of cities influences the urban heat island effect. Journal of the American Planning Association, 67(2), 186-198. doi:10.1080/01944360108976228

Syndnor, T. D., Bumgardner, M., \& Todd, A. (2007). The potential impacts of emerald ash borer (Agrilus planipennis) on Ohio, U.S., communities. Arboriculture \& Urban Forestry, 33(1), 48-54.

Talarchek, G. M. (1990). The urban forest of New Orleans: An exploratory analysis of relationships. Urban Geography, 11(1), 65-86. doi:10.2747/0272-3638.11.1.65

Thomas, J. (2012). The official blog of the district department of transportation: Impervious surface removal. Retrieved July 3, 2015, from http://ddotdish.com/2012/02/17/impervious-surface-removal/

Tobler, W. R. (1970). A computer movie simulating urban growth in the Detroit region. Economic Geography, 46, 234-240.

Trowbridge, P. J., \& Bassuk, N. (2004). Trees in the urban landscape: Site assessment, design, and installation. New York, NY: J. Wiley \& Sons.

Troy, A. R., Grove, J. M., O’Neil-Dunne, J. P. M., Pickett, S. T. A., \& Cadenasso, M. L. (2007). Predicting opportunities for greening and patterns of vegetation on private urban lands. Environmental Management, 40(3), 394-412. doi:10.1007/s00267-006-0112-2

Ulrich, R. S. (1984). View through a window may influence recovery from surgery. Science, 224(4647), 420-421.

United Nations, Department of Economic and Social Affairs, Population Division (2014). World urbanization prospects: The 2014 revision, highlights (ST/ESA/SER.A/352). New York, NY: United Nations.

Voogt, J. A., \& Oke, T. R. (2003). Thermal remote sensing of urban climates. Remote Sensing of Environment, 86(3), 370-384. doi:http://dx.doi.org/10.1016/S0034-4257(03)00079-8 
Wackernagel, M., \& Rees, W. E. (1997). Perceptual and structural barriers to investing in natural capital: Economics from an ecological footprint perspective. Ecological Economics, 20(1), 3-24.

Wackernagel, M., Onisto, L., Bello, P., Callejas Linares, A., Susana López Falfán, I., Méndez García, J., et al. (1999). National natural capital accounting with the ecological footprint concept. Ecological Economics, 29(3), 375-390.

Walker, G. (2010). Environmental justice: Concepts, evidence and politics. New York, NY: Routledge.

Walks, A., \& Twigge-Molecey, A. (2013). Income inequality and polarization in Canada's cities: An examination and new form of measurement (Research Paper No. 227). Toronto, ON: Cities Centre, University of Toronto. Retrieved from http://neighbourhoodchange.ca/documents/2015/02/income-inequality-and-polarizationin-canadas-cities-an-examination-and-new-form-of-measurement.pdf

Weng, Q. (2001). A remote sensing--GIS evaluation of urban expansion and its impact on surface temperature in the Zhujiang Delta, China. International Journal of Remote Sensing, 22(10), 1999-2014. doi:10.1080/01431160118847

White, M. A. (2013). Sustainability: I know it when I see it. Ecological Economics, 86, 213-217.

Whitlow, T. H., \& Bassuk, N. L. (1988). Ecophysiology of urban trees and their management: The North American experience. Hortscience, 23(3), 542-546.

Wiersma, Y. F., Davis, T. L., Eberendu, E. C., Gidge, I., Jewison, M., Martin, H. C., et al. (2012). Hurricane lgor impacts at northern latitudes: Factors influencing tree fall in an urban setting. Arboriculture \& Urban Forestry, 38(3), 92-98.

Wilson, S. J. (2012). Canada's wealth of natural capital: Rouge national park. Vancouver, BC: David Suzuki Foundation. Retrieved from http://www.davidsuzuki.org/publications/downloads/2012/report Rouge Natural Capital web.pdf

World Commission on Environment and Development. (1987). Report of the world commission on environment and development: Our common future. United Nations. Retrieved from http://www.un-documents.net/our-common-future.pdf

World Health Organization, Regional Office for Europe. (2006). Air quality guidelines: Global update 2005: Particulate matter, ozone, nitrogen dioxide, and sulfur dioxide (WHO/SDE/PHE/OEH/06.02). Geneva, CH: World Health Organization.

Wu, J. (2013). Landscape sustainability science: Ecosystem services and human well-being in changing landscapes. Landscape Ecology, 28(6), 999-1023.

Wyckoff, P. H., \& Webb, S. L. (1996). Understory influence of the invasive Norway maple (Acer platanoides). Bulletin of the Torrey Botanical Club, 123(3), 197-205.

Xiao, Q., McPherson, E. G., Simpson, J. R., \& Ustin, S. L. (1998). Rainfall interception by Sacramento's urban forest. Journal of Arboriculture, 24(4), 235-244.

Zhang, P., Imhoff, M. L., Wolfe, R. E., \& Bounoua, L. (2010). Characterizing urban heat islands of global settlements using MODIS and nighttime lights products. Canadian Journal of Remote Sensing, 36(3), 185-196. 
Zipperer, W. C., Sisinni, S. M., Pouyat, R. V., \& Foresman, T. W. (1997). Urban tree cover: An ecological perspective. Urban Ecosystems, 1(4), 229-246. 


\section{GLOSSARY: IMPORTANT ACRONYMS AND ABBREVIATIONS}

\begin{tabular}{|c|c|}
\hline ANOVA & Analysis Of Variance \\
\hline CBA & Cost Benefit Analysis \\
\hline CBD & Central Business District \\
\hline CT & Census Tract \\
\hline DA & Dissemination Area \\
\hline DED & Dutch Elm Disease \\
\hline DPI & Damage Potential Index \\
\hline $\mathrm{EAB}$ & Emerald Ash Borer \\
\hline EDM & Environmental Decision-Making \\
\hline GIS & Geographic Information System \\
\hline GWR & Geographically Weighted Regression \\
\hline LISA & Local Indicator of Spatial Autocorrelation \\
\hline MCDA & Multi-Criteria Decision Analysis \\
\hline $\mathrm{MHI}$ & Median Household Income \\
\hline MLC & Maximum Likelihood Classification \\
\hline MPI & Median Personal Income \\
\hline NDVI & Normalized Difference Vegetation Index \\
\hline OLS & Ordinary Least Squares \\
\hline PCA & Principal Components Analysis \\
\hline PCC & Potential Canopy Cover \\
\hline $\mathrm{RCC}$ & Realized Canopy Cover \\
\hline TCC & Total Canopy Cover \\
\hline UFRED & Urban Forest \& Ecological Disturbance \\
\hline UHI & Urban Heat Island \\
\hline UTCC & Urban Tree Canopy Cover \\
\hline
\end{tabular}

